\title{
Effect of Electron Beam Radiation on Microbial Inactivation, Radio-resistance and Nutritional Quality of Food
}

\author{
Adiam Tsegai Tesfai \\ West Virginia University
}

Follow this and additional works at: https://researchrepository.wvu.edu/etd

\section{Recommended Citation}

Tesfai, Adiam Tsegai, "Effect of Electron Beam Radiation on Microbial Inactivation, Radio-resistance and Nutritional Quality of Food" (2013). Graduate Theses, Dissertations, and Problem Reports. 5006.

https://researchrepository.wvu.edu/etd/5006

This Dissertation is protected by copyright and/or related rights. It has been brought to you by the The Research Repository @ WVU with permission from the rights-holder(s). You are free to use this Dissertation in any way that is permitted by the copyright and related rights legislation that applies to your use. For other uses you must obtain permission from the rights-holder(s) directly, unless additional rights are indicated by a Creative Commons license in the record and/ or on the work itself. This Dissertation has been accepted for inclusion in WVU Graduate Theses, Dissertations, and Problem Reports collection by an authorized administrator of The Research Repository @ WVU.

For more information, please contact researchrepository@mail.wvu.edu. 


\title{
Effect of Electron Beam Radiation on Microbial Inactivation, Radio-resistance and Nutritional Quality of Food
}

\author{
Adiam Tsegai Tesfai
}

Dissertation submitted to the Davis College of Agriculture, Natural Resources and Design in partial fulfillment of the requirements for a degree of

\section{Doctor of Philosophy}

in

\author{
Animal and Food Sciences \\ Jacek Jaczynski, Ph.D., Chair \\ Janet C. Tou, Ph.D. \\ Kristen E. Matak, Ph.D. \\ Jianbo Yao, Ph.D. \\ Gary K. Bissonnette, Ph.D.
}

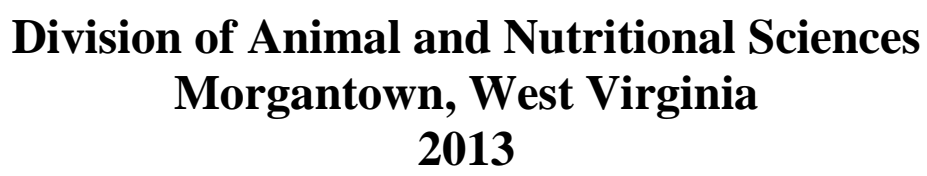

Keywords: Ionizing radiation, electron beam, food irradiation, Radio-resistance, E.coli, Salmonella Typhimurium, Nutritional quality

Copyright 2013 Adiam Tesfai 


\section{ABSTRACT \\ Effect of Electron Beam Radiation on Microbial Inactivation, Radio-resistance and Nutritional Quality of Food}

\section{Adiam Tsegai Tesfai}

A non-thermal food processing method, Electron beam radiation efficiently inactivates foodborne pathogens. However, foodborne pathogens may develop resistance in response to sublethal stresses. Thus it is important to study the response of food microorganisms to e-beam and understand the mechanism underlying their survival abilities. The overall objective of this study was to examine the inactivation of foodborne microorganisms by electron beam radiation at sublethal levels, understand the radio-resistance development to this processing method and also to determine the effects of e-beam on chemical changes of nutrients in infant formula.

Four independent studies are included in this dissertation, in the first study, development of radio-resistant Salmonella Typhimurium in egg as a microbial response to e-beam at sublethal levels was investigated and the $\mathrm{D}_{10}$-value for $S$. Typhimurium was determined after repetitive processing with e-beam at sub-lethal doses. Survivors were enumerated on non-selective (TSA) and selective (XLD) media. Survivors from the highest dose were isolated and used in subsequent e-beam cycle. This process was repeated four times for a total of five e-beam cycles. $\mathrm{D}_{10}$-values for $S$.Typhimurium ATCC strain 14028 were $0.59 \pm 0.031$ and $0.46 \pm 0.022 \mathrm{kGy}$ on TSA and XLD, respectively. However, following the fifth e-beam cycle, the respective $\mathrm{D}_{10^{-}}$ values increased $(\mathrm{P}<0.05)$ to $0.69 \pm 0.026$ and $0.61 \pm 0.029 \mathrm{kGy}$. S. Typhimurium showed a trend ( $\mathrm{P}>0.05$ ) to develop radio-resistance faster on selective media, likely due to facilitated selection of radio-resistant cells within microbial population following each e-beam cycle. For all five ebeam cycles, $S$. Typhimurium had higher $(\mathrm{P}<0.05) \mathrm{D}_{10}$-values on non-selective media, indicating that sub-lethal injury followed by cellular repair and recovery are important for radio-resistance and inactivation of this microorganism.

To further investigate the radio resistance development of microorganisms to repetitive ebeam sublethal doses, in the second study DNA repair deficient E.coli DH5 $\alpha$ that have mutations 
of $r e c A$ and gyrA genes was used. The objective was to determine if repetitive processing with ebeam at sub-lethal doses increases $\mathrm{D}_{10}$-value of $E$. coli $\mathrm{DH} 5 \alpha$ in ground beef. Five cycles of ebeam were conducted. $\mathrm{D}_{10}$-values increased $(\mathrm{P}<0.05)$ significantly with each cycle. Following the third cycle $\mathrm{D}_{10}$-values were $0.32 \pm 0.006$ and $0.32 \pm 0.002 \mathrm{kGy}$ for survivors enumerated on non-selective and selective media, respectively; the fourth cycle $0.39 \pm 0.007$ and $0.40 \pm 0.019$ kGy; and the fifth cycle $0.46 \pm 0.006$ and $0.46 \pm 0.020 \mathrm{kGy}$. The result of the study indicates $E$. coli DH5 $\alpha$ increases radio-resistance to e-beam as a result of repetitive exposure to sub-lethal doses despite its DNA repair deficiency.

The third study investigated the role of recA and gyrA genes in E.coli DH5 $\alpha$ that had become resistant to repetitive e-beam radiation in the previous study and its ability to repair the damage caused by e-beam. Genomic DNA from E.coli DH5a, radio-resistant A2 and A4 were extracted, and DNA fragments of the gyrA and recA genes containing the mutations were amplified, cloned and sequenced. E.coli DH5 $\alpha$ and radio-resistant A2 and A4 were compared to a reference genome for identification of nucleotide polymorphisms, insertions, and deletions that may have contributed to its radio- resistance. Results of the study demonstrated that E.coli DH5 $\alpha$ was able to reverse its mutation after sub lethal e- beam radiations. The study revealed that DNA repair deficient $E$. coli $\mathrm{DH} 5 \alpha$ increased radio-resistance to e-beam as a result of repetitive exposure to sub-lethal doses despite its DNA repair deficiency due to its ability to reverse its mutation. Understanding the resistance development of microorganisms is important in designing a food process control and efficacy of the processing method.

The last study examined the effect of e-beam on chemical changes of nutrients in infant formula. Dehydrated infant milk formula was processed with e-beam at 0 (control) to $25 \mathrm{kGy}$. Amino acid, fatty acid, and mineral profiles (AAP, FAP, and MP, respectively), as well as protein degradation and lipid oxidation, were determined. Our results demonstrate proteins, lipids, and minerals in infant milk formula were stable when processed with e-beam up to 25 kGy. 


\section{ACKNOWLEDGEMENTS}

First and foremost, I thank God, for the endless blessings in my life, which have made me who I am today. I could never have done any of this without the faith I have in Him.

This dissertation appears in its current form due to the assistance and guidance of several people, which I would like to offer my sincere gratitude.

I am truly indebted and thankful to my supervisor Dr. Jacek Jaczynski, his guidance and encouragements throughout the project have been extremely helpful. His mentorship was paramount in providing a well-rounded experience consistent to my long-term career goals. Without his guidance this dissertation would not have been possible.

I also wish to extend my gratitude to my committee members, Dr. Janibo Yao, Dr. Janet Tou, Dr. Kristen Matak and Dr. Gary Bissonnette for their guidance in my research. Special thanks to Dr. Janibo Yao for his helpful discussion in Chapter 3.

Furthermore I would like to thank Sarah Beamer, for her assistance and her friendship during my entire stay at WVU. I will always be grateful to her assistance inside and outside of the lab. My colleagues Dr. Reza Tahergorabi, Lei Wang and Meghan Manor for their valuable discussion and assistance in the lab.

My sincerest thanks to all my friends, especially those in Morgantown, who made my stay, feel at home far away from home.

I am very much indebted to my family. Words cannot express how much each of you has done for me throughout my education and life; I appreciate everything you have done.

Last but not least, I thank my fiancé Ghideon Solomon whom I love with all my heart, for his unconditional love, support and patience. 


\section{TABLE OF CONTENTS}

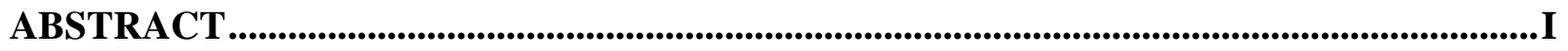

ACKNOWLEDGEMENTS ...................................................................................................III

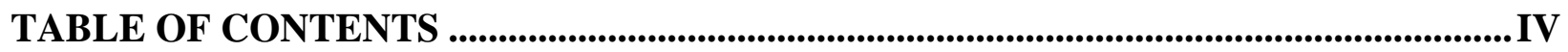

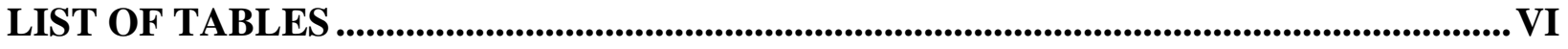

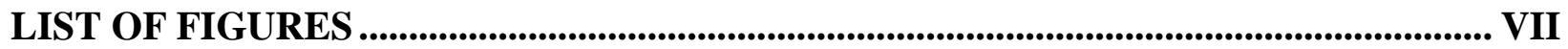

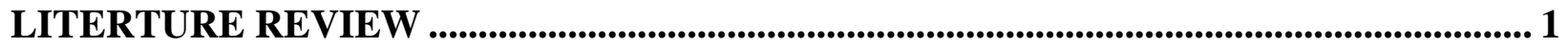

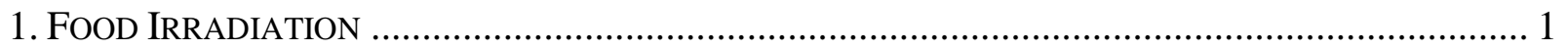

2. RADIATION SOURCES USED IN FOOD PROCESSING ............................................................. 3

3. MICROBIAL INACTIVATION FROM E-BEAM RADIATION....................................................... 4

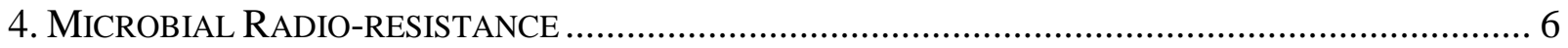

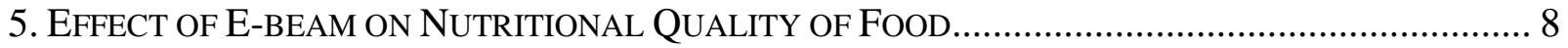

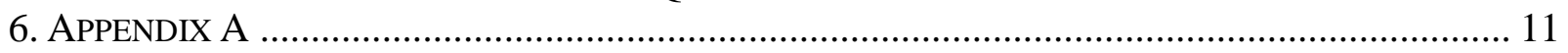

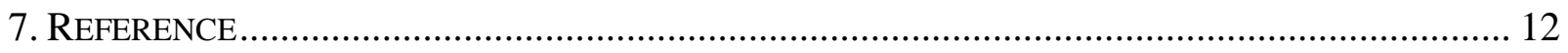

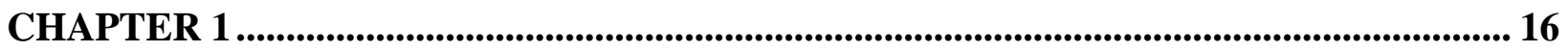

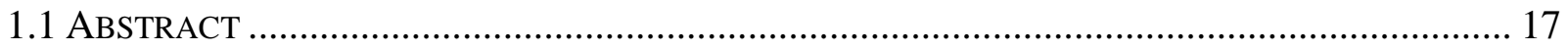

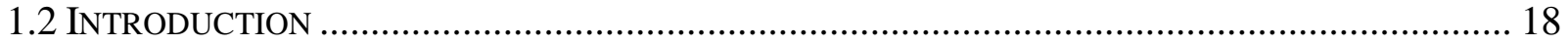

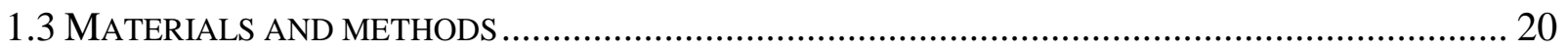

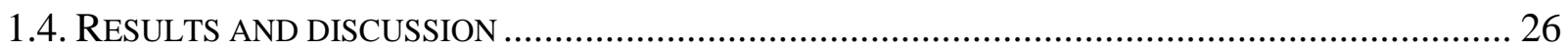

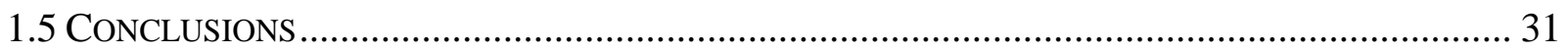

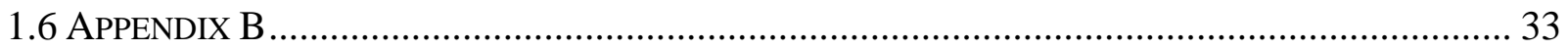

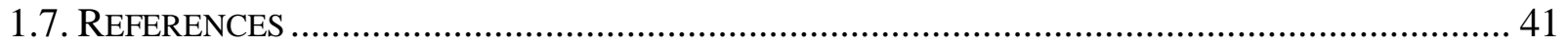

CHAPTER 2 ................................................................................................................................. 44

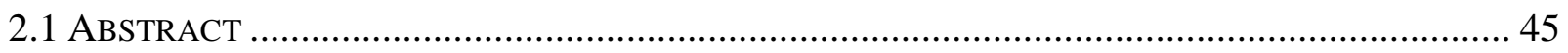

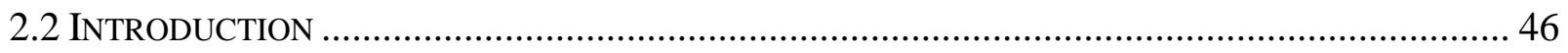

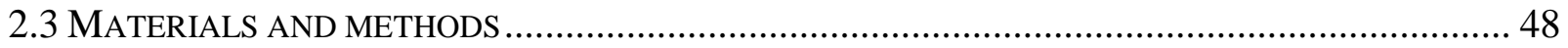

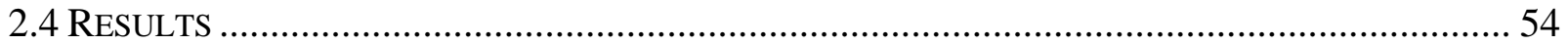

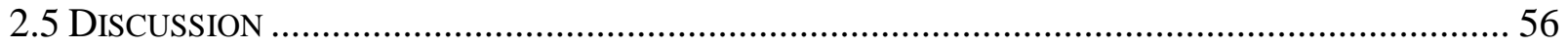

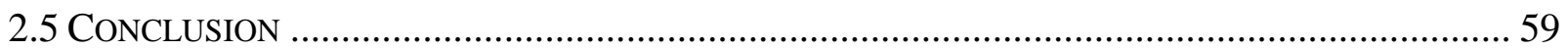

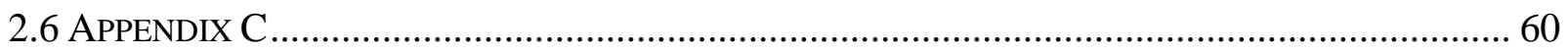

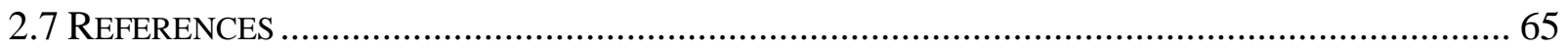

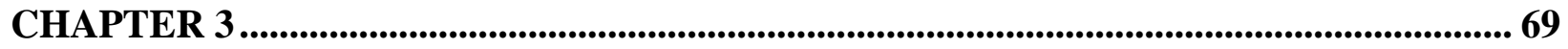

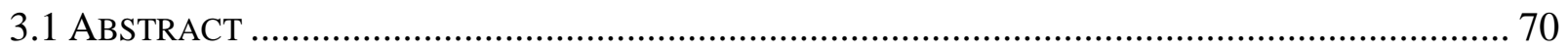

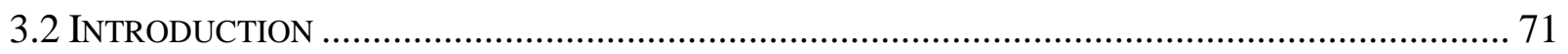

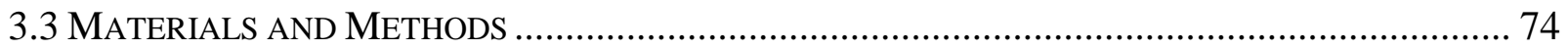

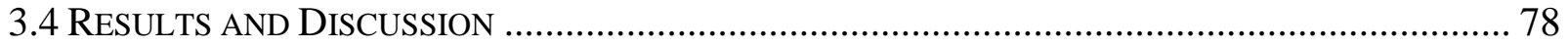

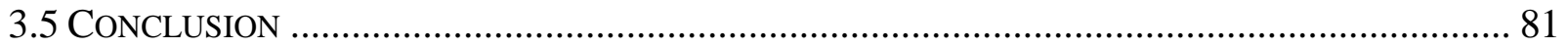

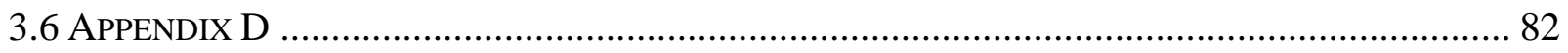




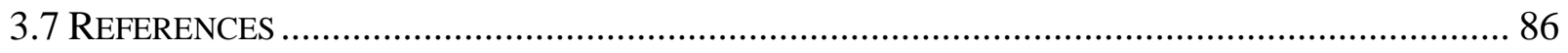

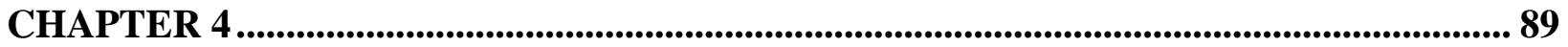

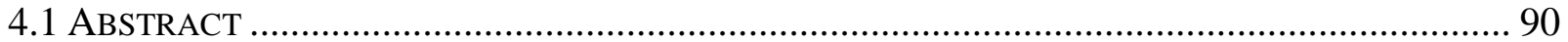

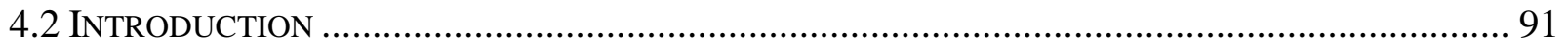

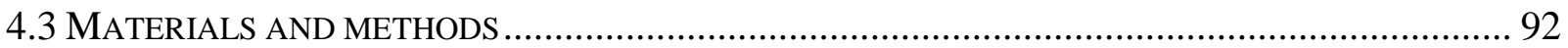

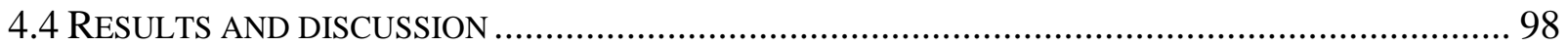

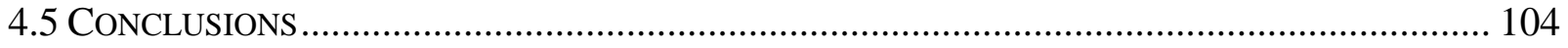

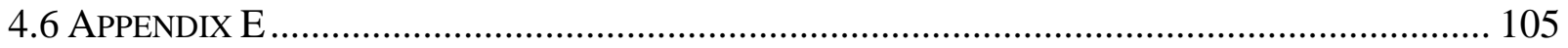

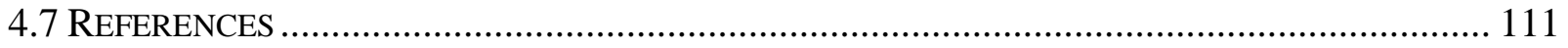

DISSERTATION SUMMARY AND IMPLICATIONS ...................................................... 116 


\section{LIST OF TABLES}

CHAPTER 1

TABLE 1.

CHAPTER 2

$\begin{array}{ll}\text { TABLE } 1 . & 60\end{array}$

CHAPTER 3

TABLE 1.

82

TABLE 2.

82

TABLE 3.

82

TABLE 4.

83

CHAPTER 4

TABLE 1.

105

TABLE 2.

106

TABLE 3.

107 


\section{LIST OF FIGURES}

LITERATURE REVIEW

FIGURE $1 . \quad 11$

FIGURE $2 . \quad 11$

CHAPTER 1

FIGURE $1 . \quad 34$

FIGURE 2.

FIGURE $3 . \quad 36$

FIGURE $4 . \quad 37$

FIGURE $5 . \quad 38$

FIGURE 6. $\quad 39$

FIGURE $7 . \quad 40$

CHAPTER 2

FIGURE 1

FIGURE 2. $\quad 62$

FIGURE 3. 63

FIGURE $4 . \quad 64$

CHAPTER 3

FIGURE $1 . \quad 84$

FIGURE 2.

CHAPTER 4

FIGURE 1. 108

FIGURE 2. 109

FIGURE $3 . \quad 110$ 


\section{LITERTURE REVIEW}

\section{Food Irradiation}

Food irradiation is a process by which food is exposed to a defined dose of ionizing radiation under controlled conditions. It can be used for wide purposes, to reduce insect infestation of grain, dried spices, fruits and vegetables; inhibit sprouting in tubers and bulbs; retard postharvest ripening of fruits; inactivate parasites in meats and fish; eliminate spoilage microbes from fresh fruits and vegetables; extend shelf life in poultry, meats, fish, and shellfish; decontaminate poultry and beef; and sterilize foods and feeds (Arvanitoyannis, 2010). The words “irradiation” and “radiation” are often used interchangeably; however the word irradiation is a more general term referring to the exposure of food to radiation to achieve a technical goal where “radiation” describes a type of energy (Matak and Jaczynski, 2009). This exposure halts spoilage by retarding enzymic action or destroying microorganisms and it can also inactivate foodborne pathogenic organisms. Irradiation affects cells and microorganisms by damaging their DNA, breaking down cell membranes and interrupting enzymic pathways until organisms can no longer successfully continue the process of cell division. The major effect of irradiation is to generate short-lived and transient radicals (e.g. the hydroxy radical, the hydrogen atom and solvated electrons) that in turn damage DNA and intercellular structures.

Research on food irradiation dates back to the turn of the $19^{\text {th }}$ century and the use of ionizing radiation for food preservation began in the early 1920s. The first US patent was obtained in 1921, on the use of x-ray to kill parasites in pork (Arvanitoyannis, 2010). The use of food irradiation increased after 1947 when researchers found that meat and other foods could be 
sterilized by high energy. In the early 1950's, the U.S. Army began a series of experiments with fruits, vegetables, dairy products, fish and meats to establish the safety and effectiveness of irradiation (Wilkinson \& Gould, 1996). It has been improved since then and it is the most studied food processing method to date (Diehl, 2002).

The energy of constituent particles or photons of ionizing radiation is expressed in electron volts (eV), or more conveniently in Million Electron Volts: $\mathrm{MeV}\left(1 \mathrm{MeV}=1.602 * 10^{-13}\right.$ $\mathrm{J})$. Dosimetry is the measurement of absorbed radiation dose that is commonly referred as dose. Microbial inhibition by ionizing irradiation is a function of dose where "dose" describes the amount of radiation absorbed by the food product. The unit commonly used for dose is the Gray (Gy) or Joules per kilogram, where 1 Gray= 1 Joule (J) of energy absorbed per kilogram (kg) of irradiated food (Matak and Jaczynski, 2009; EFSA, 2011).

Irradiation is a safe process that leaves no residual radioactivity in the food and has been approved by over 50 countries worldwide (IFIC, 2002). Both FDA and USDA require irradiated food products be labeled with the international food irradiation symbol, the radura shown in Figure 1. and must contain the words "treated with radiation" or "treated by irradiation" on the packaging.

Food irradiation has proven to be an effective means of reducing the population of harmful biological contaminants and bacterial pathogens. Thus, United States government regulatory agencies have approved the use of irradiation processing of various foods. Low dose irradiation ( $<0.5 \mathrm{kGy}$ ) is used to kill fruit flies and other pests for disinfection; $(<2 \mathrm{kGy})$ delay sprouting of vegetables and aging of fruits; medium doses (1 - $10 \mathrm{kGy}$ ) is used to reduce the levels of bacterial pathogenic organisms, high dose (>10kGy) is used to achieve sterility of 
product (Komolprasert and Morehouse, 2004). Sterilization dose (> $42 \mathrm{KGy}$ ) is used to sterilize foods for patients with compromised immune systems and NASA astronauts (WHO, 1999).

\section{Radiation Sources Used in Food Processing}

The three types of ionizing irradiation sources allowed to be used in food irradiation applications are Gamma rays, electron beam radiation and X-rays. The source of Gamma rays is from radioactive nuclides, e-beam radiation from energetic electrons of particle accelerators and X-rays emitted by high-energy electron beams (Codex Alimentarius Commission (CAC), 2003). These types of radiation are called “ionizing'” because their energy is high enough to dislodge electrons from atoms and molecules and to convert them to electrically charged particles called ions (EFSA, 2011). Electron beam radiation, one of the radiation sources is unitized for use in this dissertation.

\section{E- beam radiation}

Electron radiation (e-beam) is a process that involves using electrons to treat an object for a variety of purposes. E-beam utilizes high-energy electrons for pasteurization or sterilization effect in contrast to thermal and high-pressure types of food processing. Electron beams traveling at nearly the speed of light are produced from accelerators, such as in a linear accelerator or a Van de Graaff generator. The maximum e- beam energy allowed for food processing is $10 \mathrm{MeV}$. Research demonstrates that foods irradiated with accelerated electrons with energies of less than $10 \mathrm{MeV}$, will not induce radioactivity in foods (WHO, 1981).

When processing food with e- beam radiation, electrons are accelerated to the speed of light by a linear accelerator and transferred to an e-beam gun, which subsequently passes high- 
energy electrons onto the food that is subjected to processing, resulting in microbial inactivation. Depending on the e-beam dose, pasteurization or sterilization can be achieved. E-beam radiation is a non-thermal food processing and does not alter the temperature of processed food (Jaczynski and Park, 2003). Therefore, food quality degradation due to heat is not a concern for e-beam processing.

The electron source in e- beam is electricity (Diehl, 1995) and, unlike gamma radiation, e-beam does not use radio-isotopes and create radioactive waste. Recently e-beam irradiation has become more common than gamma irradiation as e-beam does not require replenishment of the source as does cobalt-60 to produce radiation and they can be turned on only as needed (Tahergorabi et al., 2012). While the overall antimicrobial properties of gamma radiation and ebeam are comparable, e-beam enables application of high dose rates (e-beam, $10^{3}-10^{5} \mathrm{~Gy} / \mathrm{sec}$; gamma, 0.01-1 Gy/sec), resulting in a shorter processing time. However, e-beam, unlike gamma radiation, has a limited penetration depth. The high-energy electrons can effectively penetrate approximately 2 inches in typical food products and consequently inactivate foodborne pathogens (Jaczynski and Park, 2003). Therefore, the size and dimensions as well as specific density of food products should be carefully considered prior to e-beam processing. The e-beam dose is the quantity of radiation energy absorbed by food as it is subjected to e-beam processing (Tahergorabi et al., 2012).

\section{Microbial Inactivation from e-beam radiation}

Ionizing radiation including e-beam inactivates microorganisms by dual action involving lethal DNA changes (direct effects) and free radicals generated during water radiolysis (indirect effects). The direct effects are due to the breakage of chemical bonds between base pairs within 
microbial DNA resulting in reproductive death of microorganisms. It can induce both single stranded and double stranded breaks of DNA. The direct effect of e- beam microbial inactivation is described in Figure 2. The indirect effects occur when free radicals from ionization of water molecules disintegrate the microbial cell membrane.

The radiolysis of water products includes the hydroxyl radical, hydrogen atom, and hydrated electron (Urbain, 1986). The hydroxyl radical is the most important of all, $90 \%$ of the damage is due to hydroxyl radicals formed in the hydration layer around the DNA molecule (Farkas, 1988; Asad et al., 2004). The indirect radiation damage is predominant in living cells, resulting in a break in the phosphodiester backbone in one strand of the molecule (single-strand break) or in both strands at the same place (double-strand break) (Farkas, 1997). Irradiation also damages membrane structure, which interferes with the normal metabolism of cells, such as generation of energy, and inhibits cell growth and eventually leads to cell death (Farkas, 1988).

It is generally believed that DNA is the most critical target of ionizing radiation and inactivation of microorganisms by ionizing radiation is a result of damage to their DNA (WHO, 1988). When a population of microorganisms is irradiated, a proportion of the cells will be damaged or killed, depending on the dose. A common measure of the radiation sensitivity in bacteria is the $\mathrm{D}_{10}$ value, which is the radiation dose required to achieve one log cycle or $90 \%$ reduction of the initial microbial population (Urbain, 1986).

The survival of microbial cells upon irradiation depends on the nature and extent of direct damage produced inside the cell, the number, nature, longevity of irradiation-induced reactive species, and the inherent ability of cells to withstand the assaults and undergo repair. The DNA repair mechanism is a universal stress response following irradiation (Fitt and Sharma, 1991). 
Extracellular conditions such as $\mathrm{pH}$, temperature, and chemical composition of the food in which microorganisms are suspended have very strong impact on the survival of microorganisms upon irradiation.

Generally, radiation injured microorganisms may lose their ability to proliferate under nutrient limited conditions where uninjured microorganisms can survive. Several physical stresses that have been demonstrated to cause potentially lethal damage include: heat, cold, drying, freeze-drying, freezing, irradiation. One of the most significant characteristics of injured organisms is their temporary inability to grow on selective media. This is significant because selective media are commonly employed for the enumeration of viable bacteria, including pathogens, as a means of assessing the efficacy of a food process. The inability of some injured organisms to grow on selective media has been associated with lesions in the cellular membrane (Lucht, 1998).

\section{Microbial Radio-resistance}

Ionizing radiation affects cells and microorganisms by damaging their DNA beyond its ability to repair, breaking down cell membranes and interrupting enzymatic pathways. An organism's radiation resistance (radio-resistance) is defined by the maximum dose it can survive (Daly, 1994). The integrity of chromosomal DNA must be conserved following exposure to radiation to ensure survival. When microorganisms are treated with DNA damaging agents they stop DNA replication by blocking movement of polymerase along a template strand (Barista, 1997; Mostafavi, 2012). Generally, it is believed microorganisms that are capable of repairing the breaks induced by ionizing radiation are radiation resistant where as microorganisms that are sensitive to radiation cannot repair double- strand breaks (WHO, 1981). Understanding the 
resistance of microorganisms to radiation is very important in order to determine the efficacy of irradiation on food products.

Radiation sensitivity of organisms increases with the complexity of an organism. Differences in radiation sensitivities within groups of similar organisms are related to differences in their chemical and physical structure and the ability to recover from radiation injury (Murano and Hayes, 1995).

Radiation resistant microorganisms have earned a great deal of attention in order to understand the mechanism underlying their survival. The mechanism of radiation resistance was studied in one of the most radiation resistant bacteria, Deionococcus radiodurans. The extreme resistance development of $D$. radiodurans has been attributed to its efficient DNA repair ability after it is damaged by ionizing radiation (Makarova et al., 2001). For damaged DNA to be repaired with the help of an intact homologous sequence, the two DNAs need to find each other among numerous unrelated sequences and trade strands to make possible one-strand repair of the damage in the affected sequence (Kuzimanov, 1999).

Krisko and Miroslav (2011) reported cell death by radiation is caused primarily by oxidative damage with consequential loss of maintenance activities including DNA repair. They suggested oxidative damage to proteins might also contribute to the killing of cells exposed to radiation (Krisko and Miroslav, 2011). Radio-resistance can also be attributed to effective system of anti-oxidant protection of cellular constituents, including those required for double-strand repair in order to continue reproducing after doses of radiation causing hundreds of double strand breaks per nucleus (Krisko et al., 2012).

Microorganisms that survive a given stress often can gain resistance to that stress or other 
stresses via cross-protection or various other mechanisms (Wesche et al., 2009). Several environmental stress and food preservation methods are known to induce adaptive responses within the bacterial cell. Thus, it is important to study the response of microorganisms and their mechanism to food processing techniques.

\section{Effect of E-beam on Nutritional Quality of Food}

The safety and nutritional adequacy of food irradiation has been extensively studied, following comprehensive review, the Joint Expert Committee on Food Irradiation representing FAO/IAEA/WHO (Food and Agriculture Organization/International Atomic Energy Agency/World Health Organization) concluded that irradiation of any food up to $10 \mathrm{kGy}$ causes no toxicological hazards and introduces no nutritional or microbiological problems (WHO, 1981). Based on their review, macronutrients such as carbohydrates, proteins, and fats are not largely affected by ionizing radiation even at doses over $10 \mathrm{kGy}$. According to the Institute of Food Technologists’ Expert Panel on Food Safety and Nutrition, nutrient losses associated with irradiation are less than those associated with cooking or many other food-processing methods. The impact of irradiation on the food nutritional quality depends on the kind of food, radiation dose, the packaging atmosphere, the temperature during irradiation processing and postirradiation storage, the presence or the absence of oxygen, and the storage time (Stefanova et al., 2010).

Chemical changes can occur via primary radiolysis or secondary indirect effects. Primary effects result due to direct absorption of energy by irradiated food while secondary indirect effect 
is due to high reactivity of the free radicals and excited molecular ions produced form reactive intermediates. The free radical can undergo a variety of reactions leading to stable chemical products, often referred to as radiolytic products. Proteins when subjected to ionizing radiation absorb energy that leads to protein denaturation. Globular proteins irradiated in dilute solutions could undergo aggregation (Diehl, 1995).

Irradiation can produce protein radiolysis, which may cause the formation of free amino acids (Erkan and Ozden, 2007). It can also change the structure of a protein, primarily by breaking hydrogen bonds and other linkages in the long chains that make up proteins. Gamma irradiation of hazelnuts at $10 \mathrm{kGy}$ induced aggregation and denaturation of proteins resulting in moderate effects on the protein structure (Dogan et al., 2007). Hein et al. (2000) have also reported radiation-induced change in amino acids. The dose applied determines the effect; a high dose will change the primary structure while moderate doses will affect the secondary and tertiary structures (Arvanitoyannis, 2010). Proteins absorb less energy when subjected to ionizing radiation than heat. Thus, proteins denature significantly less when subjected to ionizing radiation than to heat (Venugopal et.al, 1999).

Several chemical reactions can be produced due to irradiation of lipids. The lipid concentration, physical status (liquid or solid), and unsaturation profile determines the intensity radiation effect (EFSA, 2011). Ionizing radiation induced radiolysis of water can also generate free radicals such as $\mathrm{OH}^{-}, \mathrm{H}^{+}$and hydrated electron, all of which react with the food constituents. Since the hydroxyl radical is an oxidizing agent and the hydrated electron is the reducing agent, free radical oxidizing and reducing reactions can be expected in food. The most susceptible site for free radical attack in a lipid molecule is adjacent to the double bonds. Thus the most affected 
lipids during irradiation are thus the polyunsaturated fatty acids that bear two or more double bonds (Oraei et al., 2011). Irradiation has been reported to accelerate lipid oxidation (Stewart, 2001). Lipid oxidation effect is more relevant in foods with larger fat content and highunsaturated fatty acids content due to free radicals formed during irradiation. Using low temperature during processing and reducing the presence of oxygen can minimize lipid oxidation (Stefanova et al., 2010).

Similar to several thermal food processing methods, losses of vitamins can be caused by e- beam radiation. The radiation sensitivity of vitamins decreases in the following sequences (Diehl, 1995; Stefanova et al., 2010): Fat-soluble vitamins: vitamin E > carotene > vitamin A > vitamin $\mathrm{D}>$ vitamin $\mathrm{K}$. Water-soluble vitamins: vitamin $\mathrm{B} 1>$ vitamin $\mathrm{C}>$ vitamin $\mathrm{B} 6>$ vitamin B2 > folate, niacin, vitamin B. Electron beam radiation affects the nutritional quality of food depending on doses applied, temperature during processing and type of food.

\section{Organization of the dissertation}

Chapter 1, 2 and 3 will discuss about the effect of e- beam on microbial inactivation and radioresistance development of food-borne microorganisms to e- beam.

Chapter 4 will discuss the effect of e-beam on chemical changes of nutrients in infant formula. 


\section{Appendix A}

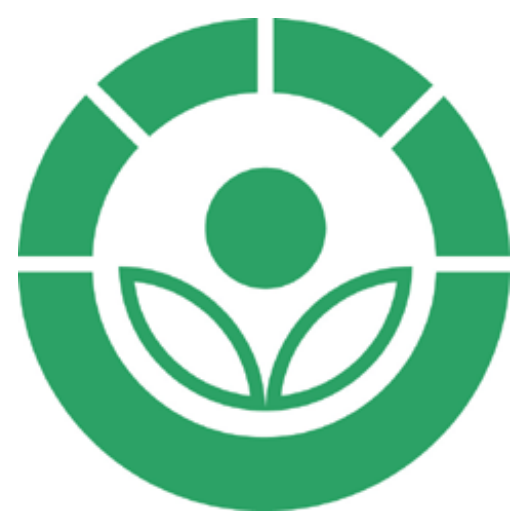

Figure 1: The International Food Irradiation Symbol-the Radura (Source: USDA).
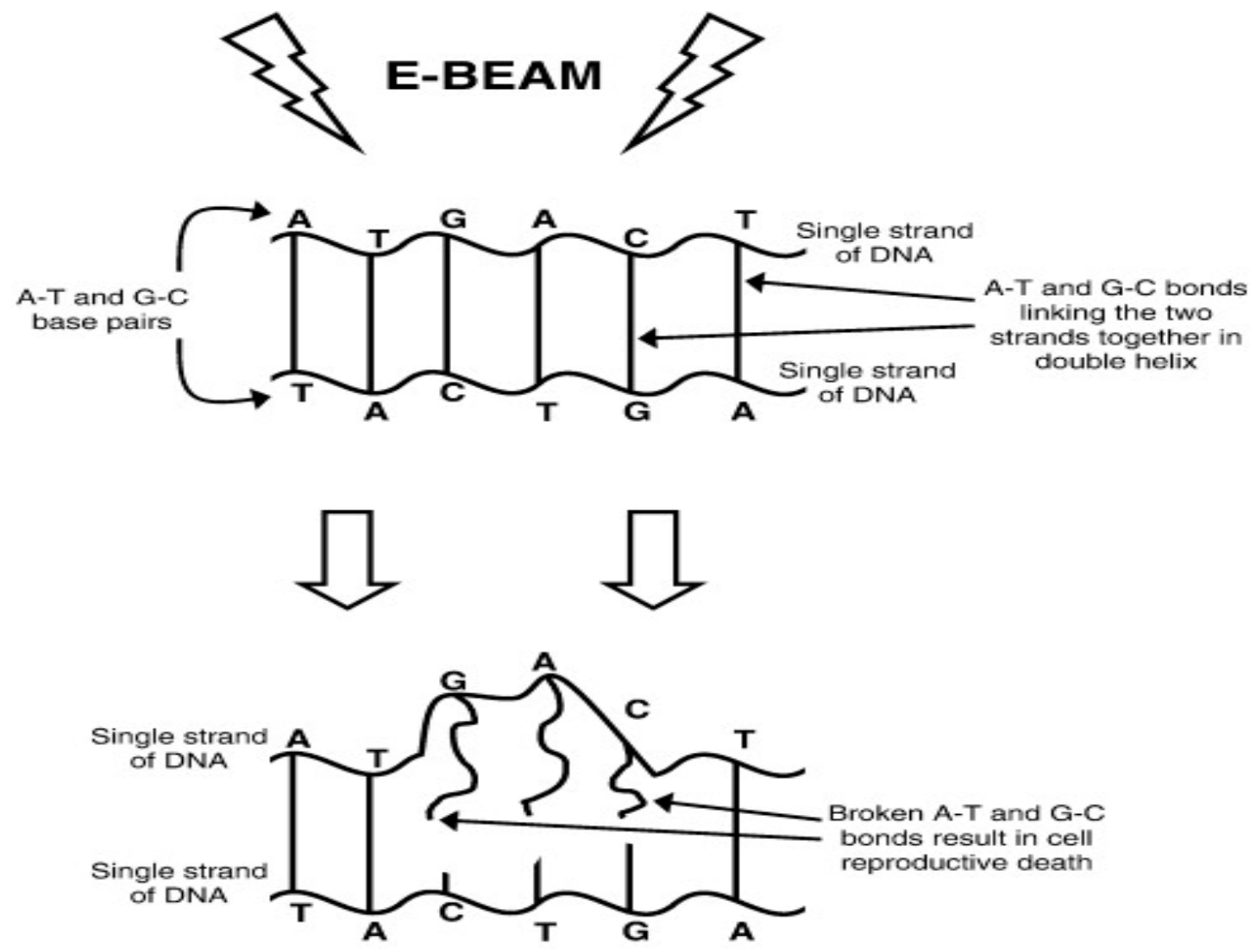

Figure 2. Direct effect of microbial inactivation by e-beam targets the genetic material (DNA and RNA) and breaks the base pairs G-C (guanine-cytosine) and T-A (thymine-adenine), resulting in reproductive death of microorganisms (Adapted from Tahergorabi et al., 2012) 


\section{Reference}

Ahn, D. U., \& Lee, E. J. (2006). Mechanisms and prevention of quality changes in meat by irradiation. Food irradiation research and technology, 127-142.

Ahn, D. U., Kim, I. S., \& Lee, E. J. (2013). Irradiation and additive combinations on the pathogen reduction and quality of poultry meat. Poultry science, 92(2), 534-545.

Arvanitoyannis, I. S. (2010). Irradiation of food commodities: techniques, applications, detection, legislation, safety and consumer opinion. Academic Press.

Arvanitoyannis, I. S., \& Stratakos, A. C. (2010). Irradiation of Poultry and Eggs. Irradiation of Food Commodities: Techniques, Applications, Detection, Legislation, Safety and Consumer Opinion, 223.

Asad, N. R., Asad, L. M. B. O., de Almeida, C. E. B., Felzenszwalb, I., Cabral-Neto, J. B., \& Leitão, A. C. (2004). Several pathways of hydrogen peroxide action that damage the E. coli genome. Genetics and Molecular Biology, 27, 291-303.

Battista, J. R. (1997). Against All Odds: The Survival Strategies of Deinococcus radiodurans. Annual Review of Microbiology, 51,203-224.

Codex Alimentarius Commission. (2003). Codex general standard for irradiated foods. Rome: Food and Agricultural Organization: CODEX STAN 106-1983: Rev. 1-2003

Daly, M. J. (1994). In vivo damage and recA-dependent repair of plasmid and chromosomal DNA in the radiation-resistant bacterium Deinococcus radiodurans. Journal of bacteriology. 176, 3508-3517

Diehl, J. F (1995). Safety of irradiated food. (Vol. 68). CRC Press.

Diehl, J. F. (2002). Food irradiation: past, present and future. Radiation Physics and Chemistry, 63(3), 211-215.

Dogan A, Siyakus G and Severcan F, (2007). FTIR spectroscopic characterization of irradiated hazelnut (Corylus avellana L.). Food Chemistry 100, 1106-1114.

EFSA Panel on Food Contact Materials, Enzymes, Flavorings and Processing Aids (CEF) (2011). Scientific Opinion on the Chemical Safety of Food Irradiation. EFSA Journal 9(4),1930.

Erkan, N. and Ozden, O., (2007). The changes of fatty acid and amino acid compositions in sea bream (Sparus aurata) during irradiation process. Radiation Physics and Chemistry, 76(10), 1636- 1641.

Farkas J. (1988). Irradiation of dry food ingredients, Boca Raton, Florida: CRC Press. 
Farkas, J. (1987). Decontamination including parasite control of dried chilled and frozen foods by irradiation, Acta Alimentaria, 16(4), 351-384.

Farkas, J. (1998). Irradiation as a method for decontaminating food. International Journal of Food Microbiology, 44, 189-204

Farkas, J. (2004). Charged particle and photon interactions with matter, In: Mozumder, A. \&Hatano, Y. (eds): Food Irradiation, Marcel Dekker, New York, pp. 785-812.

Farkas, J., \& Mohacsi-Farkas, C. (2011). History and future of food irradiation. Trends in Food Science \& Technology, 22(2), 121-126.

Food and Drug Administration (FDA) (2007). Irradiation in the production, processing, and handling of food. (Proposed rule), Fed Regist 2007 Apr 4;72(64),16291-16306.

Fitt PS, Sharma N. (1991). Starvation as an inducer of error-free DNA repair in Escherichia coli. Mutation Research, 262,145-150.

Grecz, N., Rowley, D. B., \& Matsuyama, A. (1983). The action of radiation on bacteria and viruses. Preservation of food by ionizing radiation, 2, 167-218.

Hall, J. D., \& Mount, D. W. (1981). Mechanisms of DNA replication and mutagenesis in ultraviolet-irradiated bacteria and mammalian cells. Progress in nucleic acid research and molecular biology, 25, 53-126.

Hansen MT. (1982). Rescue of mitomycin C- or psoralen-inactivated Micrococcus radiodurans by additional exposure to radiation or alkylating agents. Journal of Bacteriology, 152,976-82.

Hein WG, Simat TJ and Steinhart H. (2000). Detection of irradiated food: - Determination of non-protein bound o-tyrosine as a marker for the detection of irradiated shrimps. European Food Research and Technology, 210, 299-304.

International Food Information Council (IFIC). (2002). Food irradiation: A global food IFIC, Washington, DC.

Jaczynski, J., \& Park, J. W. (2003a). Microbial inactivation and electron penetration in surimi seafood during electron beam processing. Journal of Food Science, 68(5), 1788-1792.

Joint FAO/IAEA/WHO Study Group on High-Dose Irradiation: Wholesomeness of Food Irradiated with Doses above 10 kGy) (1997). Geneva, Switzerland

Joint, F. A. O. (1999). High-dose irradiation: wholesomeness of food irradiated with doses above 10 kGy: report of a Joint FAO/IAEA/WHO study group. 
Joint FAO/IAEA/WHO Study Group. (1999). High-dose irradiation: Wholesomeness of food irradiated with doses above $10 \mathrm{kGy}$. WHO technical report series, 890,49-77.

Morehouse, K. M., \& Komolprasert, V. (2004). Irradiation of food and packaging: an overview. In ACS SYMPOSIUM SERIES (pp. 1-13). Washington, DC; American Chemical Society; 1999.

Murano, E. A., \& Hayes, D. J. (1995). Food irradiation: a sourcebook. Iowa State Pr.

Kuzminov, A. (1999). Recombinational Repair of DNA Damage in Escherichia coli and Bacteriophage $\lambda$. Microbiology and Molecular Biology Reviews, 63(4), 751-813.

Krisko, A., \& Radman, M. (2010). Protein damage and death by radiation in Escherichia coli and Deinococcus radiodurans. Proceedings of the National Academy of Sciences, 107(32), 14373-14377.

Krisko, A., Leroy, M., Radman, M., \& Meselson, M. (2012). Extreme anti-oxidant protection against ionizing radiation in bdelloid rotifers. Proceedings of the National Academy of Sciences, 109(7), 2354-2357.

Lucht, L., Blank, G., \& Borsa, J. (1998). Recovery of foodborne microorganisms from potentially lethal radiation damage. Journal of Food Protection, 61(5), 586-590.

Makarova, K. S., Aravind, L., Wolf, Y. I., Tatusov, R. L., Minton, K. W., Koonin, E. V., \& Daly, M. J. (2001). Genome of the extremely radiation-resistant bacterium Deinococcus radiodurans viewed from the perspective of comparative genomics. Microbiology and Molecular Biology Reviews, 65(1), 44-79.

Matak KE and Jaczynski J.(2009). Food Preservation with Electron Beam. Food Science Research and Technology. (pp. 229-245) New York, NY: Nova Science Publishers Inc.

Mostafavi, H. A., Mirmajlessi, S. M., \& Fathollahi, H. (2012). The potential of food irradiation: benefits and limitations. Trends in vital Food and control engineering. Rijeka: InTech, 43-68.

Mozumder, A., \& Hatano, Y. (Eds.). (2003). Charged particle and photon interactions with matter: chemical, physicochemical, and biological consequences with applications. CRC Press.

Murray T.K.(1983). Nutritional aspects of Food Irradiation, Recent advances in Food Irradiation, edited by P.S. Elias, A.J. Cohen, Elsevier Biomedical, pp.203-216.

Oraei, M., Motalebi, A. A., Hoseini, E., Javan, S., \& Hemmasi, A. H. (2011). Effect of Gamma Irradiation on Fatty Acid Composition of Rainbow Trout (Oncorhynchus mykiss) Fillets. Iranian Journal of Fisheries Sciences, 10(2), 276-285. 
Sharan, R. N., Ryo, H. and Nomura, T. (2007). Critical role of RecA and RecF proteins in strand break rejoining and maintenance of fidelity of rejoining following -radiation-induced damage to pMTa4 DNA in E. coli, International Journal of Radiation Biology, 83(2), 89 -97.

Sommers C. H, Fan X. (2006). Food Irradiation Research and Technology. IFT Press.

Stefanova, R., Vasilev, N. V., \& Spassov, S. L. (2010). Irradiation of food, current legislation framework, and detection of irradiated foods. Food Analytical Methods, 3(3), 225-252.

Stewart, E. M. (2001). Food irradiation chemistry, food irradiation principles and applications. New York: John Wiley Sons Inc.

Tahergorabi, R., Matak, K. E., \& Jaczynski, J. (2012). Application of electron beam to inactivate Salmonella in food: Recent developments. Food Research International, 45(2), 685-694.

Tesfai, A. T., Beamer, S. K., Matak, K. E., \& Jaczynski, J. (2011). Microbial radio-resistance of Salmonella Typhimurium in liquid whole egg subjected to repetitive irradiation with electron beam. Radiation Physics and Chemistry, 80(4), 591-596.

Urbain, W. M. (1973). Food irradiation. Trans. Amer. Nucl. Soc., v. 16, pp. 53-54, 16.

Urbain, W. M. (1986). Food Irradiation. Academic Press. New York, 52-57.

Venugopal, V., Doke, S. N., \& Thomas, P. (1999). Radiation processing to improve the quality of fishery products. Critical reviews in food science and nutrition, 39(5), 391-440.

Wesche, A. M., Gurtler, J. B., Marks, B. P., \& Ryser, E. T. (2009). Stress, sublethal injury, resuscitation, and virulence of bacterial foodborne pathogens. Journal of Food Protection, 72(5), 1121-1138.

World Health Organization (1981). Report of a Joint FAO/WHO/IAEA Expert Committee, WHO Technical Report Series, No. 659.

World Health Organization (1988). Food Irradiation: a Technique for Preserving and Improving the Safety of Food, Geneva.

World Health Organization. (1999). High-dose irradiation: wholesomeness of food irradiated with doses above 10 kGy. WHO Technical Report Series \#890. Geneva: World Health Organization.

Wilkinson V.M. \& Gould G. W. (1996). Food Irradiation (a reference guide). Woodhead Publishing Limited. 


\section{CHAPTER 1}

Microbial Radio-resistance of Salmonella Typhimurium in Egg Increases Due to Repetitive Irradiation with Electron Beam

Adiam T. Tesfai, Sarah K. Beamer, Kristen E. Matak, and Jacek Jaczynski

Radiation Physics and Chemistry (2011), 80, 591-596. 


\subsection{Abstract}

Ionizing radiation improves food safety. However, foodborne pathogens develop increased resistance in response to sub-lethal stresses such as heat, $\mathrm{pH}$, antibiotics, etc. Therefore, it is hypothesized that foodborne pathogens may develop increased radio-resistance to electron beam (e-beam) radiation. The objective was to determine if $\mathrm{D}_{10}$-value for Salmonella Typhimurium in de-shelled raw egg (egg white and yolk mixed together) increases due to repetitive processing with e-beam at sub-lethal doses. Survivors were enumerated on nonselective (TSA) and selective (XLD) media. Survivors from the highest dose were isolated and used in subsequent e-beam cycle. This process was repeated four times for a total of five e-beam cycles. $\mathrm{D}_{10}$-values for $S$. Typhimurium enumerated on TSA and XLD following each e-beam cycle were calculated as inverse reciprocal of the slope of survivor curves. $\mathrm{D}_{10}$-values for the ATCC strain were $0.59 \pm 0.031$ and $0.46 \pm 0.022 \mathrm{kGy}$ on TSA and XLD, respectively. However, following the fifth e-beam cycle, the respective $\mathrm{D}_{10}$-values increased $(\mathrm{P}<0.05)$ to $0.69 \pm 0.026$ and $0.61 \pm 0.029 \mathrm{kGy}$. S. Typhimurium showed a trend $(\mathrm{P}>0.05)$ to develop radio-resistance faster on selective media, likely due to facilitated selection of radio-resistant cells within the microbial population following each e-beam cycle. For all five e-beam cycles, $S$. Typhimurium had higher $(\mathrm{P}<0.05) \mathrm{D}_{10}$-values on non-selective media, indicating that sub-lethal injury followed by cellular repair and recovery are important for radio-resistance and inactivation of this microorganism. This study demonstrated that e-beam efficiently inactivates $S$. Typhimurium in raw egg; however, similar to other inactivation techniques and factors affecting microbial growth, $S$. Typhimurium develops increased radio-resistance if repetitively processed with e-beam at sublethal doses. 
Key words: S. Typhimurium, electron beam, food irradiation, microbial inactivation kinetics, non-thermal food preservation, and microbial inactivation.

\subsection{Introduction}

Contamination of food products with Salmonella poses a public health problem and is a cause of foodborne illness worldwide (Bell and Kyriakides, 2002; Farkas, 1998; Sarjeant et al., 2005). There are more than 2,500 serotypes of Salmonella reported, but Salmonella enterica subsp. enterica serotype Typhimurium (S. Typhimurium) is the number one leading serotypecausing salmonellosis worldwide (Brenner et al., 2000; Galanis et al., 2006). S. Typhimurium is often found in many food products, but the most common sources are poultry, cheese, and eggs (Centers for Disease Control and Prevention, 2009a). According to the CDC report, every year in the U.S. approximately 40,000 people are reported ill due to salmonellosis (Centers for Disease Control and Prevention, 2009a). There have been several recent high-profile outbreaks of foodborne salmonellosis the United States. These outbreaks implicated food products that had not been commonly thought of as typical transmission vehicles for $S$. Typhimurium. For example, the CDC has reported 529 confirmed cases in 43 states implicating peanut butter and peanut butter containing products (Centers for Disease Control and Prevention, 2009b). The increasing incidence of $S$. Typhimurium in different food products may be associated with the adaptability of this microorganism to various unfavorable conditions (Anriany et al., 2001).

Ionizing radiation as a non-thermal means to improve microbial food safety has received considerable attention. Electron beam (e-beam) irradiation is highly effective for inactivating foodborne pathogenic microorganisms (Black and Jaczynski, 2006; 2007; 2008; Jaczynski and Park, 2003a; Levanduski and Jaczynski, 2008; James et al., 2010; Hvizdzak et al., 2010). As with other types of ionizing radiation such as gamma and X-rays, e-beam inactivates 
microorganisms directly by lethal damage of microbial DNA and indirectly by free radicals generated during water radiolysis that disintegrate microbial cell membrane (Urbain, 1986). Ebeam inactivates pathogens non-thermally; and therefore, may be used to inactivate Salmonella in raw egg (Alvarez et al., 2007). Although dependent on a particular food product, e-beam does not affect protein functionality and other food quality attributes within typical doses required for microbial inactivation (Jaczynski and Park, 2003b; 2004).

Adaptation of $S$. Typhimurium to various stresses has been reported in literature. $S$. Typhimurium can adapt to several environmental stresses at sub-lethal levels such as nutrient starvation, $\mathrm{pH}$ extremes, oxidative stress, osmotic shock, and heat shock (Foster and Spector, 1995). It has been demonstrated that acid-adapted $S$. Typhimurium develops cross-protection, resulting in increased tolerance against other environmental stresses (Leyer et al., 1993). This may be influenced by changes in properties of cell surface due to the synthesis of specific outer membrane proteins (i.e., shock proteins). The acid shock proteins are expressed as a microbial response to stressful $\mathrm{pH}$ conditions and result in increased acid tolerance. This has been associated with enhanced resistance to heat and osmotic stress (i.e., cross-protection) (Leyer et al., 1993). The acid adaptation/tolerance has also been associated with cross-protection against ionizing radiation, resulting in increased radio-resistance of Escherichia coli O157:H7 (Buchanan et al., 1998; 1999; 2004). Development of increased microbial resistance to antibiotics resulting in cross-protection against e-beam has also been suggested for nalidixic acid resistant Salmonella enterica subsp. enterica serotype Montevideo (James et al., 2010). A possibility of development of radio-resistant Salmonella (a major foodborne pathogen worldwide) in egg (staple food worldwide) as a microbial response to e-beam (novel non-thermal antimicrobial processing technology) at sub-lethal levels is in unknown. To our knowledge there 
have been no published reports in this area. Therefore, it is critical to study this microbial behavior in food as it has both, practical meaning and scientific significance.

It is hypothesized that $S$. Typhimurium will develop increased $(\mathrm{P}<0.05)$ radio-resistance in egg if exposed repetitively to e-beam processing at sub-lethal doses. The objective of this challenge study was to determine if repetitive exposure to e-beam at sub-lethal doses increases $(\mathrm{P}<0.05) \mathrm{D}_{10}$-value for $S$. Typhimurium in de-shelled raw egg (egg white and yolk mixed together).

\subsection{Materials and methods}

\subsubsection{Sample preparation}

Fresh raw eggs were purchased from a local supermarket. Preliminary tests (data not shown) confirmed that Salmonella was below detectable levels in eggs used in this study. Egg shells were thoroughly cleaned followed by sanitation with $70 \%$ ethanol and allowed to air dry under UV in a bio-safety cabinet (Class II Type A/B3, NuAire, Inc., Plymouth, MN). Sanitized eggs were aseptically broken, transferred into a laboratory blender (model S13L31, Waring Laboratory, Torrington, CT) and homogenized for 1 min. The egg sample prepared in this manner will hereafter be called de-shelled raw egg. All equipment used to handle the eggs such as blenders, spatulas, etc. was cleaned and sanitized with ethanol, followed by drying under UV in the bio-safety cabinet. Whenever applicable, aseptic technique under bio-safety cabinet was used for transfer, handling, etc. of Salmonella. 


\subsubsection{Microorganism and culture conditions}

Salmonella enterica subsp. enterica serotype Typhimurium ATCC strain 14028

(hereafter called S. Typhimurium) was used in this study (Brenner et al., 2000). S. Typhimurium lyfo-disks were reconstituted by crushing one pellet using sterile spatula in $0.4 \mathrm{~mL}$ of sterile trypticase soy broth (TSB) (Becton Dickinson and Company, Sparks, MD). The content was aseptically transferred to $3.6 \mathrm{~mL}$ of sterile TSB and allowed to grow aerobically at $35^{\circ} \mathrm{C}$ for $24 \mathrm{~h}$ in an incubator/shaker set at 150 rpm (C24 Incubator/Shaker, New Brunswick Scientific, Edison, NJ). The $4 \mathrm{~mL} S$. Typhimurium culture was aseptically transferred to $76 \mathrm{~mL}$ of sterile TSB and allowed to grow aerobically at $35^{\circ} \mathrm{C}$ for $24 \mathrm{~h}$ in the incubator/shaker set at $150 \mathrm{rpm}$. Preliminary studies (data not shown) confirmed that this procedure yielded a $S$. Typhimurium culture at stationary phase of growth and approximately $10^{9} \mathrm{CFU} / \mathrm{mL}$.

The 24-h S. Typhimurium culture was used as an inoculum for the de-shelled raw egg. Inoculum was added to the egg at 5\% (v/v). Following inoculation, the de-shelled raw egg (egg white and yolk mixed together) was aerobically incubated (Isotemp Incubator, Fisher Scientific, Pittsburgh, PA) at $35^{\circ} \mathrm{C}$ for $24 \mathrm{~h}$. Preliminary studies (data not shown) verified that this procedure resulted in a concentration of $S$. Typhimurium at approximately $10^{9} \mathrm{CFU} / \mathrm{mL}$ of deshelled raw egg. Distilled and de-ionized water $\left(\mathrm{ddH}_{2} \mathrm{O}\right)$ was periodically added to account for moisture loss due to evaporation during incubation and the sample was periodically mixed to ensure adequate distribution of microbial cells in the de-shelled raw egg.

Following incubation, individual samples of approximately $12 \mathrm{~g}$ of inoculated de-shelled raw egg were separately packed $(10$ x 15 cm Kapak SealPAK pouches, Kapak Corporation, Minneapolis, MN) and aerobically sealed (Kapak sealer, Kapak Corporation, Minneapolis, MN). Each sample was spread evenly, resulting in a thickness below $1 \mathrm{~mm}$ in order to ensure complete 
penetration of e-beam and even distribution of absorbed dose throughout the sample (Jaczynski and Park, 2003a). The samples were stored at $-80^{\circ} \mathrm{C}$ until shipment. The storage time did not exceed one week.

\subsubsection{Treatment}

Samples were packed and shipped according to an approved institutional protocol in a heavy-duty styrofoam cooler filled with dry ice. Samples were shipped overnight to an e-beam processing facility (Sterigenics International, San Diego, CA). At the e-beam facility, the samples were allowed to equilibrate to $4^{\circ} \mathrm{C}$ overnight in a refrigerator prior to e-beam processing. The samples at refrigeration temperature $\left(4^{\circ} \mathrm{C}\right)$ were subjected to one-sided e-beam with energy fixed at $10 \mathrm{MeV}$ and doses between 0.0-4.0 kGy were applied. The applied e-beam doses were confirmed with film dosimeters (Jaczynski and Park, 2003a). The film dosimeters (FWT-60 series radiochromatic dosimeters, Far West Technology, Inc., Goleta, CA) were attached to the bottom of the Kapak pouches prior to e-beam processing. The absorbed doses were determined following e-beam processing at $605 \mathrm{~nm}$ using a spectrophotometer (Cary 100 UV-Vis, Varian, Inc., Palo Alto, CA). The absorbed doses were used to calculate $\mathrm{D}_{10}$-values. Immediately following e-beam treatment, samples were frozen, packed, and shipped overnight back to the food microbiology laboratory at West Virginia University. Upon arrival, the e-beam processed samples were stored at $-80^{\circ} \mathrm{C}$ until analysis. The storage time did not exceed one week. Preliminary studies (data not shown) determined that the freeze-thaw cycles used in the experiments did not $(\mathrm{P}>0.05)$ affect the survival of $S$. Typhimurium; and therefore, did not confound the results. All of the experiments had samples that were not exposed to beam (i.e., $0.0 \mathrm{kGy}$ ). These samples were used as control samples. The control samples received the 
same treatment as all other samples except for e-beam irradiation; i.e., they were shipped to the e-beam facility in the same heavy-duty styrofoam cooler and stored under the same conditions, but were not irradiated with e-beam. Three separate e-beam experiments $(\mathrm{n}=3)$ were conducted.

\subsubsection{Bacterial enumeration of S. Typhimurium survivors}

The samples were equilibrated to $4^{\circ} \mathrm{C}$ overnight in a refrigerator prior to enumeration. The e-beam processed samples were manually pummeled for $1 \mathrm{~min}$ followed by mixing in a stomacher (Bag Mixer 400, Interscience, St. Nom, France) set at medium speed for 1 min in order to obtain equal distribution of survivors within the Kapak pouch. For serial dilutions, $10 \mathrm{~g}$ of each e-beam processed sample was aseptically placed into $90 \mathrm{~mL}$ of dilutent (Butterfield phosphate buffer, Hardy Diagnostics, Santa Maria, CA). Further serial dilutions were aseptically made by taking $10 \mathrm{~mL}$ of diluted sample and transferring it into a $90 \mathrm{~mL}$ diluent bottle, followed by shaking the bottle to uniformly distribute survivors. Survivors were enumerated on nonselective (Tryptic-Soy Agar, TSA) (Becton Dickinson and Company, Sparks, MD) and selective (Xylose-Lysine-Deoxycholate agar, XLD) (Thermo Fisher Scientific Remel Products, Lenexa, KS) media using a standard spread-plating technique. An aliquot of $0.1 \mathrm{~mL}$ of each serial dilution was pipetted and spread on the TSA and XLD plates. The plates were incubated at $35^{\circ} \mathrm{C}$ for $24 \mathrm{~h}$ and discrete Salmonella colonies were counted. All bacterial enumerations were performed in duplicate and the mean values are reported as CFU/g.

\subsubsection{Isolation of S. Typhimurium survivors for repetitive e-beam processing}

Following the 24-h incubation on the TSA and XLD plates, colonies of $S$. Typhimurium survivors from the highest e-beam dose that resulted in survival were randomly isolated 
separately from the TSA and XLD plates. Therefore, two separate isolates of S. Typhimurium were obtained. One isolate was from TSA plates, while the second isolate was from the XLD plates. The highest dose applied in the present study was $4 \mathrm{kGy}$; however, there were no detectable survivor colonies at that dose. Survivor colonies were isolated from the highest dose that resulted in survival of $S$. Typhimurium, which was lower than 4 kGy (i.e., the highest dose applied). The isolates from TSA and XLD plates were separately incubated in sterile TSB as previously described in "Microorganism and culture conditions".

As described in "Sample preparation”, the 24-h S. Typhimurium cultures were used as inocula for the next sample of the de-shelled raw egg and cycle of e-beam processing. The isolation of $S$. Typhimurium survivors following e-beam processing was repeated four times and a total of five cycles of e-beam processing were conducted. In the first cycle of e-beam processing, the ATCC S. Typhimurium strain 14028 was used. The $S$. Typhimurium survivors isolated following the first cycle of e-beam processing were designated as A1 (hereafter called isolate A1), while the $S$. Typhimurium survivors isolated following the second cycle of e-beam processing using isolate A1 were designated as A2 (hereafter called isolate A2). Isolates A3 and A4 were obtained accordingly.

\subsubsection{Determining $D_{10}$-values}

Following each cycle of e-beam processing, the counts of S. Typhimurium survivors enumerated on TSA and XLD plates were separately plotted on a logarithmic scale as a function of e-beam dose (kGy). Therefore, for each cycle of e-beam processing two sets of separate survivor curves were constructed. One set of survivor curves corresponded to S. Typhimurium survivors enumerated on TSA (non-selective media) plates, while the second set to survivors 
enumerated on the XLD (selective media) plates. Each set had three individual curves that were used to determine three $\mathrm{D}_{10}$-values (three $\mathrm{D}_{10}$-values for TSA and three $\mathrm{D}_{10}$-values for XLD). The $\mathrm{D}_{10}$-values were determined by calculating the negative reciprocal of the slope of the survivor curves (equation 1) (Jaczynski and Park, 2003a). $\mathrm{D}_{10}$-value is recognized as the radiation dose required to achieve one log cycle or $90 \%$ reduction of the initial microbial population (Urbain, 1986).

$$
\log \left(\frac{N}{N_{0}}\right)=-\frac{1}{D} * t
$$

$\mathrm{N}$ - concentration of survivors after e-beam dose,

$\mathrm{N}_{0}$ - initial microbial concentration,

$\mathrm{D}-\mathrm{D}_{10}$-value, decimal reduction dose,

t - e-beam dose.

\subsubsection{Statistics}

Five cycles of e-beam processing were conducted, three separate experiments $(n=3)$ per each cycle. The de-shelled raw egg samples were randomly assigned to e-beam doses. All bacterial enumerations in each of the three separate experiments were performed in duplicate and the mean values of the duplicate counts are reported as CFU/g. The mean values of the duplicate counts in each of the three separate experiments were log-converted and analyzed by linear regression using MS Office Excel software (Version 2007) in order to determine three $\mathrm{D}_{10^{-}}$ values. One-way analysis of variance (ANOVA) was performed to detect significant differences in microbial survival with increasing e-beam dose. The PROC GLM software was used to 
determine significant differences between mean $\mathrm{D}_{10}$-values for $S$. Typhimurium enumerated on TSA and XLD media within each cycle of e-beam processing (Figures 1-5). The same software was used to determine significant differences between mean $\mathrm{D}_{10}$-values for $S$. Typhimurium following all cycles of e-beam processing within each media type (Figure 6, Table 1). All statistical analyses were performed using SAS (Version 9) and differences were considered significant when $\mathrm{P}<0.05$ (SAS Institute, 2002).

\subsection{Results and discussion}

Survivor curves were plotted for S. Typhimurium ATCC strain 14028 (Figure 1) and each successive isolate (A1, A2, A3, and A4) following repetitive exposure to e-beam (Figures 2-5). Linear regression analysis of survivor curves yielded high correlation coefficients $\left(\mathrm{R}^{2}\right)$. In addition, ANOVA analysis showed that the log-converted counts of $S$. Typhimurium survivors decreased $(\mathrm{P}<0.05)$ as the e-beam dose increased for all five cycles on both TSA and XLD media. Therefore, $\mathrm{D}_{10}$-values for each isolate and the original ATCC strain were calculated from the survivor curves as a function of e-beam dose (Table 1). The ATCC strain had not been subjected to e-beam radiation prior to this experiment and the respective $\mathrm{D}_{10}$-values were the lowest at $0.59 \pm 0.031 \mathrm{kGy}$ on TSA and $0.46 \pm 0.022 \mathrm{kGy}$ (Figure 1 ) on XLD. The highest $(\mathrm{P}<0.05) \mathrm{D}_{10}$-values on TSA $(0.69 \pm 0.026 \mathrm{kGy})$ and XLD $(0.61 \pm 0.029 \mathrm{kGy})$ were determined for the isolate A4 following the fifth cycle of e-beam processing (Figure 5). These results prove that $S$. Typhimurium has the capability to develop increased $(\mathrm{P}<0.05)$ radio-resistance if repetitively exposed to e-beam. Microbial radio-resistance increased by $117 \%$ and $133 \%$ for survivors of isolate A4 enumerated on TSA and XLD, respectively when compared to the original $S$. Typhimurium ATCC strain. Furthermore, the selective media (XLD) allowed faster increase of 
radio-resistance than non-selective media (TSA), although it was a not significant $(\mathrm{P}=0.058)$ trend (Figure 7).

$\mathrm{D}_{10}$-value of $0.44 \pm 0.04 \mathrm{kGy}$ for $S$. Typhimurium irradiated with ${ }^{60} \mathrm{Co}$ in the de-shelled raw egg has been reported (Alvarez et al., 2007). $\mathrm{D}_{10}$-value of $0.53 \pm 0.031 \mathrm{kGy}$ for $S$.

Typhimurium irradiated with ${ }^{137}$ Cs under aerobic conditions in mechanically deboned chicken has also been reported (Thayer et al., 1990). Similar $\mathrm{D}_{10}$-values were also determined in the present study ranging from $0.46 \pm 0.022 \mathrm{kGy}$ for $S$. Typhimurium ATTC 14028 in the de-shelled raw egg enumerated on XLD media to $0.69 \pm 0.026 \mathrm{kGy}$ for isolate A4 enumerated on TSA (Table 1). However, in the present study e-beam was used instead of gamma radiation and $S$. Typhimurium ATTC 14028 showed a development of increased $(\mathrm{P}<0.05)$ radio-resistance as response to repetitive e-beam irradiation.

Figure 6 shows the development of increased radio-resistance in the original ATCC strain and each successive isolate derived from this strain with respect to the enumeration on both media (i.e., TSA and XLD). The ANOVA analysis proved that the more microorganisms were subjected to e-beam processing, the greater $(\mathrm{P}<0.05)$ was their radio-resistance (i.e., $\mathrm{D}_{10}$-value) to e-beam (Figure 6). For both TSA and XLD media, the PROC GLM analysis indicated that the second cycle of e-beam processing yielding isolate A1 resulted in D-values that were not ( $\mathrm{P}>0.05$ ) different from $\mathrm{D}_{10}$-values for the ATCC strain and isolate A2. However, there was a significant increase $(\mathrm{P}<0.05)$ of the $\mathrm{D}_{10}$-values between isolates $\mathrm{A} 1$ and $\mathrm{A} 3$ as well as $\mathrm{A} 4$ enumerated on both types of media (Figure 6). Many studies have demonstrated that $S$. Typhimurium responds to stressful environmental conditions with physiological changes that enhance microbial survival (Foster and Spector, 1995; Humphrey, 2004; Karatzas et al., 2008). Exposure of $S$. Typhimurium to repetitive cycles of acid challenge increased microbial resistance 
to acid and additionally triggered development of heat adaptation in one line of the isolates (Karatzas et al., 2008). It has been shown that acid-adapted $S$. Typhimurium cells increase heat resistance (Leyer and Johnson, 1993) and radio-resistance (James et al., 2010). Therefore, it has been theorized that acid habituation may synergistically increase microbial radio-resistance to ionizing radiation, resulting in cross-protection (Buchanan et al., 2004). The cross-protection of acid-adapted $S$. Typhimurium may be influenced by changes in cell surface properties due to the synthesis of specific outer membrane proteins (Leyer and Johnson, 1993). It is likely; therefore, that the repetitive exposure of $S$. Typhimurium to e-beam in the present study triggered similar microbial response mechanism resulting in changes of cell surface properties; and consequently, might have contributed to the development of increased radio-resistance.

When S. Typhimurium survivors were enumerated on nutrient-rich non-selective media (TSA) allowing recovery of injured cells, the resultant $\mathrm{D}_{10}$-value were greater $(\mathrm{P}<0.05)$ for all five cycles when compared to the selective media (XLD) (Figures 1-5). The comparison between $\mathrm{D}_{10}$-values for microorganisms enumerated on selective vs. non-selective media allows determination of whether or not e-beam resulted in the sub-lethal injury and cellular repair of $S$. Typhimurium survivors (Ray, 1979). The consistently higher $(\mathrm{P}<0.05) \mathrm{D}_{10}$-values in the present study for $S$. Typhimurium enumerated on TSA than on XLD following all five e-beam cycles (Figures 1-5) indicate that e-beam resulted in the sub-lethal injury of some of the cells. Furthermore, as evidenced by the higher counts on the TSA plates, this injury was not sustained, but instead some of the survivors repaired cellular damage, recovered and grew on the TSA plates. Therefore, the results of the present study demonstrate that e-beam similarly to gamma irradiation $\left({ }^{60} \mathrm{Co}\right)$ of $S$. Typhimurium in chicken meat results in inactivation as well as cellular injury (Lamuka et al., 1992). Alvarez et al. (2007) inoculated de-shelled raw egg with S. 
Enteritidis, $S$. Typhimurium, and $S$. Senftenberg that were subjected to gamma radiation $\left({ }^{137} \mathrm{Cs}\right)$ followed by heat treatment. As opposed to other reports (Lamuka et al., 1992; Sarjeant et al., 2005) as well as the present study, Alvarez et al. (2007) did not ( $\mathrm{P}>0.05)$ observe irradiationinduced cell injury. However, the difference may be partially explained by different selective medium used by Alvarez et al. (2007). In the present study, XLD was used as a selective medium, whereas Alvarez et al. (2007) used 3\% (w/v) NaCl supplement in the TSA medium (TSA-SC) as a selective factor for Salmonella. However, it has been demonstrated that Salmonella adapts to osmotic shock (i.e., ionic stress $-\mathrm{NaCl}$ ) as well as develops crossprotection when stressed osmotically (Foster and Spector, 1995; Leyer and Johnson, 1993). Additionally, e-beam was used in the present study instead of ${ }^{137} \mathrm{Cs}$. Gamma irradiation with ${ }^{137} \mathrm{Cs}$ had a dose rate of $0.095 \mathrm{kGy} / \mathrm{min}$ (1), which is about 1000 -fold slower than typical e-beam such as in the present study. Some studies have demonstrated that dose rate has an effect on the rate on microbial inactivation. Since there was no $(\mathrm{P}>0.05)$ difference between $\mathrm{D}_{10}$-values determined on TSA and TSA-SC, the average $\mathrm{D}_{10}$-values for $S$. Enteritidis, $S$. Typhimurium, and S. Senftenberg were $0.50,0.43$, and $0.64 \mathrm{kGy}$, respectively (Alvarez et al., 2007). These values are similar to the values in the present study and to the previously reported $\mathrm{D}_{10}$-values for Salmonella (Monk et al., 1994; Sherry et al., 2004; Thayer et al., 1990).

Licciardello et al. (1969) demonstrated that gamma radiation $\left({ }^{60} \mathrm{Co}\right)$ of $S$. Typhimurium, S. Newport, $S$. Thompson, and $S$. Heidelberg induces radio-resistance. In this early study, the radio-resistant cells were described as "plumper" than their parent strains and showed a marked pleomorphism. Percent survival was determined as an indicator of the radio-resistance (Licciardello et al., 1969). However, $\mathrm{D}_{10}$-value is a well established and widely recognized indicator of microbial resistance/inactivation rates. Statistical analysis was not performed in this 
early study, either. In comparison, $\mathrm{D}_{10}$-values as a standard kinetics of microbial inactivation were determined and statistically compared following each cycle of e-beam irradiation on both selective (XLD) and non-selective (TSA) media in the present study. Conversely, Licciardello et al. (1969) enumerated survivors on non-selective (TSYE - Tryptic-Soy-Yeast-Extract) agar, which only accounted for fully viable cells and not for radiation-injured ones. Therefore, gamma radiation induced injury and cellular repair could not be determined. Also, Licciardello et al. (1969) used ${ }^{60} \mathrm{Co}$ as a source of ionizing radiation, which provides slow dose rate. The much slower dose rate as compared to e-beam may allow for initiation of cellular repair mechanisms; and consequently, some recovery of injured cells. However, despite these differences between the present study and the early study by Licciardello et al. (1969), the present study proves the same trend that $S$. Typhimurium develops increased radio-resistance if repetitively exposed to ebeam.

Davis and Sinskey (1973) characterized a radio-resistant mutant S. Typhimurium LT2. This microorganism exhibited stepwise increase of radio-resistance to gamma and UV radiations. Similarly to Licciardello et al. (1969), the radio-resistant cells were generally larger and also contained 1.8-2.1 times more RNA and protein than parent cells, but DNA contents were similar. It was suggested that the development of radio-resistance was a result of selection that favored mutations leading to increased capacity to repair microbial DNA (Davis and Sinskey, 1973). For all five cycles of e-beam processing in the present study, $S$. Typhimurium had higher $(\mathrm{P}<0.05)$ $\mathrm{D}_{10}$-values when enumerated on TSA than XLD plates, indicating that sub-lethal injury, followed by cellular repair and recovery are important for radio-resistance of this microorganism. The radio-resistance was developed at a faster rate on XLD than TSA plates (Figure 7); although this trend was not significant $(\mathrm{P}=0.058)$. Therefore, similar to Davis and Sinskey’s (1973) 
suggestion, the present study confirms importance of cellular repair mechanisms in microbial radio-resistance.

The direct mechanism of microbial inactivation due to ionizing radiation including ebeam involves DNA damage (Urbain, 1986). Therefore, exposure of Salmonella to radiation results in high frequency of mutations in DNA fragments responsible for repair and replication, particularly, in rpoS genes (i.e., RNA polymerase S) (LeClerc et al., 1996). Thus, changes in rpoS may be important in the development of increased radio-resistance of $S$. Typhimurium to ebeam. We intend to investigate this concept with micro-arrays and comparative genomic sequences analysis (CGSA). Micro-arrays use RNA for comparative surveys of large populations. In CGSA, DNA (not RNA) of radio-resistant Salmonella is compared to a reference genome for identification of nucleotide polymorphisms, insertions, and deletions that may have contributed to survival of Salmonella exposed to e-beam.

\subsection{Conclusions}

E-beam is a non-thermal process that may be an alternative method to efficiently control S. Typhimurium in egg. $S$. Typhimurium has been shown to develop increased resistance to a variety of stresses such as low $\mathrm{pH}$, increased temperature and ionic strength, and antibiotics. Repetitive irradiation of S. Typhimurium ATCC 14028 inoculated in de-shelled raw egg (egg white and yolk mixed together) with e-beam resulted in an increase $(\mathrm{P}<0.05)$ of $\mathrm{D}_{10}$-values from $0.59 \pm 0.031$ to $0.69 \pm 0.026 \mathrm{kGy}$ when enumerated on TSA plates and $0.46 \pm 0.022$ to $0.61 \pm 0.029$ kGy on XLD plates. While e-beam can efficiently inactivate $S$. Typhimurium in food products including egg, similar to other inactivation techniques and environmental stresses, $S$.

Typhimurium has a capability to develop increased radio-resistance if repetitively processed with e-beam. The $\mathrm{D}_{10}$-values for $S$. Typhimurium enumerated on non-selective media (TSA) were 
greater $(\mathrm{P}<0.05)$ than on selective $(\mathrm{XLD})$ media for all five cycles of e-beam irradiation, indicating that sub-lethal injury followed by cellular repair and recovery are important aspects of microbial inactivation with e-beam.

\section{Acknowledgments}

Special thanks to Sterigenics International for allowing us to use e-beam facility. Our appreciation extends to Carl A. Zinn and Richard Vallejo of Sterigenics for invaluable technical expertise with e-beam and Aunchalee Aussanasuwamakul for assistance with statistical analysis. This research was funded by the USDA Hatch program (project nr WVA00429). 


\subsection{Appendix B}

Table 1. Increased radio-resistance ( $\mathrm{D}_{10}$-value) of $S$. Typhimurium in de-shelled raw egg subjected to e-beam.Data are given as mean \pm standard deviation $(\mathrm{SD})(\mathrm{n}=3)$. Mean $\mathrm{D}_{10}$-values in rows with different letters indicate significant differences $(\mathrm{P}<0.05)$ within the media type.

\section{S. Typhimurium isolate}

\begin{tabular}{|c|c|c|c|c|c|c|}
\hline $\begin{array}{l}\text { Media } \\
\text { Type }\end{array}$ & & $\begin{array}{c}\text { ATCC } \\
(14028)\end{array}$ & A1 & A2 & A3 & A4 \\
\hline \multirow{4}{*}{ TSA } & $\Gamma$ & T & & & & \\
\hline & $\mathrm{D}_{10}$-value $\pm \mathrm{SD}$ & $\begin{array}{c}0.59 \pm 0.031 \\
\text { с }\end{array}$ & $\begin{array}{c}0.58 \pm 0.007 \\
\text { c }\end{array}$ & $\begin{array}{c}0.61 \pm 0.016 \\
\text { bc }\end{array}$ & $\begin{array}{c}0.62 \pm 0.012 \\
\mathrm{~b}\end{array}$ & $\begin{array}{c}0.69 \pm 0.026 \\
\mathrm{a}\end{array}$ \\
\hline & $\mathrm{R}^{2}$ & 0.98 & 0.98 & 0.92 & 0.99 & 0.99 \\
\hline & $\begin{array}{l}\text { \% increase of } \\
\text { radio-resistance }\end{array}$ & 100 & 98 & 103 & 105 & 117 \\
\hline \multirow{4}{*}{ XLD } & | & & & & & \\
\hline & $\mathrm{D}_{10}$-value $\pm \mathrm{SD}$ & $\begin{array}{c}0.46 \pm 0.022 \\
\mathrm{~d}\end{array}$ & $\begin{array}{c}0.49 \pm 0.014 \\
\mathrm{~cd}\end{array}$ & $\begin{array}{c}0.51 \pm 0.020 \\
\text { bc }\end{array}$ & $\begin{array}{c}0.53 \pm 0.005 \\
\mathrm{~b}\end{array}$ & $\begin{array}{c}0.61 \pm 0.029 \\
\mathrm{a}\end{array}$ \\
\hline & $\mathrm{R}^{2}$ & 0.98 & 0.99 & 0.95 & 0.96 & 0.99 \\
\hline & $\begin{array}{l}\% \text { increase of } \\
\text { radio-resistance }\end{array}$ & 100 & 107 & 111 & 115 & 133 \\
\hline
\end{tabular}




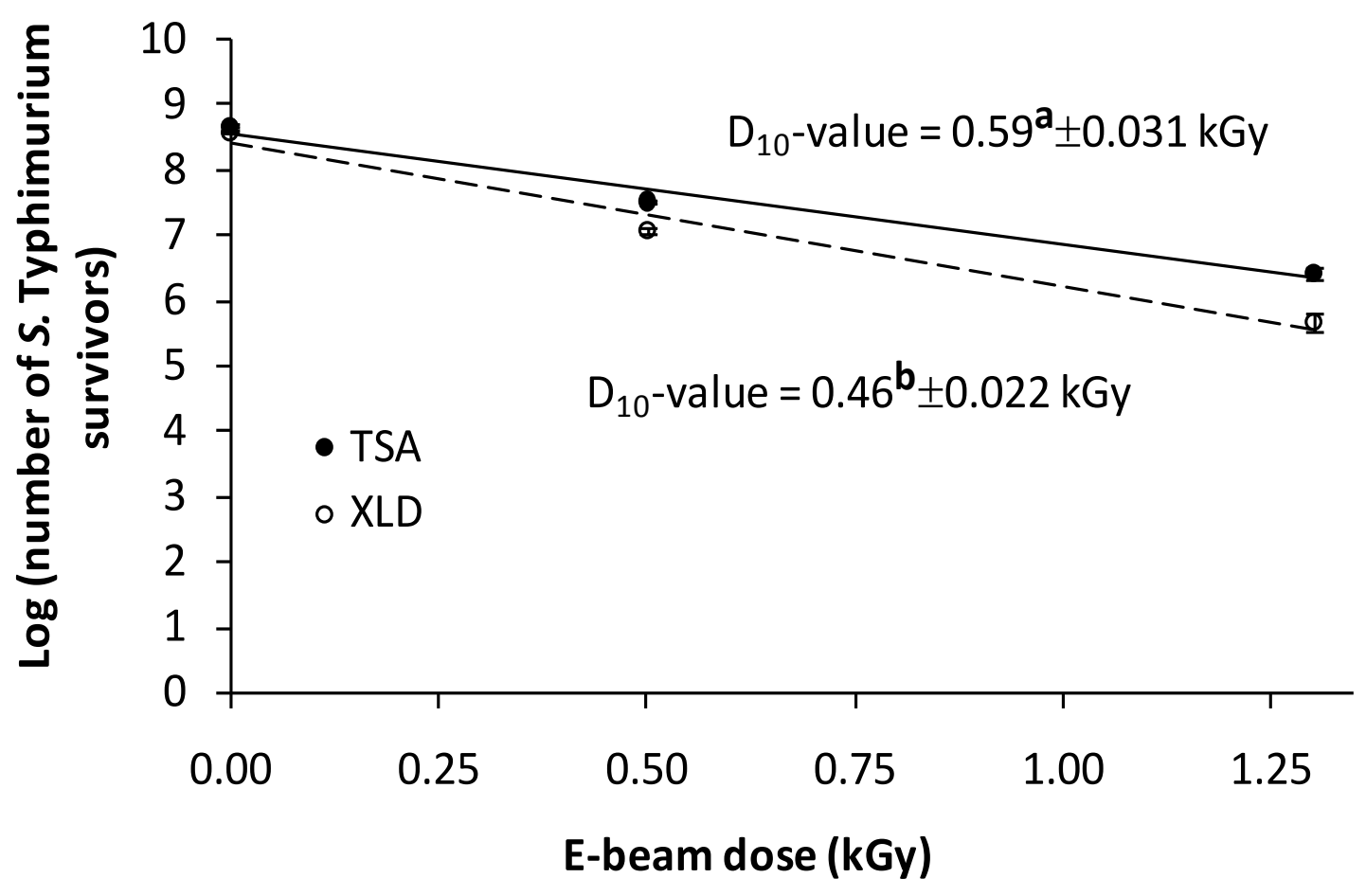

\section{Figure 1:}

Survivor curves for S. Typhimurium ATCC 14028 in de-shelled raw egg subjected to e-beam and enumerated on selective (XLD) and non-selective (TSA) media. Different superscript letters following $\mathrm{D}_{10}$-values indicate significant differences $(\mathrm{P}<0.05)$. 


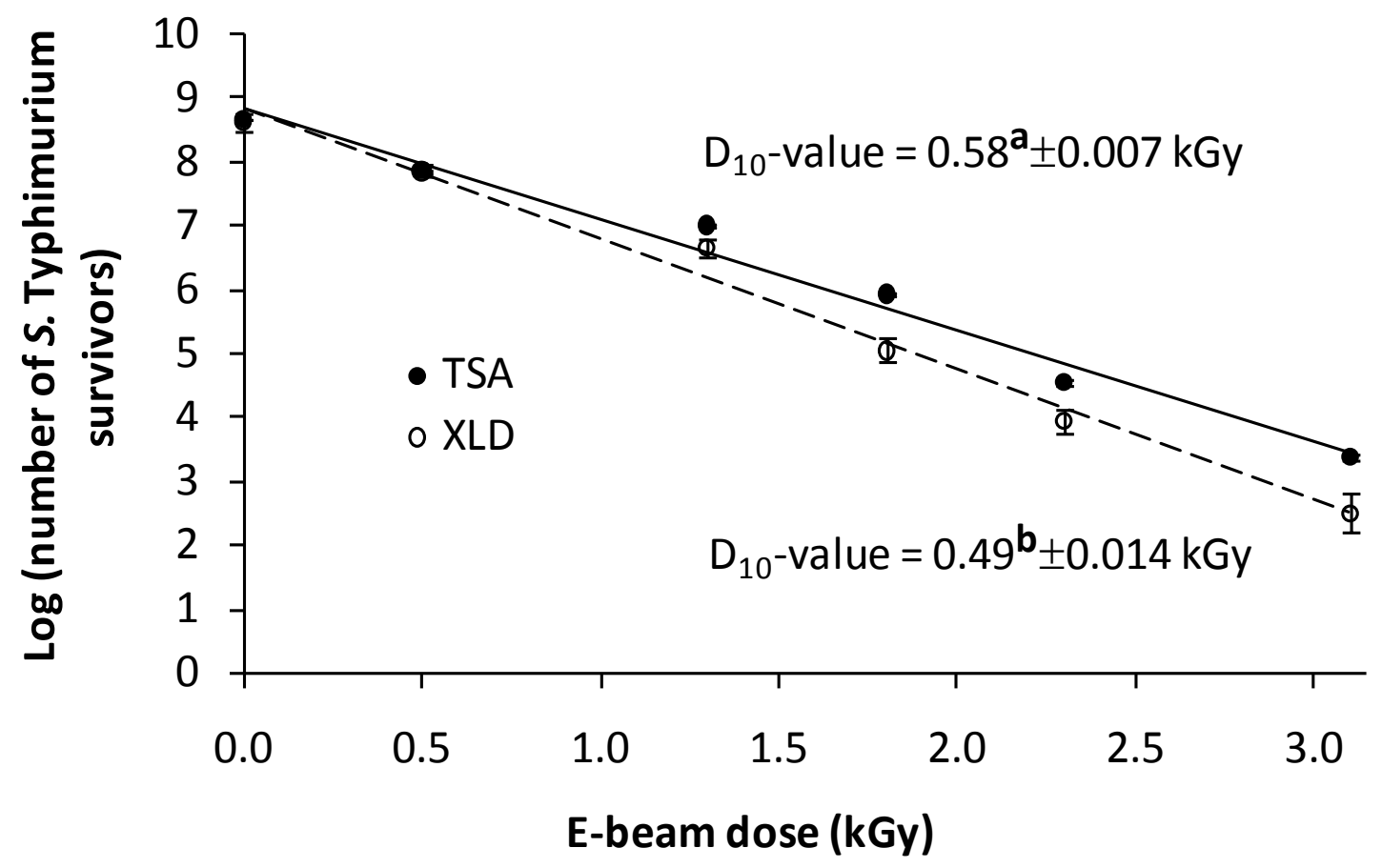

Figure 2:

Survivor curves for S. Typhimurium isolate A1 in de-shelled raw egg subjected to e-beam and enumerated on selective (XLD) and non-selective (TSA) media. Different superscript letters following $\mathrm{D}_{10}$-values indicate significant differences $(\mathrm{P}<0.05)$. 


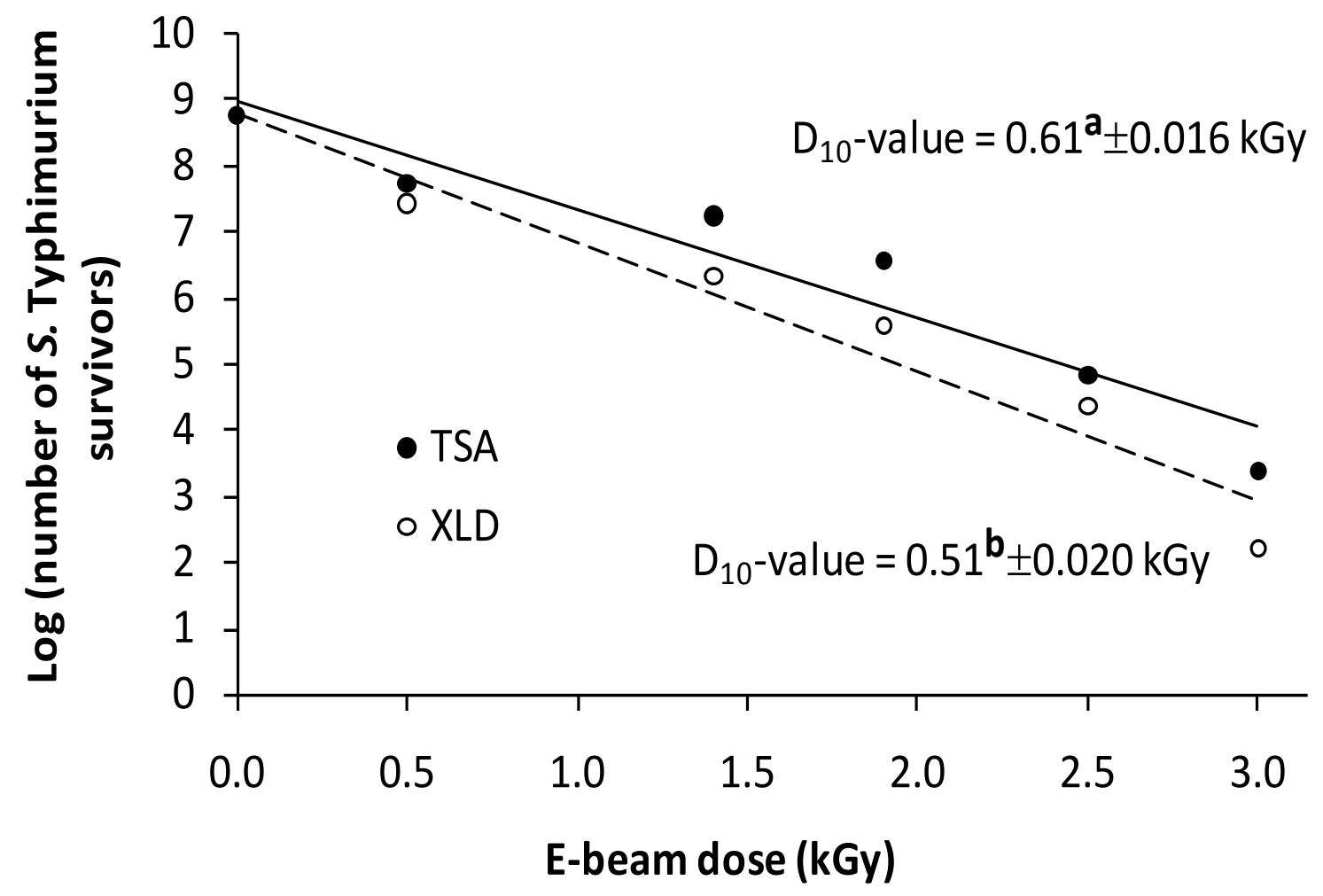

Figure 3

Survivor curves for $S$. Typhimurium isolate A2 in de-shelled raw egg subjected to e-beam and enumerated on selective (XLD) and non-selective (TSA) media. Different superscript letters following $\mathrm{D}_{10}$-values indicate significant differences $(\mathrm{P}<0.05)$. 


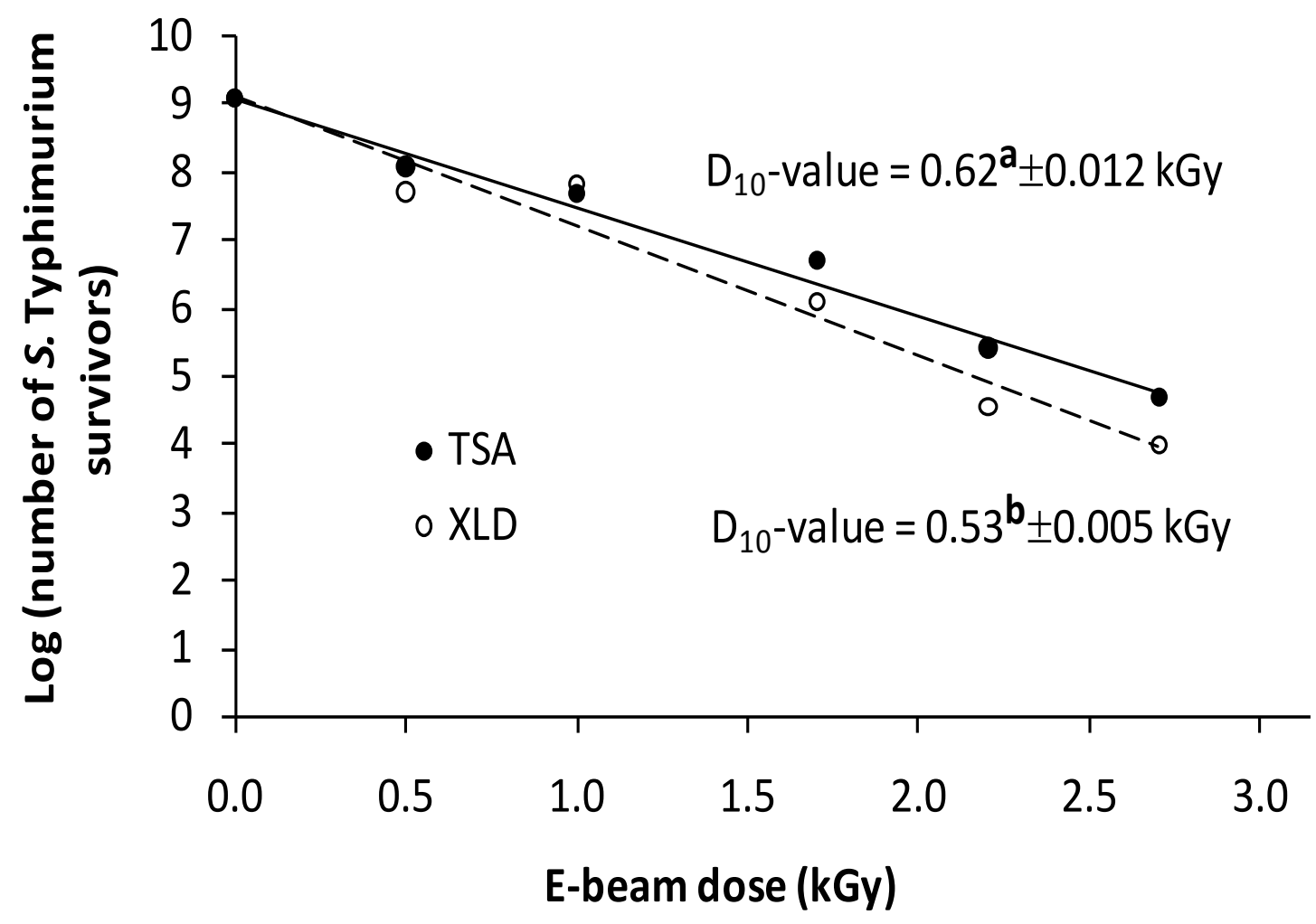

Figure 4

Survivor curves for $S$. Typhimurium isolate A3 in de-shelled raw egg subjected to e-beam and enumerated on selective (XLD) and non-selective (TSA) media. Different superscript letters following $\mathrm{D}_{10}$-values indicate significant differences $(\mathrm{P}<0.05)$. 


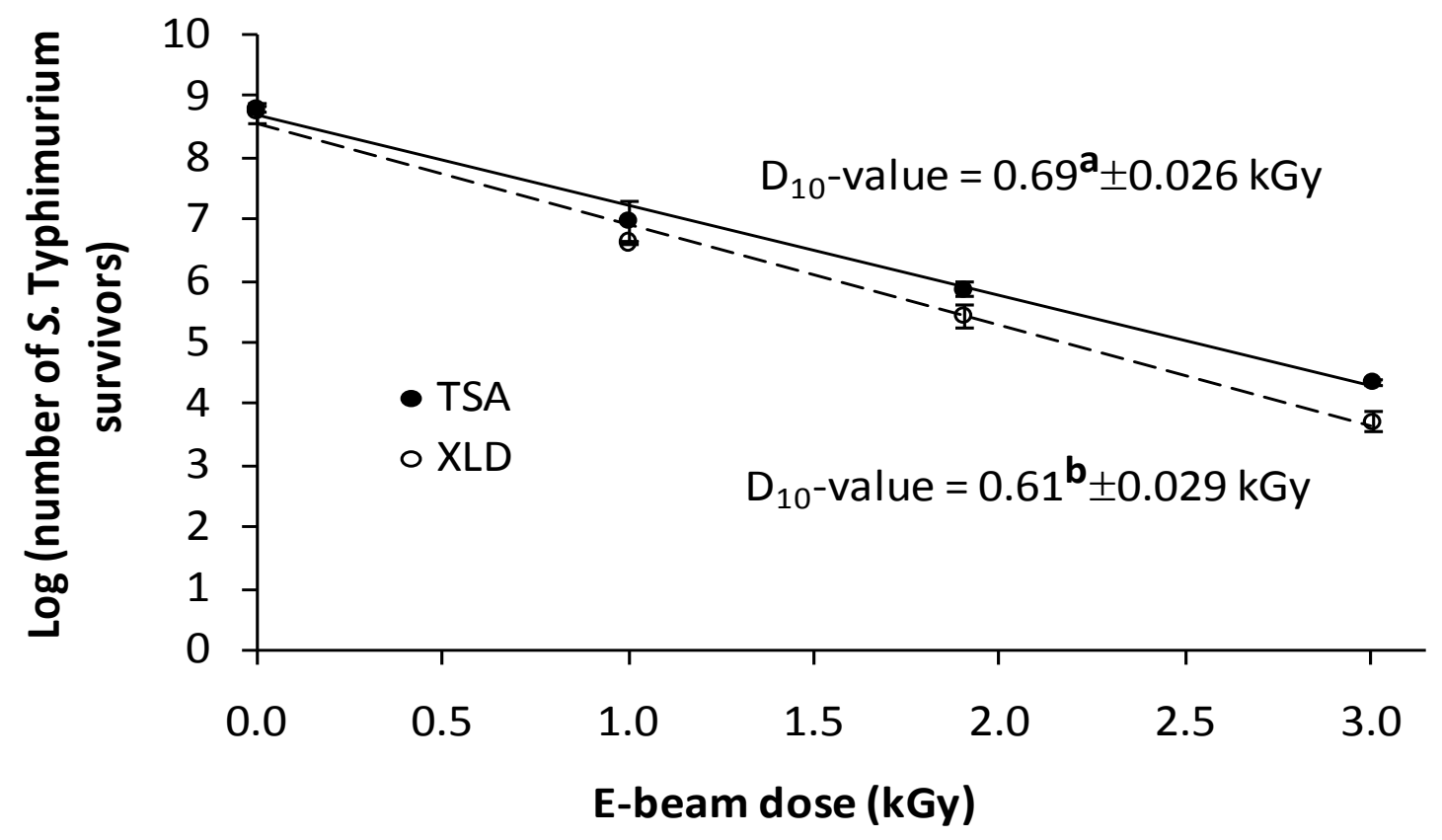

\section{Figure 5}

Survivor curves for $S$. Typhimurium isolate A4 in de-shelled raw egg subjected to e-beam and enumerated on selective (XLD) and non-selective (TSA) media. Different superscript letters following $\mathrm{D}_{10}$-values indicate significant differences $(\mathrm{P}<0.05)$. 


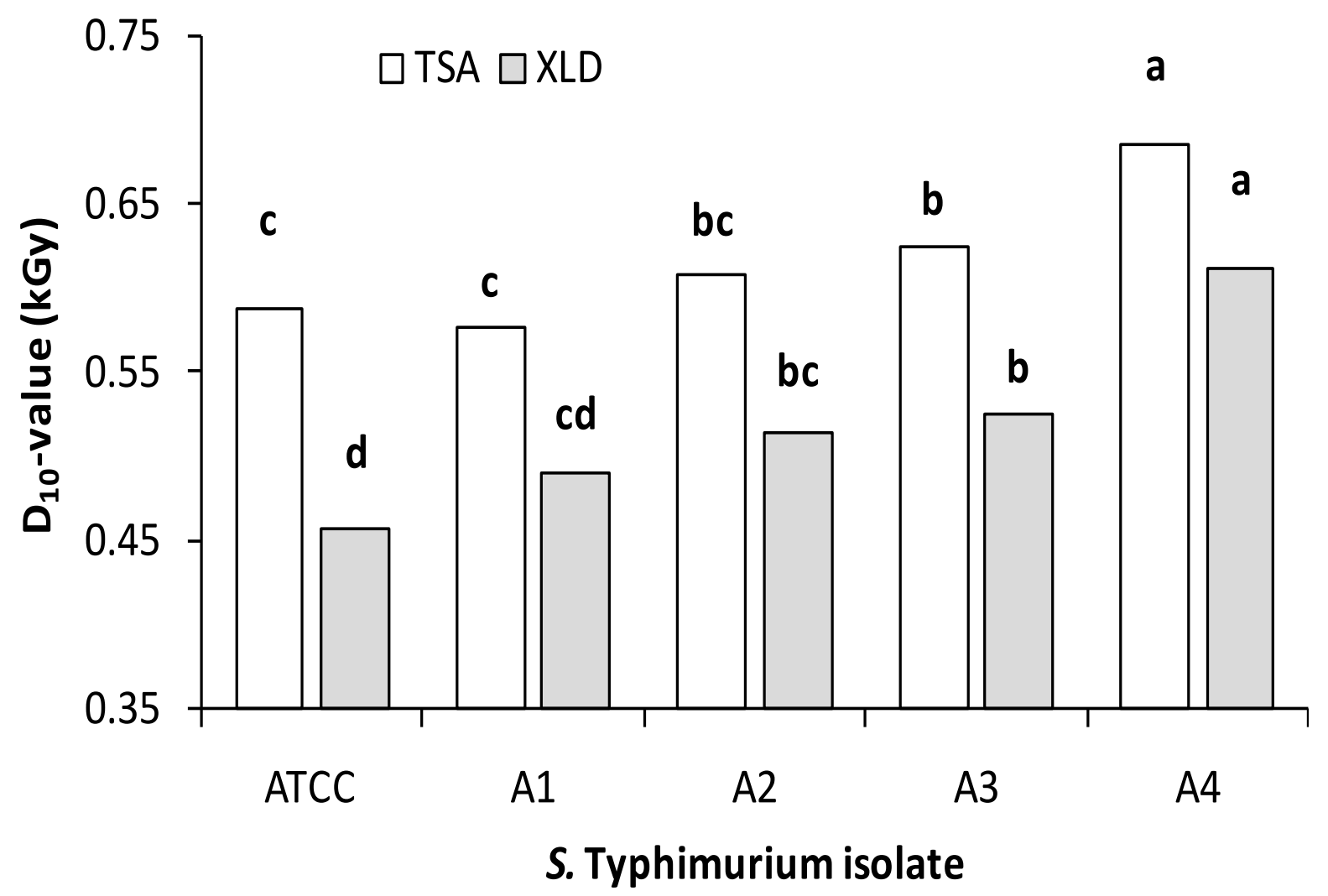

Figure 6

$\mathrm{D}_{10}$-values for $S$. Typhimurium (ATCC 14028 and isolates A1-A4) in de-shelled raw egg repetitively subjected to e-beam. Different letters on the top of data bars indicate significant differences $(\mathrm{P}<0.05)$ within media type (TSA and XLD). 


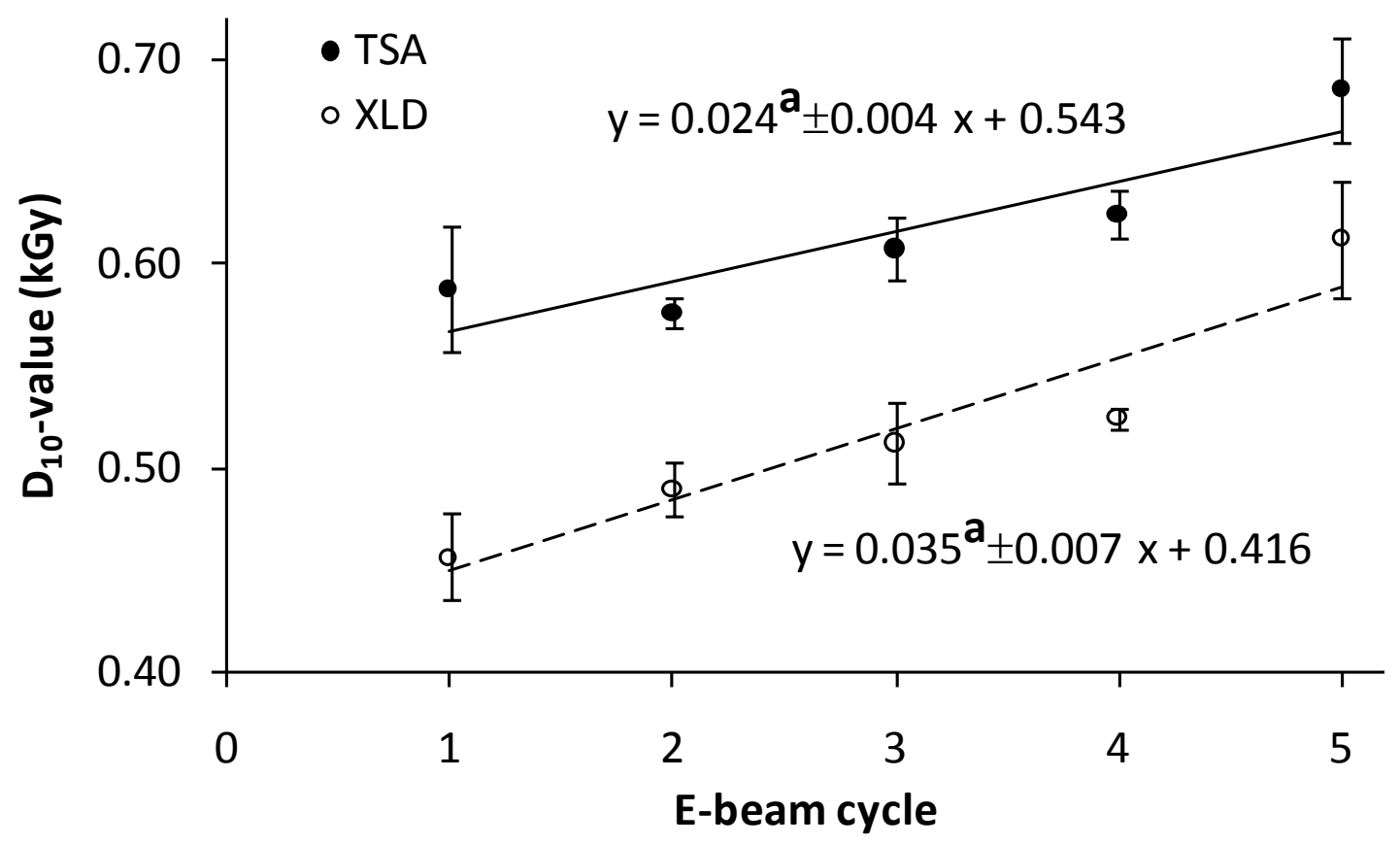

Figure 7

The rate of radio-resistance (i.e., $\mathrm{D}_{10}$-value) development for $S$. Typhimurium enumerated on selective (XLD) and non-selective (TSA) media as a function of repetitive e-beam processing (i.e., five e-beam cycles). Different superscript letters following slopes indicate significant differences $(\mathrm{P}<0.05)$. Although the rate is not different; $\mathrm{P}=0.058$ which indicates a trend for faster development of radio-resistance of $S$. Typhimurium on selective media (XLD). 


\subsection{References}

Alvarez, I., Niemira, B.A., Fan, X., Sommers, C.H., (2007). Modeling the irradiation followed by heat inactivation of Salmonella inoculated in liquid whole egg. J. Food Sci. 72(5), M145M152.

Anriany, Y.A., Weiner, R.M., Johnson, J.A., Rezende, C.E., Joseph, S.W.,( 2001). Salmonella enterica serovar Typhimurium DT104 displays a rugose phenotype. App. Environ. Microb. 67, 4048-4056.

Bell, C., Kyriakides, A., (2002). Salmonella, a practical approach to the organism and its control in foods. Blackwell Science, London.

Black, J.L., Jaczynski, J., (2006). Temperature effect on inactivation kinetics of Escherichia coli O157:H7 by electron beam in ground beef, chicken breast meat, and trout fillets. J. Food Sci. 71(6), M221-M227.

Black, J.L., Jaczynski, J., (2007). Effect of ionic strength on inactivation kinetics of Escherichia coli O157:H7 by electron beam in ground beef, chicken breast meat, and trout fillets. Int. J. Food Sci. Tech. 42(7), 894-902.

Black, J.L., Jaczynski, J., (2008). Effect of water activity on inactivation kinetics of Escherichia coli 0157:H7 by electron beam in ground beef, chicken breast meat, and trout fillets. Int. J. Food Sci. Tech. 43(4), 579-586.

Brenner, F.W., Villar, R.G., Angulo, F.J., Tauxe, R., Swaminathan, B., (2000). Salmonella nomenclature. J. Clin. Microbiol. 38(7), 2465-2467.

Buchanan, R.L., Edelson, S.G., Boyd, G., (1999). Effects of pH and acid resistance on the radiation resistance of enterohemorrhagic Escherichia coli. J. Food Protect. 62, 219-228.

Buchanan, R.L., Edelson, S.G., Boyd, G., Marmer, B.S.,( 2004). Influence of acidulant identity on the effects of $\mathrm{pH}$ and acid resistance on the radiation resistance of Escherichia coli O157:H7. Food Microbiol. 21, 51-57.

Buchanan, R.L., Edelson, S.G., Snipes, K., Boyd, G., (1998). Inactivation of Escherichia coli O157:H7 in apple juice by irradiation. App. Environ. Microb. 64, 4533-4535.

Centers for Disease Control and Prevention, (2009a). Salmonellosis - Division of Foodborne, Bacterial and Mycotic Diseases. Accessed June 2, 2010.

http://www.cdc.gov/nczved/dfbmd/disease_listing/salmonellosis_gi.html.

Centers for Disease Control and Prevention, (2009b). Multistate outbreak of Salmonella infections associated with peanut butter and peanut butter-containing products - United States, 
2008-2009. Accessed June 2, 2010.

http://www.cdc.gov/mmwr/preview/mmwrhtml/mm58e0129a1.htm.

Davis, R., Sinskey, J.A., (1973). Radiation-resistant mutants of Salmonella Typhimurium LT2: Development and characterization. J. Bacteriol. 113(1), 133-144.

Farkas, J., (1998). Irradiation as a method for decontaminating food. Int. J. Food Microbiol. 44, 189-204.

Foster, J.W., Spector, M., (1995). How Salmonella survives against the odds. Annu. Rev. Microbiol. 49, 145-174.

Galanis, E., Lo Fo Wong, D.M.A., Patrick, M.E., Binsztein, N., Cieslik, A., Chalermchikit, T., Aidara-Kane, A., Ellis, A., Angulo, F.J., Wegener, H.C., (2006). Web-based surveillance and global Salmonella distribution, 2000-2002. Emerg. Infect. Dis. 12, 381-388.

Humphrey, T., (2004). Salmonella, stress responses and food safety. Nat. Rev. Microbiol. 2(6), 504-509.

Hvizdzak, A.L., Beamer, S., Jaczynski, J., Matak, K.E., (2010). Use of electron beam irradiation for the reduction of Salmonella enterica serovars Typhimurium and Tennessee in peanut butter. J. Food Protect. 73(2), 353-357.

Jaczynski, J., Park, J.W., (2004). Physicochemical changes in Alaska pollock surimi and surimi gel as affected by electron beam. J. Food Sci. 69(1), 53-57.

Jaczynski, J., Park, J.W., (2003a). Microbial inactivation and electron penetration in surimi seafood during electron beam processing. J. Food Sci. 68(5), 1788-1792.

Jaczynski, J., Park, J.W., (2003b). Physicochemical properties of surimi seafood as affected by electron beam and heat. J. Food Sci. 68(5), 1626-1630.

James, D.L., Jaczynski, J., Matak, K. E. (2010). Electron beam irradiation on nalidixic acid resistant Salmonella Montevideo in cooked tomato puree of various pH values. J. Food Safety, in press.

Karatzas, K.A.G., Hocking, P.M., Jorgensen, F., Mattick, K., Leach, S., Humphrey. T.J.,( 2008). Effects of repeated cycles of acid challenge and growth on the phenotype and virulence of Salmonella enterica. J. Appl. Microbiol. 105(5), 1640-1648.

Lamuka, P.O., Sunki, G.R., Chawan, C.B., Rao, D.R., Shackelford, L.A., (1992). Bacteriological quality of freshly processed broiler chickens as affected by carcass pretreatment and gamma irradiation. J. Food Sci. 57, 330-332.

LeClerc, J.E., Li, B., Payne, W.L., Cebula, T.A., (1996). High mutation frequencies among Escherichia coli and Salmonella pathogens. Science, 274, 1208-1211. 
Levanduski, L., Jaczynski, J.,( 2008). Increased resistance of Escherichia coli O157:H7 to electron beam following repetitive irradiation at sub-lethal doses. Int. J. Food Microbiol. 121(3), 328-334.

Leyer, G.J., Johnson, E.A.,(1993). Acid adaptation induces cross-protection against environmental stresses in Salmonella Typhimurium. App. Environ. Microb. 59(6), 1842-1847.

Licciardello, J.J., Nickerson, J.T.R., Goldblith, S.A., Shannon, C.A., Bishop, W.W., (1996). Development of radiation resistance in Salmonella cultures. Appl. Microbiol. 18, 24-30.

Monk, J.D., Beuchat, L.R., Doyle, M.P.,( 1994). Irradiation inactivation of food-borne microorganisms. J. Food Protect. 58(2), 197-208.

Ray, B., (1979). Methods to detect stressed microorganisms. J. Food Protect. 42, 346-355.

Sarjeant, K.C., Williams, S.K., \& Hinton, A., (2005). The effect of electron beam irradiation on the survival of Salmonella enterica serovar Typhimurium and psychrotrophic bacteria on raw chicken breasts stored at four degrees celsius for fourteen days. Poultry Sci. 84, 955-958.

SAS Institute, (2002). SAS/STAT guide for personal computers, version 8.1. SAS Institute, Cary, NC.

Sherry, A.E., Patterson, M.F., Madden, R.H., (2004). Comparison of 40 Salmonella enterica serovars injured by thermal, high-pressure and irradiation stress. J. Appl. Microbiol. 96, 887-893.

Thayer, D.W., Boyd, G., Muller, W.S., Lipson, C.A., Hayne, W.C., Baer, S.H., (1990). Radiation resistance of Salmonella. J. Ind. Microbiol. 5, 383-390.

Urbain, W.M., (1986). Food Irradiation. Academic Press, Orlando, FL. 


\section{CHAPTER 2}

\section{Radio-resistance development of DNA repair deficient Escherichia coli DH5a in ground beef subjected to electron beam at sub-lethal doses}

Adiam T. Tesfai, Sarah K. Beamer, Kristen E. Matak, and Jacek Jaczynski

International Journal of Radiation Biology, 87:6 (2011), pages 571-578 


\subsection{Abstract}

Electron beam (e-beam) efficiently and non-thermally inactivates microorganisms in food by lethal DNA changes (direct effects) and free radicals from water radiolysis (in-direct effects). Non-pathogenic E. coli DH5 $\alpha$ is a microorganism that lacks DNA repair capability, resulting in high radio-sensitivity. Studying microbial inactivation of E. coli DH5 $\alpha$ repeatedly subjected to sub-lethal e-beam in ground beef may enhance understanding of microbial radio-resistance. Thus, the objective of this study was to determine if repetitive processing with e-beam at sublethal doses increases D-value of E. coli DH5 $\alpha$ in ground beef. Survivors from the highest ebeam dose were isolated and incubated in ground beef for the next cycle of e-beam processing. Five cycles were conducted. To acclimatize E. coli DH5 $\alpha$, first two cycles used low doses. Dvalues were determined following the third cycle. $\mathrm{D}$-values increased $(\mathrm{P}<0.05)$ significantly with each cycle. Following the third cycle D-values were $0.32 \pm 0.006$ and $0.32 \pm 0.002 \mathrm{kGy}$ for survivors enumerated on non-selective and selective media, respectively; the fourth cycle $0.39 \pm 0.007$ and $0.40 \pm 0.019 \mathrm{kGy}$; and the fifth cycle $0.46 \pm 0.006$ and $0.46 \pm 0.020 \mathrm{kGy}$. D-values on non-selective and selective media were similar $(\mathrm{P}>0.05)$ indicating absence of cell recovery in E. coli DH5 $\alpha$. E.coli $\mathrm{DH} 5 \alpha$ increases radio-resistance to e-beam as a result of repetitive exposure to sub-lethal doses despite its DNA repair deficiency.

Keywords: Escherichia coli, electron beam, food irradiation, microbial inactivation, inactivation kinetics. 


\subsection{Introduction}

Foodborne illness due to pathogenic Escherichia coli such as the serotype O157:H7 has had an unquestioned status in the United States since meat borne outbreak in 1982 (Jay et al. 2005). In 1997, a U.S. company voluntarily recalled almost 11.5-mln kg of ground beef after 20 illnesses had been associated with ground beef products contaminated with E. coli in Colorado. In 2002, there were 36 food recalls in the U.S. implicating pathogenic E. coli. All the 36 recall involved ground beef products. Individual recalls ranged in size from 9 to $19-\mathrm{mln} \mathrm{kg}$. In 1999, there were 62,458 confirmed cases of foodborne illnesses due E. coli, resulting in 1,843 hospitalizations and 52 deaths. Not only are meat products contaminated with $E$. coli often implicated in the outbreaks, but a media publicized multi-state outbreak implicating contaminated spinach and lettuce was responsible for over 205 illnesses and 3 confirmed deaths in 2006 (U.S. Food and Drug Administration 2010). The above examples from public health statistics clearly illustrate the need for a comprehensive understanding of inactivation of E. coli in food, particularly meat.

Ionizing radiation effectively inactivates microorganisms including foodborne pathogens (Arvanitoyannis et al. 2009, O’Bryan et al. 2008, Farkas 1998, Black and Jaczynski 2008, 2007, 2006, Chalise et al. 2007, James et al. 2010, Hvizdzak et al. 2010, Matak et al. 2010). Therefore, application of ionizing radiation to food processing enables food manufacturers to increase microbial food safety and extend shelf life of food products. Instead of radioisotopes, e-beam uses high-speed electrons generated from electricity in a linear accelerator that are passed onto the food from e-beam gun. Since e-beam inactivates microorganisms non-thermally, it may be used to inactivate E. coli in fresh food products including ground beef without cooking it. Although dependent on a particular food product, e-beam does not affect protein functionality 
and other food quality attributes within typical doses required for microbial inactivation (Jaczynski and Park 2004, 2003b). Ionizing radiation including e-beam inactivates microorganisms by dual action involving lethal DNA changes (direct effects) and free radicals generated during water radiolysis (indirect effects). The direct effects are due to the breakage of chemical bonds between base pairs within microbial DNA resulting in reproductive death of microorganisms, while the indirect effects occur when the radiolysed water molecules (i.e., free radicals) disintegrate microbial cell membrane (Urbain 1986).

Subjecting microorganisms to various stressors at sub-lethal levels such as nutrient starvation, $\mathrm{pH}$ extremes, hyperoxia, high ionic strength, heat shock, antibiotics, etc. may result in selection of isolates that are more resistant to the imposed stress (Humphrey 2004). Therefore, it is likely that foodborne pathogens may develop increased resistance to e-beam. The development of radiation resistant (or radio-resistant) isolates plays an important role in determining the effectiveness of e-beam processing for food products. Thus, understanding of the development of increased microbial radio-resistance is critical from both, a practical and scientific point of view.

Radio-resistance depends on the ability of microorganisms to repair the damage caused by irradiation to microbial DNA and cell integrity. E. coli employs gene recA to mediate recombination pathway to repair damage in the DNA strands. The $r p o S$ gene has also been suggested as a crucial component of the DNA repair. If the rpoS gene is intact, E. coli develops greater resistance to various stressors (Arnold and Kaspar 1995). Genetic mechanisms are invariably involved in the development of increased resistance of E. coli to stress and they are likely as critical in microbial radio-resistance. Increased radio-resistance of Salmonella to $\gamma$-rays has also been attributed to enhanced DNA repair (Davis and Sinskey 1973). 
Non-pathogenic E. coli DH5 $\alpha$ is a very radio-sensitive microorganism (Sommers and Rajkowski 2008). This E. coli contains mutations of the recA and gyrA genes that are necessary for DNA repair and replication. Therefore, recA and gyrA mutants have impaired ability to repair and recombine their DNA strands making the mutants sensitive to ionizing radiation, ultra violet (UV), and chemicals (Bridges 1971, Mount et al. 1975, Sedgwick and Bridges 1972, Sharan et al. 2007, Cox 2007, Orser et al. 1995, Kornberg and Baker 2005). Therefore, studying microbial inactivation kinetics of this DNA-repair deficient E. coli DH5 $\alpha$ in a staple food such as fresh ground beef will enhance understanding of microbial radio-resistance to e-beam and may indicate some other, genetic or non-genetic factors involved in radio-resistance.

It is hypothesized that despite its incapability to repair DNA, E. coli DH5 $\alpha$ will develop significant increase $(\mathrm{P}<0.05)$ of radio-resistance in fresh ground beef if exposed repetitively to ebeam processing at sub-lethal doses. The objective of this challenge study was to determine if repetitive exposure to e-beam at sub-lethal doses increases $(\mathrm{P}<0.05) \mathrm{D}$-value for $E$. coli $\mathrm{DH} 5 \alpha$ in fresh ground beef.

\subsection{Materials and methods}

\subsubsection{Sample preparation}

Fresh lean ground beef was purchased from a local grocery store and only this ground beef was used in this study. The ground beef was vacuum packed and stored at $-80^{\circ} \mathrm{C}$ until needed. Preliminary tests (data not shown) confirmed that the total coliform counts in the ground beef sample were below detectable levels. All laboratory equipment used to handle ground beef such as spatulas, containers, etc. was autoclaved or cleaned and sanitized with ethanol, followed by drying under UV in the bio-safety cabinet (Class II Type A/B3, NuAire, Inc., Plymouth, MN, 
USA). Whenever applicable, aseptic technique under the bio-safety cabinet was used for transfer, handling, etc. of E. coli DH5 $\alpha$.

Escherichia coli DH5a luxS supE44 AlacU169 ( $\varphi$ 80dlacZAM15) hsdR17 recA1 endA1 gyrA96 thi-1 relA1 (hereafter called E. coli) (Invitrogen Inc., Carlsbad, CA, USA) lyfo-disks were reconstituted by crushing one pellet using sterile spatula in $0.4 \mathrm{ml}$ of sterile trypticase soy broth (TSB) (Becton Dickinson and Company, Sparks, MD, USA). The content was aseptically transferred to $3.6 \mathrm{ml}$ of sterile TSB and allowed to grow aerobically at $35^{\circ} \mathrm{C}$ for $24 \mathrm{~h}$ in an incubator/shaker set at 150 rpm (C24 Incubator/Shaker, New Brunswick Scientific, Edison, NJ, USA). The $4 \mathrm{ml}$ aliquot of the E. coli culture was aseptically transferred to $76 \mathrm{ml}$ of sterile TSB and allowed to grow aerobically at $35^{\circ} \mathrm{C}$ for $18 \mathrm{~h}$ in the incubator/shaker set at $150 \mathrm{rpm}$.

Preliminary studies (data not shown) confirmed that this procedure yielded an E. coli culture at stationary phase of growth and approximately $10^{9}$ colony forming units (CFU)/ml.

The 18-h E. coli culture was used as an inoculum for ground beef. Prior to inoculation, the ground beef sample was thawed overnight in a refrigerator and the inoculum was added at $5 \%(v / w)$ to a thawed sample of ground beef. Following inoculation, the ground beef sample was aerobically incubated (Isotemp Incubator, Fisher Scientific, Pittsburgh, PA, USA) at $35^{\circ} \mathrm{C}$ for $24 \mathrm{~h}$. Preliminary studies (data not shown) verified that this procedure resulted in a concentration of E. coli at approximately $10^{9} \mathrm{CFU} / \mathrm{g}$ of ground beef. Distilled and de-ionized water $\left(\mathrm{ddH}_{2} \mathrm{O}\right)$ was periodically added to account for moisture loss due to evaporation during incubation and the sample was periodically mixed to ensure even distribution of microbial cells in the meat sample.

Following incubation, 18 individual samples of approximately $12 \mathrm{~g}$ each of inoculated beef were separately packed (Kapak SealPAK pouches, Kapak Corporation, Minneapolis, MN, 
USA) and aerobically sealed (Kapak sealer, Kapak Corporation). Each sample was spread evenly, resulting in a thickness below $1 \mathrm{~mm}$ in order to ensure complete penetration of e-beam and even distribution of absorbed dose throughout the sample (Jaczynski and Park 2003a, Levanduski and Jaczynski 2008). The samples were stored at $-80^{\circ} \mathrm{C}$ until shipment. The storage time did not exceed one week.

\subsubsection{Treatment}

Samples were packed and shipped according to an approved institutional protocol in a heavy-duty styrofoam cooler filled with dry ice. Samples were shipped overnight to an e-beam processing facility (Sterigenics International, San Diego, CA, USA). At the e-beam facility, the samples were allowed to equilibrate to $4^{\circ} \mathrm{C}$ overnight in a refrigerator prior to e-beam processing. The samples at refrigeration temperature $\left(4^{\circ} \mathrm{C}\right)$ were subjected to one-sided e-beam with energy fixed at $10 \mathrm{MeV}$ and doses between 0.0-4.0 kGy were applied. The applied e-beam doses were confirmed with film dosimeters (Jaczynski and Park 2003a, Levanduski and Jaczynski 2008). The film dosimeters (FWT-60 series radiochromatic dosimeters, Far West Technology, Inc., Goleta, CA) were attached to the bottom of the Kapak pouches prior to e-beam processing. The absorbed doses were determined following e-beam processing using a spectrophotometer (Cary 100 UV-Vis, Varian, Inc., Palo Alto, CA, USA) with a fixed wavelength at $605 \mathrm{~nm}$. The absorbed doses were used to calculate D-values.

Immediately following the e-beam treatment, samples were frozen, packed, and shipped overnight back to the food microbiology laboratory at West Virginia University (WVU). Upon arrival at WVU, the e-beam processed samples were stored at $-80^{\circ} \mathrm{C}$ until analysis. The storage time did not exceed one week. Preliminary studies (data not shown) determined that the freeze- 
thaw cycles used in the experiments did not $(\mathrm{P}>0.05)$ affect the survival of $E$. coli during e-beam experiments; and therefore, did not confound the results. All of the experiments had control samples that were not exposed to beam (i.e., $0.0 \mathrm{kGy}$ ). The control samples received the same treatment as all other samples except for e-beam irradiation; i.e., they were shipped to the e-beam facility in the same heavy-duty styrofoam cooler and stored under the same conditions, but were not irradiated with e-beam. Three separate e-beam experiments $(n=3)$ were conducted.

\subsubsection{Bacterial enumeration of E. coli survivors}

The samples were equilibrated to $4^{\circ} \mathrm{C}$ overnight in a refrigerator prior to enumeration. Each sample was enumerated by aseptically placing $10 \mathrm{~g}$ of the e-beam processed sample using a sterile spatula into a sterile filter stomacher bag (Two-Chamber Filter Bag, Fisher Scientific). An aliquot of $90 \mathrm{ml}$ of dilutent (Butterfield phosphate buffer, Hardy Diagnostics, Santa Maria, CA, USA) was aseptically added to the filter stomacher bag and homogenized at medium speed for 2 min in a stomacher (Bag Mixer 400, Interscience, St. Nom, France). Further serial dilutions were aseptically made by taking $10 \mathrm{ml}$ of diluted sample and transferring it into a $90 \mathrm{ml}$ diluent bottle, followed by shaking the bottle to uniformly distribute survivors. Survivors were enumerated on non-selective (Tryptic Soy Agar, TSA) (Becton Dickinson and Company, Sparks, MD, USA) and selective (Petrifilm ${ }^{\mathrm{TM}}$ E. coli/Coliform Count Plate, 3M ${ }^{\mathrm{TM}}$, St. Paul, MN, USA) media using a standard spread-plating technique. An aliquot of 0.1 and $1.0 \mathrm{ml}$ of each serial dilution was pipetted and spread on TSA and $3 \mathrm{M}^{\mathrm{TM}}$ Petrifilm ${ }^{\mathrm{TM}}$ plates, respectively. The TSA and $3 \mathrm{M}^{\mathrm{TM}}$ Petrifilm ${ }^{\mathrm{TM}}$ plates were incubated at $35^{\circ} \mathrm{C}$ for 24 and $48 \mathrm{~h}$, respectively (AOAC method 991.14 1995). Only plates with 0-150 colonies were counted. All bacterial enumerations were performed in duplicate and the mean values are reported as CFU/g. 
Isolation of E. coli survivors for repetitive e-beam processing

Following incubation of the TSA and $3 \mathrm{M}^{\mathrm{TM}}$ Petrifilm ${ }^{\mathrm{TM}}$ plates, colonies of E. coli survivors from the highest e-beam dose that resulted in survival were randomly isolated separately from the TSA and $3 \mathrm{M}^{\mathrm{TM}}$ Petrifilm ${ }^{\mathrm{TM}}$ plates. Therefore, two separate isolates of $E$. coli were obtained. One isolate was from TSA plates, while the second isolate was from the $3 \mathrm{M}^{\mathrm{TM}}$ Petrifilm ${ }^{\mathrm{TM}}$ plates. The highest dose applied in the present study was $4 \mathrm{kGy}$; however, there were no detectable survivor colonies at that dose. Survivor colonies were isolated from the highest dose that resulted in survival of $E$. coli, which was lower than 4 kGy (i.e., the highest dose applied). The isolates from TSA and $3 \mathrm{M}^{\mathrm{TM}}$ Petrifilm ${ }^{\mathrm{TM}}$ plates were separately incubated aerobically in $3.6 \mathrm{ml}$ of sterile TSB at $35^{\circ} \mathrm{C}$ for $24 \mathrm{~h}$ in an incubator/shaker set at $150 \mathrm{rpm}$. The $3.6 \mathrm{ml}$ aliquots of $E$. coli cultures were separately added to $76 \mathrm{ml}$ of sterile TSB and aerobically incubated at $35^{\circ} \mathrm{C}$ for $18 \mathrm{~h}$ in an incubator/shaker set at $150 \mathrm{rpm}$. Aseptic technique under the bio-safety cabinet was used for all transfers and handling of E. coli. Preliminary studies (data not shown) confirmed that this procedure yielded $E$. coli cultures at stationary phase of growth and approximately $10^{9} \mathrm{CFU} / \mathrm{ml}$.

As described before (“Sample preparation”), the 18-h E. coli culture was used as the inoculum for the next sample of fresh ground beef and cycle of e-beam processing. The isolation of E. coli survivors following e-beam processing was repeated four times. Therefore, this protocol required four separate shipments to the e-beam processing facility (Sterigenics International). In the first cycle of e-beam processing, the revived E. coli DH5 $\alpha$ from Invitrogen Inc. was used. The E. coli survivors isolated following the first cycle of e-beam processing were designated as A1 (hereafter called isolate A1), while E. coli survivors isolated following the second cycle of e-beam processing using isolate A1 were designated as A2 (hereafter called 
isolate A2). Isolates A3 and A4 were obtained accordingly. However, E. coli DH5 $\alpha$ is DNA repair deficient rendering this microorganism radio-sensitive (Sommers and Rajkowski 2008). Therefore, in order to acclimatize this microorganism to e-beam, only low doses (0-0.5 kGy) were applied in the first two cycles of e-beam processing. The D-values were not calculated and data are not presented from the first two cycles.

\subsubsection{Determining D-values}

Following the second cycle of e-beam processing, the counts of $E$. coli survivors (i.e., isolates A2, A3, and A4) enumerated on TSA and $3 \mathrm{M}^{\mathrm{TM}}$ Petrifilm ${ }^{\mathrm{TM}}$ plates were separately plotted on a logarithmic scale as a function of e-beam dose (kGy). Therefore, two separate survivor curves were constructed for isolates A2, A3, and A4. One survivor curve corresponded to E. coli survivors enumerated on TSA plates (non-selective media), while the second curve to the survivors on $3 \mathrm{M}^{\mathrm{TM}}$ Petrifilm ${ }^{\mathrm{TM}}$ plates (selective media). The D-value was determined by calculating the negative reciprocal of the slope of the survivor curve (equation 1) (Jaczynski and Park 2003a). D-value is recognized as the radiation dose needed to achieve one log cycle or $90 \%$ reduction of the microbial population (Urbain 1986).

$$
\log \left(\frac{N}{N_{0}}\right)=-\frac{1}{D} * t \ldots \ldots \ldots \ldots \ldots \ldots \ldots \ldots \text { Equation } 1
$$

$\mathrm{N}$ - concentration of survivors after e-beam dose,

$\mathrm{N}_{0}$ - initial microbial concentration,

D - D-value, decimal reduction dose,

t - e-beam dose. 


\subsubsection{Statistics}

Five cycles of e-beam processing were conducted, three separate experiments $(n=3)$ per each cycle. The ground beef samples were randomly assigned to e-beam doses in each experiment. All bacterial enumerations were performed in duplicate and the mean values are reported as CFU/g. One-way analysis of variance (ANOVA) was performed to detect significant differences in microbial survival with increasing e-beam dose. The enumeration counts (CFU/g) of E. coli survivors for isolates A2, A3, and A4 were log-converted and analyzed by linear regression using MS Office Excel software (Version 2007) in order to determine D-values. The PROC GLM software was used to determine significant differences between mean D-values for E. coli enumerated on TSA and $3 \mathrm{M}^{\mathrm{TM}}$ Petrifilm ${ }^{\mathrm{TM}}$ plates within each cycle of e-beam processing (Figures 1-3). The same statistical software was used to determine significant differences between mean D-values for E. coli isolates A2, A3, and A4 within each media type (Table I and Figure 4). All statistical analyses were performed using SAS (Version 9) and differences were considered significant when $\mathrm{P}<0.05$ (SAS 2002).

\subsection{Results}

The average D-values for E. coli DH5 $\alpha$ isolates A2, A3, and A4 enumerated on TSA and $3 \mathrm{M}^{\mathrm{TM}}$ Petrifilm ${ }^{\mathrm{TM}}$ plates are presented in Table I. The ANOVA analysis showed that the logconverted counts of $E$. coli survivors for isolates A2, A3, and A4 decreased $(\mathrm{P}<0.05)$ significantly as the e-beam dose increased on both TSA and $3 \mathrm{M}^{\mathrm{TM}}$ Petrifilm ${ }^{\mathrm{TM}}$ plates. Therefore, D-values were calculated from the survivor curves as a function of e-beam dose (Figures 1-3). In addition, the GLM analysis proved that the more the microorganisms were subjected to e- 
beam, the greater $(\mathrm{P}<0.05)$ their respective $\mathrm{D}$-values regardless of the media type (non-selective TSA or selective $3 \mathrm{M}^{\mathrm{TM}}$ Petrifilm $\left.{ }^{\mathrm{TM}}\right)$; and hence, their radio-resistance.

Following the third cycle of e-beam processing, the resultant isolate A2 had the lowest $(\mathrm{P}<0.05) \mathrm{D}$-values. The $\mathrm{D}$-values were $0.32 \pm 0.006$ and $0.32 \pm 0.002 \mathrm{kGy}$ for A2 survivors enumerated on TSA and $3 \mathrm{M}^{\mathrm{TM}}$ Petrifilm ${ }^{\mathrm{TM}}$, respectively (Figure 1). However, when these survivors were incubated in ground beef and subjected to the fourth cycle of e-beam processing, the $\mathrm{D}$-values for the resultant isolate A3 increased $(\mathrm{P}<0.05)$ to $0.39 \pm 0.007$ and $0.40 \pm 0.010 \mathrm{kGy}$ on TSA and $3 \mathrm{M}^{\mathrm{TM}}$ Petrifilm ${ }^{\mathrm{TM}}$, respectively (Figure 2). The final fifth cycle of e-beam processing yielded increased $(\mathrm{P}<0.05) \mathrm{D}$-values for isolate A4 at $0.46 \pm 0.006$ and $0.46 \pm 0.020$ kGy for survivors enumerated on TSA and $3 \mathrm{M}^{\mathrm{TM}}$ Petrifilm ${ }^{\mathrm{TM}}$, respectively (Figure 3). E. coli DH5 $\alpha$ isolate A2, A3, and A4 survived 1.9, 2.7, and $3.2 \mathrm{kGy}$ (absorbed doses confirmed with dosimetry), respectively. However, the highest e-beam dose applied was 4 kGy and there were no detectable survivors at this dose.

It is important to note that although $\mathrm{D}$-values increased $(\mathrm{P}<0.05)$ for each subsequent cycle of e-beam processing, the $\mathrm{D}$-values within each cycle were similar $(\mathrm{P}>0.05)$ for the survivors enumerated on selective and non-selective media. These results indicate that despite its incapability to repair the DNA, E. coli DH5 $\alpha$ has the capability to develop increased $(\mathrm{P}<0.05)$ radio-resistance if repetitively exposed to sub-lethal e-beam. Therefore, besides DNA repair mechanisms; there may also be some other cellular events that lead to the development of increased microbial radio-resistance to ionizing radiation. 


\subsection{Discussion}

The original E. coli DH5 $\alpha$ (from Invitrogen Inc.) was radio-sensitive (Sommers and Rajkowski 2008) and had never been exposed to ionizing radiation. Therefore, in order to acclimatize the original E. coli DH5 $\alpha$ and isolate A1 had been subjected to low e-beam doses (0$0.5 \mathrm{kGy}$ ) in the first two cycles of e-beam processing. Sommers and Rajkowski (2008) subjected E. coli DH5 $\alpha$ (from Invitrogen Inc.) in Butterfield's phosphate buffer to gamma radiation using ${ }^{137}$ Cs. The D-value was $0.051 \mathrm{kGy}$ demonstrating high radio-sensitivity. The D-values for $E$. coli DH5 $\alpha$ isolates A2, A3, and A4 were higher than the D-value for the original E. coli DH5 $\alpha$ determined by Sommers and Rajkowski (2008). The higher D-values in the present study were probably caused by the development of increased radio-resistance in E. coli DH5 $\alpha$ induced by repetitive processing with e-beam at sub-lethal doses and different food matrices (i.e., ground beef vs. Butterfield's phosphate buffer).

D-values for the pathogenic serotype O157:H7 range depending on several conditions. The D-values reported for E. coli O157:H7 in meat products range from 0.19 to $0.63 \mathrm{kGy}$ (Sommers and Boyd 2006a, 2006b, Thayer and Boyd 1993, 2001, Black and Jaczynski 2008, 2007, 2006, Levanduski and Jaczynski 2008). Relatively high D-values between 1.11 and 1.43 kGy have been reported for E. coli O157:H7 inoculated in broccoli sprouts (Rajkowski et al. 2003). These published D-values ranging from 0.19 to $1.43 \mathrm{kGy}$ for E. coli O157:H7 indicate a profound effect of food matrix on microbial radio-resistance. Microorganisms typically survive irradiation better in food products compared to standard buffers such as Butterfield's phosphate buffer, etc. due to protective effect of food constituents such as proteins and lipids. In addition, microbial cells inoculated into food products and irradiated under stress such as low water activity $\left(\mathrm{A}_{\mathrm{w}}\right)$ and high ionic strength (IS) typically exhibit increased radio-resistance. E. coli also 
develops increased acid resistance in foods, which results in “cross-protection” against other stressors including ionizing radiation (Buchanan et al. 1999).

Leyer et al. (1995) demonstrated “cross-protection” and suggested that microbial adaptation to various stressors is influenced by specific outer membrane proteins ("shock proteins”). The expression of “shock proteins” has been associated with enhanced resistance to heat and osmotic stress (i.e., “cross-protection”) (Leyer et al. 1995). Cheville et al. (1996) suggested that $r p o S$ gene encodes these protective proteins and/or increases their transcription. Lin et al. (1996) and Yuk and Marshall (2003) confirmed that this gene is involved in the development of increased acid and heat resistance in E. coli. The "shock proteins" may also play an important role in the development of the increased radio-resistance of $E$. coli observed in the present study.

To understand the mechanism of microbial radio-resistance Sharan and Nomura (2007) subjected recA and recF E. coli mutant to gamma radiation. They attempted to elucidate the role of $r e c A$ and $r e c F$ proteins in the repair of radiation-induced DNA damage. Their results indicated that there was no difference between the mutant and $E$. coli that was expressing recA and recF proteins. They concluded that the damage to microbial DNA caused by ionization radiation may require other factors involved in the post-radiation cellular repair. The e-beaminduced radio-resistance of $E$. coli $\mathrm{DH} 5 \alpha$ in the present study suggests a similar conclusion. To the contrary, in an earlier study, Davis and Sinskey (1973) suggested that the development of radio-resistance was a result of selection that favored mutations leading to the increased radioresistance and not a result of increased capacity to repair microbial DNA. However, Mount et al. (1975) demonstrated that some mutations increase radio-resistance of recA strain of $E$. coli. These authors concluded that although DNA repair is an important mechanism for microbial 
survival of ionizing radiation, other cellular mechanisms also play important roles. In the present study the development of increased radio-resistance cannot be attributed to DNA repair because E. coli DH5 $\alpha$ carries mutation of the recA and gyrA genes required for DNA repair. Yet, despite this incapability, E. coli DH5 $\alpha$ increased its radio-resistance to e-beam. Thus, other mechanisms, genetic and non-genetic, may also be involved in the development of increased microbial radioresistance. We intend to investigate the genetic component of increased microbial radioresistance with micro-arrays and comparative genomic sequences analysis (CGSA). Microarrays use RNA and allow rapid gene expression and comparative surveys of large numbers of specimens. In CGSA, DNA (not RNA) of radio-resistant E. coli is compared to a sequenced genome allowing identification of changes in the DNA that may have contributed to survival of E. coli exposed to e-beam. Preliminary experiments (data not shown) conducted in our laboratory suggest a correlation between up- and down-regulation of some genes and increased microbial radio-resistance to e-beam.

Cell injury normally occurs with ionizing radiation including e-beam. Microorganisms utilize different mechanisms to recover from these injuries under favorable growth conditions (Tesfai et al. 2010). E-beam-induced cell injury likely occurred in E. coli DH5 $\alpha$ in the present experiments. However, since E. coli DH5 $\alpha$ lacks DNA repair capabilities, the injured cells could not recover. This is why the $\mathrm{D}$-values for isolates A2, A3, and A4 did not $(\mathrm{P}>0.05)$ differ between survivors enumerated on selective and non-selective media (Figures 1-3). 


\subsection{Conclusion}

Electron beam (e- beam) can efficiently inactivate $E$. coli in fresh food products such as fresh ground beef in a non-thermal manner, similar to other inactivation techniques and environmental stressors, E. coli has a capability to develop increased radio-resistance if repetitively processed with e-beam. The potential for increased microbial resistance of foodborne pathogens such as E. coli O157:H7 has significant practical implications for the food industry and general public health. The use of genetic analysis such as for example micro-arrays will offer food processors and regulatory agencies a method for rapid detection of strains with increased radio-resistance.

\section{Acknowledgements}

This research was funded by the USDA Hatch program (project nr WVA00429). Special thanks to Sterigenics International for allowing us to use e-beam facility. Our appreciation extends to Carl A. Zinn and Richard Vallejo of Sterigenics for invaluable technical expertise with e-beam and Aunchalee Aussanasuwamakul for assistance with statistical analysis.

Declaration of interest: The authors report no conflicts of interest. The authors alone are responsible for the content and writing of the article. 


\subsection{Appendix C}

Table 1. Increased radio-resistance (D-value) of E. coli DH5 $\alpha$ in ground beef subjected to ebeam. Data are given as mean \pm standard deviation $(n=3)$. Mean $D$-values in rows with different letters indicate significant differences $(\mathrm{P}<0.05)$ within media type.

E. coli DH5 $\alpha$ isolate

\begin{tabular}{|c|ccc|}
\hline \multicolumn{2}{|c|}{ A2 } & A3 & A4 \\
\multicolumn{2}{|c|}{ Media Type } & \multicolumn{3}{c|}{} \\
\hline TSA & $\begin{array}{c}0.32 \pm 0.006 \\
\text { c }\end{array}$ & $\begin{array}{c}0.39 \pm 0.007 \\
\text { b }\end{array}$ & $\begin{array}{c}0.46 \pm 0.006 \\
\text { a }\end{array}$ \\
\hline $3 M^{\mathrm{TM}}$ Petrifilm $^{\mathrm{TM}}$ & $0.32 \pm 0.002$ & $0.40 \pm 0.010$ & $0.46 \pm 0.020$ \\
& $\mathrm{c}$ & $\mathrm{b}$ & $\mathrm{a}$ \\
\hline
\end{tabular}




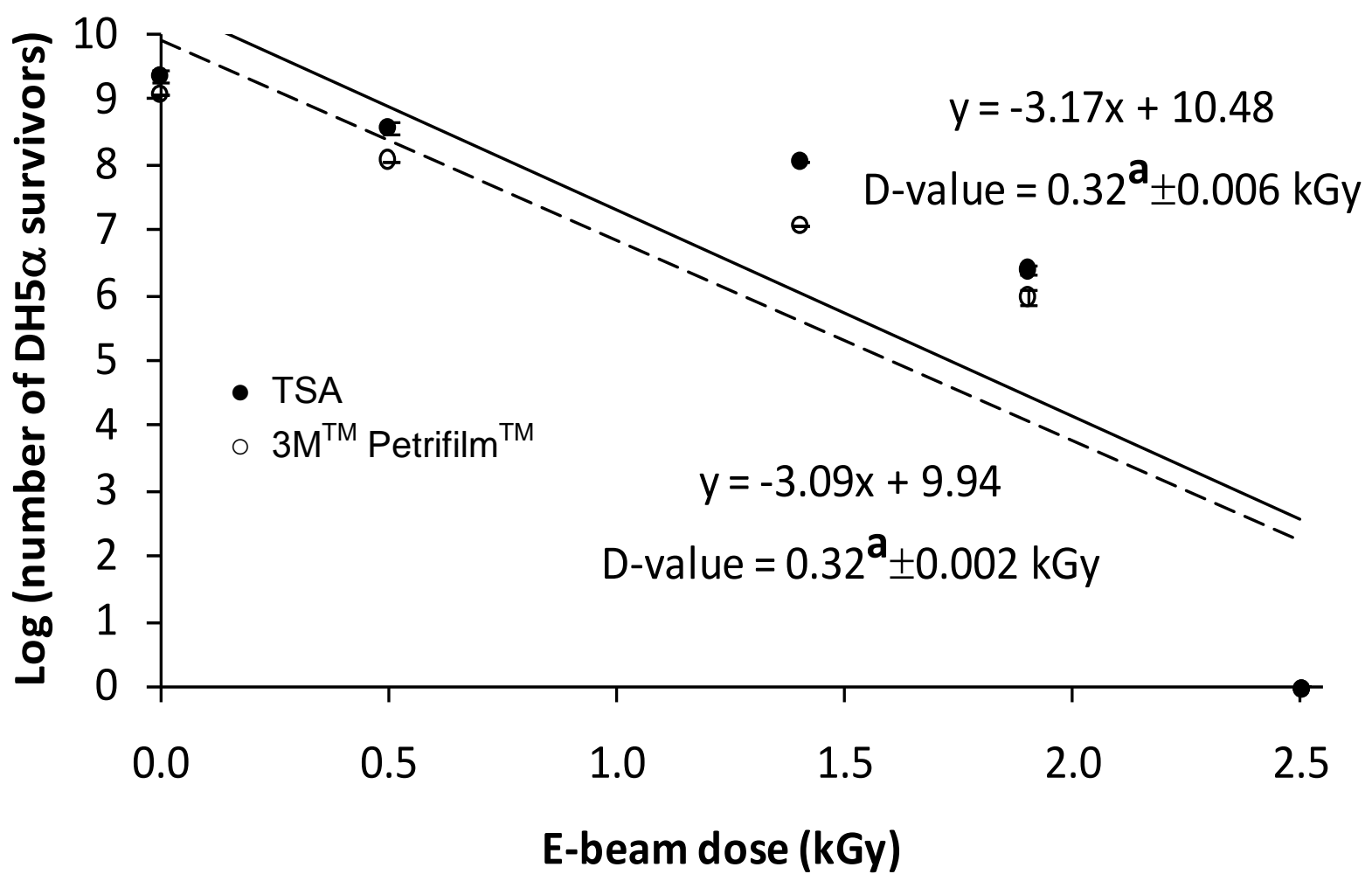

Figure 1:

Survivor curves for $E$. coli DH5 $\alpha$ isolate A2 in ground beef subjected to e-beam and enumerated on selective (3M ${ }^{\mathrm{TM}}$ Petrifilm ${ }^{\mathrm{TM}}$ ) and non-selective (TSA) media. Different superscript letters following $\mathrm{D}$-values indicate significant differences $(\mathrm{P}<0.05)$. Bars on the data points indicate standard deviation $(\mathrm{n}=3)$. 


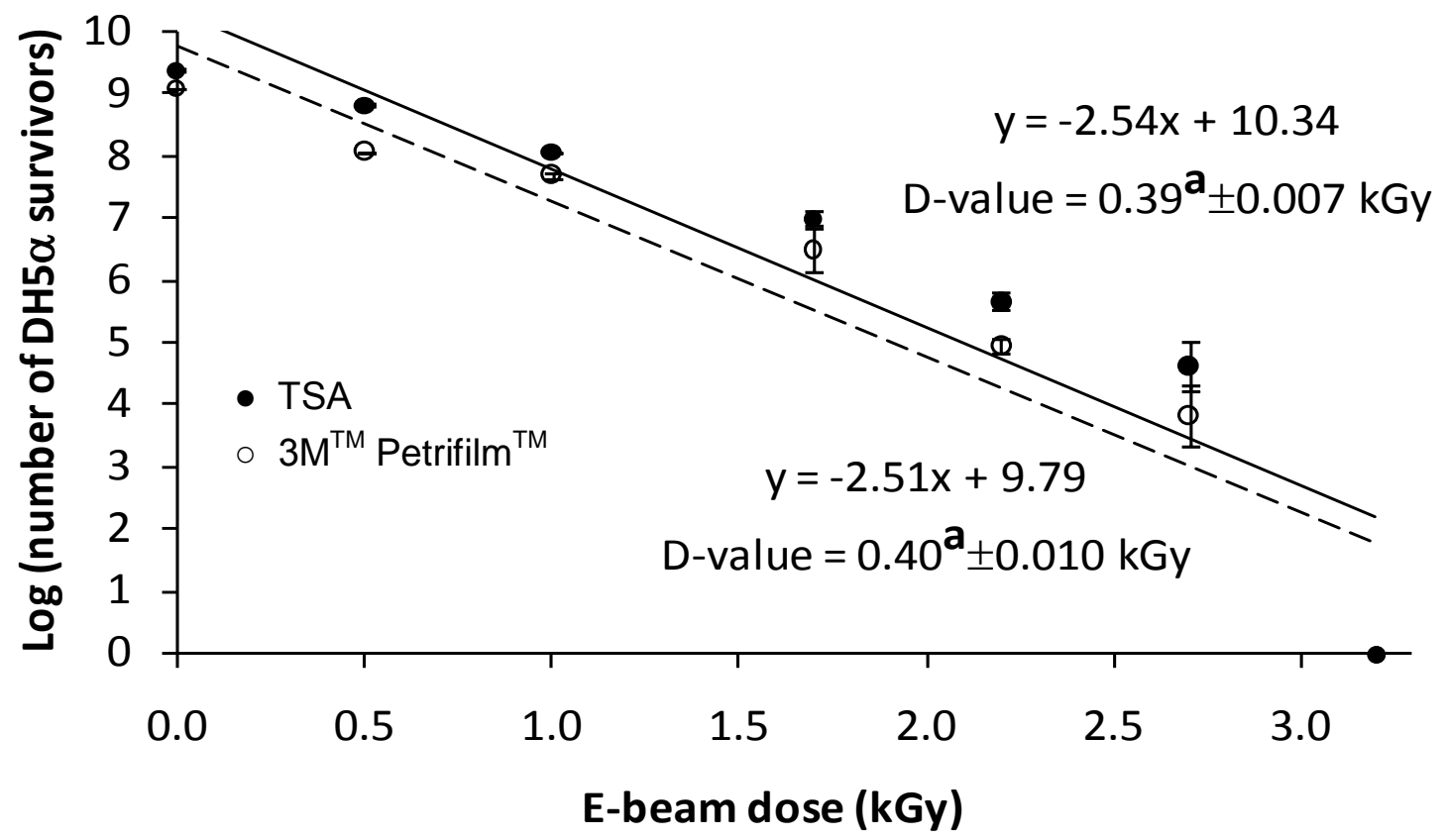

\section{Figure 2:}

Survivor curves for E. coli DH5 $\alpha$ isolate A3 in ground beef subjected to e-beam and enumerated on selective (3M ${ }^{\mathrm{TM}}$ Petrifilm ${ }^{\mathrm{TM}}$ ) and non-selective (TSA) media. Different superscript letters following $\mathrm{D}$-values indicate significant differences $(\mathrm{P}<0.05)$. Bars on the data points indicate standard deviation $(\mathrm{n}=3)$. 


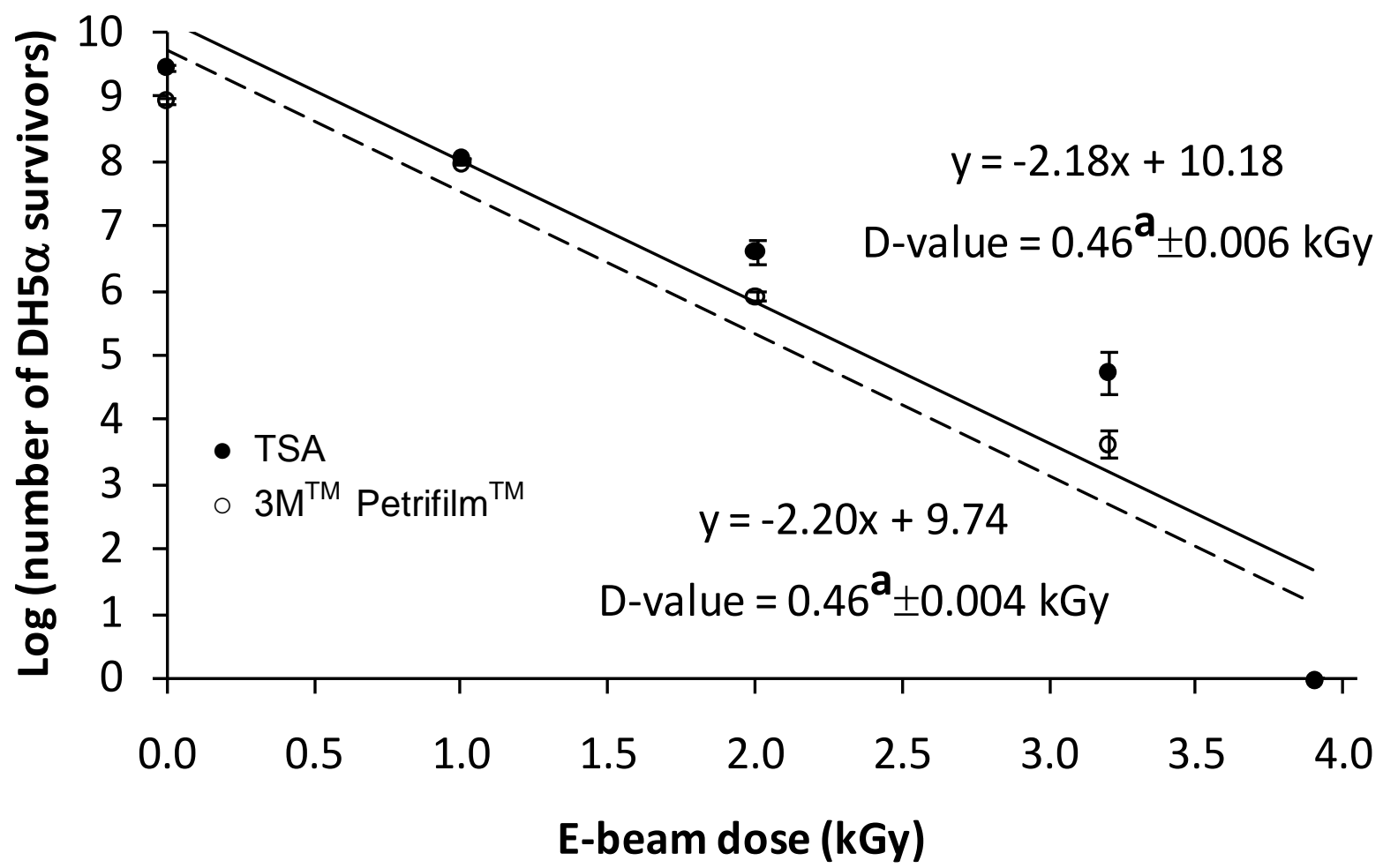

Figure 3:

Survivor curves for $E$. coli DH5 $\alpha$ isolate A4 in ground beef subjected to e-beam and enumerated on selective (3M ${ }^{\mathrm{TM}}$ Petrifilm ${ }^{\mathrm{TM}}$ ) and non-selective (TSA) media. Different superscript letters following $\mathrm{D}$-values indicate significant differences $(\mathrm{P}<0.05)$. Bars on the data points indicate standard deviation $(\mathrm{n}=3)$. 


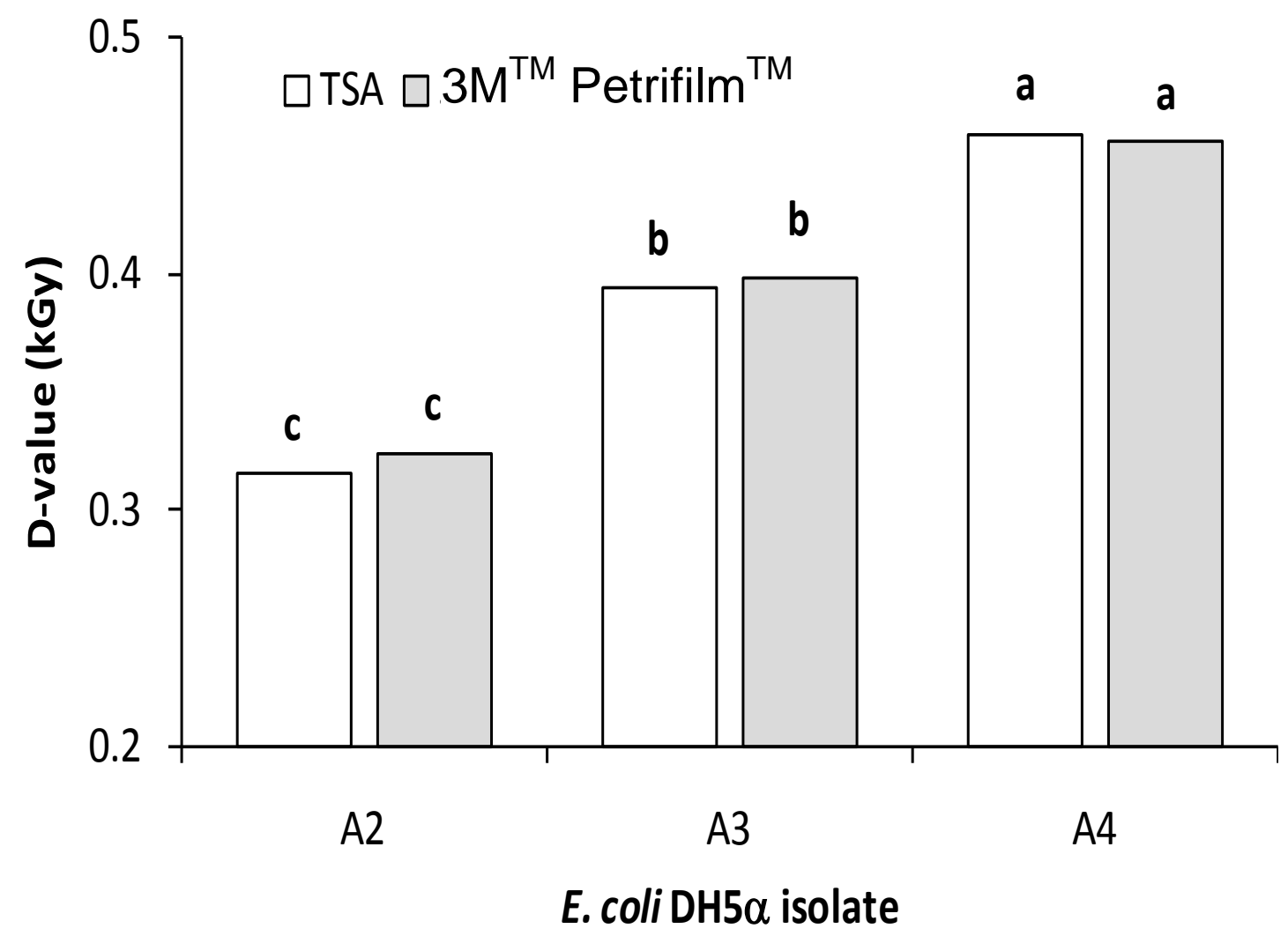

Figure 4:

D-values for E. coli DH5 $\alpha$ in ground beef subjected to e-beam. Different letters on the top of data bars indicate significant differences $(\mathrm{P}<0.05)$ within media type (TSA and $3 \mathrm{M}^{\mathrm{TM}}$ Petrifilm $\left.{ }^{\mathrm{TM}}\right)$. Bars on the data points indicate standard deviation $(\mathrm{n}=3)$. 


\subsection{References}

Arnold KW, Kaspar CW. (1995). Starvation- and stationary-phase-induced acid tolerance in Escherichia coli O157:H7. Applied and Environmental Microbiology 61:2037-2039.

Arvanitoyannis IS, Stratakos A, Mente E. (2009). Impact of irradiation on fish and seafood shelf life: A comprehensive review of applications and irradiation detection. Critical Reviews in Food Science and Nutrition 49:68-112.

Association of Official Analytical Chemists. (1995). Official Methods of Analysis. 16th ed., Gaithersburg, MD: Association of Official Analytical Chemists International.

Black JL, Jaczynski J. (2006). Temperature effect on inactivation kinetics of Escherichia coli O157:H7 by electron beam in ground beef, chicken breast meat, and trout fillets. Journal of Food Science 71:M221-M227.

Black JL, Jaczynski J. (2007). Effect of ionic strength on inactivation kinetics of Escherichia coli O157:H7 by electron beam in ground beef, chicken breast meat, and trout fillets. International Journal of Food Science and Technology 42:894-902.

Black JL, Jaczynski J. (2008). Effect of water activity on inactivation kinetics of Escherichia coli O157:H7 by electron beam in ground beef, chicken breast meat, and trout fillets. International Journal of Food Science and Technology 43:579-586.

Bridges BA. (1971). Rec $A^{+}$-dependent repair of gamma-ray damage to Escherichia coli does not require recombination between existing homologous chromosomes. Journal of Bacteriology 108:944-945.

Buchanan RL, Edelson SG, Boyd G. (1999). Effects of pH and acid resistance on the radiation resistance of enterohemorrhagic Escherichia coli. Journal of Food Protection 62:219-228.

Chalise PR, Hotta E, Matak KE, Jaczynski J. (2007). Inactivation kinetics of Escherichia coli by pulsed electron beam. Journal of Food Science 72:M280-285.

Cheville AM, Arnold KW, Buchrieser C, Cheng CM, Kaspar CW. (1996). rpoS regulation of acid, heat, and salt tolerance in Escherichia coli O157:H7. Applied and Environmental Microbiology 62:1822-1824.

Cox MM. (2007). Regulation of bacterial recA protein function. Critical Reviews in Biochemistry and Molecular Biology 42:41-63.

Davis R, Sinskey JA. (1973). Radiation-resistant mutants of Salmonella Typhimurium LT2: Development and characterization. Journal of Bacteriology 113:133-144.

Farkas J. (1998). Irradiation as a method for decontaminating food: A review. International Journal of Food Microbiology 44:189-204. 
Humphrey T. (2004). Salmonella, stress responses and food safety. Nature Reviews Microbiology 2:504-509.

Hvizdzak AL, Beamer S, Jaczynski J, Matak KE. (2010). Use of electron beam irradiation for the reduction of Salmonella enterica serovars Typhimurium and Tennessee in peanut butter. Journal of Food Protection 73:353-357.

Jaczynski J, Park JW. (2004). Physicochemical changes in Alaska pollock surimi and surimi gel as affected by electron beam. Journal of Food Science 69:53-57.

Jaczynski J, Park JW. (2003a). Microbial inactivation and electron penetration in surimi seafood during electron beam processing. Journal of Food Science 68:1788-1792.

Jaczynski J, Park JW. (2003b). Physicochemical properties of surimi seafood as affected by electron beam and heat. Journal of Food Science 68:1626-1630.

James DL, Jaczynski J, Matak KE. (2010). Electron beam irradiation on nalidixic acid resistant Salmonella Montevideo in cooked tomato puree of various $\mathrm{pH}$ values. Journal of Food Safety 30:515-525.

Jay JM, Loessner MJ, Golden DA. (2005). Foodborne gastroenteritis caused by Escherichia coli. In: Jay JM, Loessner MJ, Golden DA, editors. Modern Food Microbiology. $7^{\text {th }}$ ed. New York: Springer Science. pp 637-655.

Kornberg A, Baker TA. (2005). Repair, recombination, transformation, restriction, and modification. In: Kornberg A, Baker TA, editors. DNA replication. $2^{\text {nd }}$ ed. Sausalito, CA: University Science Books. pp 771-832.

Levanduski L, Jaczynski J. (2008). Increased resistance of Escherichia coli O157:H7 to electron beam following repetitive irradiation at sub-lethal doses. International Journal of Food Microbiology 121:328-334.

Leyer GJ, Wang L, Johnson EA. (1995). Acid adaptation of Escherichia coli O157:H7 increases survival in acidic foods. Applied and Environmental Microbiology 61:3752-3755.

Lin J, Smith MP, Chapin KC, Baik HS, Bennett GN, Foster JW. (1996). Mechanisms of acid resistance in enterohemorrhagic Escherichia coli. Applied and Environmental Microbiology 62:3094-3100.

Matak KE, Hvizdzak AL, Beamer SK, Jaczynski J. (2010). Recovery of Salmonella enterica serovars Typhimurium and Tennessee in peanut butter after electron beam exposure. Journal of Food Science 75:M462-M467.

Mount DW, Walker AC, Kosel C. (1975). Effect of tsl mutations in decreasing radiation sensitivity of a rec $A^{-}$strain of Escherichia coli K-12. Journal of Bacteriology 121:1203-1207. 
O’Bryan CA, Crandall PG, Ricke SC, Olson DG. (2008). Impact of irradiation on the safety and quality of poultry and meat products: A review. Critical Reviews in Food Science and Nutrition 48:442-457.

Orser CS, Foong FCF, Capaldi SR, Nalezny J, McKay W, Benjamin, M. B., \& Farr, S. B. (1995). Use of prokaryotic stress promoters as indicators of the mechanisms of chemical toxicity. In Vitro Toxicology 8:71-85.

Rajkowski KT, Boyd G, Thayer DW. (2003). Irradiation D-values for Escherichia coli O157:H7 and Salmonella sp. on inoculated broccoli seeds and effects of irradiation on broccoli sprout keeping quality and seed viability. Journal of Food Protection 66:760-766.

SAS Institute. (2002). SAS/STAT guide for personal computers, version 8.1. Cary, NC: SAS Institute.

Sedgwick SG, Bridges BA. (1972). Survival, mutation and capacity to repair single strand DNA breaks after gamma irradiation in different $\operatorname{Exr}^{-}$strains of Escherichia coli. Molecular and General Genetics 119:93-102.

Sharan RN, Ryo H, Nomura T. (2007). Critical role of RecA and RecF proteins in strand break rejoining and maintenance of fidelity of rejoining following $\gamma$-radiation-induced damage to pMTa4 DNA in E. coli. International Journal of Radiation Biology 83:89-97.

Sommers CH, Boyd G. (2006a). Variations in the radiation sensitivity of foodborne pathogens associated with complex ready-to-eat food products. Radiation Physics and Chemistry 75:773778.

Sommers CH, Boyd G. (2006b). Radiation sensitivity and post irradiation growth of foodborne pathogens on a ready-to-eat frankfurter on a roll product in the presence of modified atmosphere and antimicrobials. Journal of Food Protection 69:2436-2440.

Sommers CH, Rajkowski KT. (2008). Inactivation of Escherichia coli JM109, DH5a, and O157:H7 suspended in Butterfield's phosphate buffer by gamma irradiation. Journal of Food Science 73:M87-90.

Tesfai, A.T., Beamer, S. K., Matak, K. E., \& Jaczynski, J. (2011a). Microbial radio-resistance of Salmonella Typhimurium in egg increases due to repetitive irradiation with electron beam. Radiation Physics and Chemistry, 80(4), 591-596.

Thayer DW, Boyd G. (1993). Elimination of Escherichia coli O157:H7 in meats by gamma irradiation. Applied and Environmental Microbiology 59:1030-1034.

Thayer DW, Boyd G. (2001). Effect of irradiation temperature on inactivation of Escherichia coli O157:H7 and Staphylococcus aureus. Journal of Food Protection 64:1624-1626.

Urbain WM. (1986). Food Irradiation. Orlando, FL: Academic Press. 
U.S. Food and Drug Administration (2006). FDA Finalizes Report on 2006 Spinach Outbreak. Accessed on February 2, 2010.

http://www.fda.gov/NewsEvents/Newsroom/PressAnnouncements/2007/ucm108873.htm

Yuk H, Marshall DL. (2003). Heat adaptation alters Escherichia coli O157:H7 membrane lipid composition and verotoxin production. Applied and Environmental Microbiology 69:5115-5119. 


\section{CHAPTER 3}

\section{Understanding radio resistance development of E.coli $\mathrm{DH}$ $\alpha$ after exposure to e-beam radiation}

Adiam T. Tesfai, William Rittenour, Kristen E. Matak, and Jacek Jaczynski

In preparation for submission to International Journal of Radiation Biology 


\subsection{Abstract}

Electron beam radiation (e- beam) is a non-thermal inactivation method similar to pasteurization that disrupts DNA by introducing cross-links, rendering the organism unable to reproduce its DNA. Unpaired DNA double strand breaks are generally the cause of ionizing radiation induced cell killing, which is reported by increased radio sensitivity of specific repair deficient mutants. Escherichia coli $\mathrm{DH} 5 \alpha$ is a model microorganism that lacks DNA repair capability (carry mutation of the recA and gyrA genes). The objective of this study was to further understand the role of recA and gyrA genes in Escherichia coli DH5 $\alpha$ that had became resistant to repetitive e- beam radiation and its ability to repair the damage caused by e- beam. Genomic DNA from Escherichia coli DH5 $\alpha$, radio-resistant A2 and A4 were extracted, and DNA fragments of the gyrA and recA genes containing the mutations were amplified, cloned and sequenced. Sequence comparison of both genes of radio-resistant Escherichia coli DH5 $\alpha$ A2 and A4; non-irradiated Escherichia coli DH5 $\alpha$ and Escherichia coli (K-12) from gene bank database was performed. Our results demonstrate that Escherichia coli DH5 $\alpha$ was able to reverse its mutation after sub lethal e- beam irradiations. 


\subsection{Introduction}

Food-borne pathogens cause an estimated 46-million foodborne infections, along with 250,000 hospitalizations and 3,000 deaths in the United States annually and Escherichia coli is one of the major food borne microorganisms (Scallan, 2011). Escherichia coli lives everywhere in the environment and have the ability to adapt both physically and metabolically to endure harsh environmental conditions as low $\mathrm{PH}$, high temperature, high salinity, antibiotics and irradiation (Bell and Kyriakides, 1998; Tauxe, 2002; Tesfai et al., 2011). Electron beam radiation (e- beam) is a non-thermal inactivation method similar to pasteurization that disrupts DNA by introducing cross-links, rendering the organism unable to reproduce its DNA (EPA- Food Irradiation, 2007). The more complex an organism, the more susceptible its DNA is to e-beam; therefore, an organism as small as E.coli can withstand a higher dose than a more evolved organism (Tauxe, 2001). It has been established that E.coli has an ability to adapt electron-beam irradiation at levels approaching the recommended dosage of 4.5 KGys (Levanduski and Jaczynski, 2007).

Resistance to extreme environmental stress is a result of several genes working together to allow a cell to withstand the stress and repair any damage that it may incur upon the cell`s DNA. Radio-resistance is expressed as the ability to repair DNA double-strand breaks (DSB) generated by ionizing radiation (Cox and Battista, 2005).

In pervious study by Tesfai et al. (2011), we reported radio- resistance development of Escherichia coli DH5 $\alpha$ that have mutation in recA and gyrA genes. Radiation resistant cultures of Escherichia coli DH5 $\alpha$ strain were generated through a series of repeated exposures to e- beam 
irradiation followed by growth of survivors. The mutants showed stepwise increase in radioresistance and it was suggested Escherichia coli DH5 $\alpha$ that have mutation of recA and gyrA genes had the ability to recover the DNA damage induced by e- beam despite their repair deficiency. The cause of ionizing radiation induced cell killing is the presence of unpaired DNA double strand breaks which is reported by increased radio sensitivity of repair deficient mutants (Daly et al., 2010).

In order to understand the radio-resistance development of E.coli it is important to discuss the DNA repair mechanism employed. RecA mediated recombination repair pathway is employed to repair strand break types of damage in E.coli (Kuzminov, 1999). SOS response is a response mechanism induced by DNA damage in Escherichia coli. The genomic mechanism in SOS response involves recA and lexA genes among others, which regulate each other by a mixed feedback loop involving transcriptional regulation and protein-protein interaction (Shimoni, 2009). SOS response should be first induced by a signal that simply signifies some change due to DNA damage, which activates a series of reactions. The induction signal activates the recA protein protease to cleave and inactivate the LexA repressor. The SOS genes are then translated at vastly increased rate until the damage is repaired (Shimoni, 2009). Ghtman et al. (1994) reported that recA dependent homologues recombination pathways are involved for radio-resistance development and reconstruction of whole genome in the most radiation resistant microbe, Deinococcus radiodurans (Ghtman et al., 1994). Increased radio sensitivity of specific repair deficient mutants such as recA has also been reported (Daly et al., 2009). 
It is expected that the repair pathways are optimally operational in repair proficient wild type E.coli but hampered in recA and gyrA mutants due to different components of repair pathways being defective in them. Therefore the overall objective of this study was to analyze the role of recA and gyrA genes of E.coli DH5 $\alpha$ that had became resistant to stressful stumili (ebeam radiation), its ability to repair the damage caused by e- beam and thus, understand the genetic mechanisms of e- beam resistance. 


\subsection{Materials and Methods}

\subsubsection{Isolation of strains}

Escherichia coli DH5a luxS (biolumenesence S) supE44 (suppressor of amber E44) DlacU169 (deletion lactose U169) [j80 (bacteriophage phi 80) dlacZ (deletion lactose Z) DM15 (deletion M15)] hsdR17 recA1 endA1 (endonuclease A1) gyrA96 thi-1 (thiamine 1) relA1 (relaxed A1) (hereafter called E. coli) (Invitrogen Inc., Carlsbad, CA, USA) lyfo-disks were reconstituted by crushing one pellet using a sterile spatula in $0.4 \mathrm{ml}$ of sterile trypticase soy broth (TSB) (Becton Dickinson and Company, Sparks, MD, USA). The content was aseptically transferred to $3.6 \mathrm{ml}$ of sterile TSB and allowed to grow aerobically at $35^{\circ} \mathrm{C}$ for $24 \mathrm{hrs}$ in an incubator/shaker set at 150 rpm (C24 Incubator/Shaker, New Brunswick Scientific, Edison, NJ, USA). The $4 \mathrm{ml}$ aliquot of the $E$. coli culture was aseptically transferred to $76 \mathrm{ml}$ of sterile TSB and allowed to grow aerobically at $35^{\circ} \mathrm{C}$ for 24 hrs in the incubator/shaker set at $150 \mathrm{rpm}$. A 5\% inoculum size was then added to a sample of ground beef purchased from local grocery store and thawed overnight to $4{ }^{\circ} \mathrm{C}$. The total mixture was incubated (Isotemp Incubator, Fisher Scientific, Pittsburgh, PA) at $35^{\circ} \mathrm{C}$ for 24 hrs. Preliminary studies showed that the final microbial count for all samples reached approximately $10^{9} \mathrm{CFU} / \mathrm{g}$. Following incubation, 18 individual samples of approximately 10 g of inoculated beef were separately packaged into bags (KapaK Seal PAK 4” by 6” pouches, Kapak Corporation Minneapolies,MN). Each bagged sample was spread evenly to a width of approximately $1 \mathrm{~mm}$ in order to ensure complete penetration of electron beams though out the sample. Double bagging (Kapak seal PAK 6.5” by 8” pouches, Kapak Corporation, Minneapolis, MN) was utilized to ensure that no contamination occurred and samples were stored at $-80^{\circ} \mathrm{C}$ until shipment. 


\subsubsection{Treatment}

Samples were packaged in a Styrofoam cooler containing dry ice to maintain freezing temperature and maintain microbial populations without causing inactivation. Samples were shipped overnight to an e- beam processing facility (Streigencies Intertional San Diego, CA). Once received at the facility, each sample was thawed to $4^{\circ} \mathrm{C}$ before undergoing treatment. Treatment consisted of exposure of microbes to one-sided e- beam radiation in five increasing doses- 0(control), 0.5 kGy, 1.0 kGy, 1.5 kGy, 2.0 kGy, and 2.5 kGy. Each treatment was performed in triplicate for a total of 18 samples. Immediately following treatment, samples were stored in $-80^{\circ} \mathrm{C}$ freezer. Samples were packed in a Styrofoam cooler with dry ice to maintain freezing temperatures and shipped back to our facility at West Virginia University where they were stored at $-80{ }^{\circ} \mathrm{C}$ until analysis.

\subsubsection{Enumeration}

All samples were thawed to $4^{\circ} \mathrm{C}$. Each sample was enumerated by placing $10 \mathrm{~g}$ of the ebeam treated sample using a sterile spatula into a sterile filter stomacher bag (Two- chamber FILTERABAG, Fisher Scientific, Pittsburgh,PA). An aliquot of $90 \mathrm{ml}$ of diluent (Butterfiled phosphate buffer, Hardy Diagnostics, Santa Maria, CA) was aseptically added to the filter stomacher bag and the bag was placed into a stomacher (Bag Mixer 400, interscience,St. Nom, France) for 2 min. Further serial dilutions were aseptically made by taking $10 \mathrm{ml}$ diluted sample and transferring it into a $90 \mathrm{ml}$ diluent bottle, followed by manual shaking to uniformly distribute survivors. An aliquot of $1 \mathrm{ml}$ of each serial dilution was pipetted onto a petrifilm plate (Pertifilm E.Coli/Coliform Count Plate, 3M, St. Paul,MN) and spread by a petrifilm spreader. Plates were 
incubated at $35^{\circ} \mathrm{C}$ for 48 hours using AOAC method 991.14. Only plates with 15- 150 colonies were counted. Following enumeration, survivors from the highest e-beam dose were removed at random from the plates using a sterile loop and grown in $10 \mathrm{ml}$ of sterile TSB with shaking (150 rpm). A further inoculum of $2 \mathrm{ml}$ of survivors was then used as an inoculum for the next sample of ground beef and round of radiation. This process was repeated four times for a total of five exposures to increasing e- beam levels. Survivors of the fifth exposure to e- beam were isolated and grown in TSB and became strain A4.

Strains A2 and A4 are the result of a series of electron beam treatments from a radiation resistant population $E$. coli after 2 and 4 cycles of e- beam irradiation, respectively followed by growth as described previous.

The bacterial strains used in this study are shown in Table 1.

\subsubsection{Isolation of genomic DNA}

E. coli cells of interest were pelleted and re-suspended in $350 \mu \mathrm{l}$ of tissue lysis buffer (Roche High Pure PCR Template Kit) and transferred to bead beater tube containing $300 \mu \mathrm{g}$ glass beads. It was Bead beated for 30 seconds at high speed. The tubes were centrifuged at high

speed ( 20K x g) and the supernatant collected. After this step genomic DNA was extracted from the samples according to (Roche High Pure PCR Template Kit). 


\subsubsection{PCR Amplification and purification}

All primers were bought from SIGMA- ALDRICH. The PCR cycling parameter $(\sim 30$ cycles) used were:

PCR Reaction Conditions:

\begin{tabular}{|c|c|c|}
\hline Initial Denaturing & $95^{\circ} \mathrm{C} 4$ minutes & \\
\hline Denaturing & $50^{\circ} \mathrm{C} 30$ seconds & \\
\hline Annealing & $50^{\circ} \mathrm{C} 30$ seconds & 30 cycles \\
\hline Extension & $72^{\circ} \mathrm{C} 1$ minute & \\
\hline Final Extension: & $72^{\circ} \mathrm{C} 10$ minutes & \\
\hline
\end{tabular}

All PCR product samples were purified according QIAquick PCR Purification Kit (Qiagen Catalogue \# 28104). The purified recA/gyrA amplicon was collected and stored at $-20^{\circ} \mathrm{C}$. The PCR products from non-irradiated E.coli (control) founder strain and irradiated radio-resistant strains (A2 and A4) were subjected to 0.9\% agarose gel electrophoresis using TAE (Tris-acetateEDTA).

\subsubsection{Cloning, Sequencing}

Escherichia coli amplicons were cloned in to pDrive vector using a PCR cloning kit (Qiagen, Valencia, CA, USA) according to the manufacturers instructions. Ligated plasmids were then transformed in to TOP10 chemically component Escherichia coli cells (Invitrogen, Clasbad,CA,USA) according to the manufacturer`s instruction .The transformants were spread 
on Luria- Bertani (LB) agar plates containing $100 \mathrm{ug} / \mathrm{mL}$ ampicillin and a top layer of X/gal. The plates were then incubated overnight at $37^{\circ} \mathrm{C}$. white colonies were selected and cultured in $2 \mathrm{~mL}$ LB media containing $100 \mathrm{ug} / \mathrm{ml}$ ampicillin overnight at $37^{\circ} \mathrm{C}$, and plasmid DNA was isolated with a miniprep kit (Qiagen,Valencia,CA,USA) according to the manufacturer`s instructions. Plasmid DNA samples were loaded in to 96 -well plates and sent to GENWIZ (South Plainfield, NJ) for Sanger Sequencing analysis. Sequence comparison of both recA and gyrA genes of radioresistant Escherichia coli DH5 $\alpha$ A2 and A4, non-irradiated Escherichia coli DH5 $\alpha$, and Escherichia coli (K-12) from gene bank database was performed.

\subsection{Results and Discussion}

As described in the methods section, gyrA and recA genes were isolated from unirradiated E. coli $\mathrm{DH} 5 \alpha$ and e-beam treated A2 and A4. Both genes from the isolates were amplified and sequenced for comparison with E. coli K12 from gene bank database. The sequence result comparison is shown in Figure -1 for rec $A$ and Figure -2 for gyrA. Figure -1 , shows the sequenced part of the recA gene of E. coli DH5 $\alpha$, e- beam treated A2 and A4 in comparison with E. coli K12; while Figure -2 shows the sequence result of gyrA gene.

In E. Coli $D H 5 \alpha$, recA1 mutation is a single point mutation that replaces glycine 160 of the recA polypeptide with an aspartic acid residue (Bryant, 1988) .The result indicates the radioresistant A2 and A4, which were expected to be similar to the founder strain E. Coli DH5 $\alpha$, acquired back mutations of recA gene and were able to reverse to wild type E. coli K12 after repetitive e-beam radiation. Single base pair substitution was observed in the sequence result that caused substitution of an amino acid. The summary in Table -3 shows the strains of E.coli of 
investigation, their phenotypes in terms of e- beam resistance, change in nucleotide position of the $r e c A$ gene corresponding amino acid change in the protein and the position of amino acid change are described. In this case, the changed nucleotide caused a substitution of aspartic acid residue 160 of the recA polypeptide with glycine residue (Asp ${ }^{160} \rightarrow$ Gly) in both radio-resistant A2 and A4 strains (Table-3).

Results from our previous experiment indicate $E$. Coli $D H 5 \alpha$, which is recA and gyrA mutant, developed resistance to DNA damage induced by repetitive sub lethal e- beam irradiation (Tesfai et al., 2011). RecA in bacteria is highly conserved multifunctional protein that plays a central role in DNA repair and regulation of the SOS response to DNA damage (Roca and Cox, 1990). recA production is induced by DNA-damaging treatments such as UV irradiation or nalidixic acid, resulting in up to a 50-fold increase in the amount of the protein as reported by (Kuzminov, 1999). recA does not bind to DNA except in the presence of single strand breaks (Kumar, 2004). Thus, e- beam induced single strand breaks resulted in high expression of recA gene in E. Coli DH5 $\alpha$.

Daly and Minton (1996) stated that cells recovering from the effect of ionizing radiation show biphasic kinetics of double strand break (DSB) repair. The phase I, recA-independent, proceeds subsequent to recA-dependent mechanisms of DSB repair (Daly and Minton, 1996). In our experiment E. Coli DH5a surviving cells were harvested post irradiation and allowed to recover in nutrient rich medium until reaching stationary phase; this population then served as the source of the next culture to be irradiated. As it is shown, they were able to recover from the 
DNA damage due to a functional recA that was induced by mutation of the DNA repair deficient starting population E. Coli $D H 5 \alpha$.

Our results suggest the involvement of the recA gene in DNA damage repair of E. coli DH5 $\alpha$. Harris et al. (2012) have also found a similar result, that recA mutations make a clear positive contribution to radiation resistance phenotype (Harris et al., 2012). In their experiment, they generated four extremely radiation resistant population of E.coli all derived from the same founder strain MG1655 and reported, enhanced recombination DNA repair after extreme genomic degradation plays a major role in radiation resistance in E.coli but probably not sole contribution to genome reconstitution (Harris et al., 2012).

The gyrA gene is SOS inducible and affects the efficiency of DNA repair and replication (Kornberg and Baker, 1992). Using the primer pair mentioned above, a 365 base pair sequence of gyrA gene was also amplified and sequenced (Figure-2). From the gene bank database the gyrA gene sequence for E.coli K12 was downloaded and compared with the mutant and radioresistant counterparts. Sequence alteration was also observed with gyrA gene for A2 and A4 strains. Sequence result of the strains shows an identical substitution resulting for both radiation treated A2 and A4, where nucleotide sequences no 259 (A) in E. coli DH5 $\alpha$ founder strain is changed to (G), which is similar to wild type E. coli K12 (Table-4). The changed nucleotides caused a substitution of Asn ${ }^{87} \rightarrow$ Asp in both radio-resistant A2 and A4 strains (Table-4).

Ionizing radiation has a potential to induce mutations, as a number of other physical or chemical antimicrobial agents through DNA damage. Song et al. (2012) have demonstrated 
mutation of E.coli K12 when irradiated by $10 \mathrm{Kev}$ nitrogen ions for six times. They compared muti- ion irradiated E.coli with reference sequence and suggested mutation of genes increased the ability of the E.coli genome to resist damage caused by ion- radiation (Song et al., 2012). Base pair substitution was the dominant type of mutation detected genomic alteration after repetitive ionizing irradiation in E. coli K-12 (Xie et al., 2004; Harris et al., 2009), which is in agreement to our result.

\subsection{Conclusion}

Our results demonstrate that the radio resistance phenotype observed in DNA repair deficient E.coli DH5 $\alpha$ could have arisen from active DNA repair processes due to back mutation of both genes (recA and gyrA) after sub lethal e-beam irradiations. Understanding the microbial resistance of food borne microorganisms to irradiation is important and it has implication for determining the efficacy of irradiation in reducing levels of those microorganisms in food.

\section{Acknowledgments}

Special thanks to Dr. Brett J. Green and CDC/NIOSH/HELD for allowing us to use their laboratory and valuable discussions. Our appreciation extends to Carl A. Zinn and Richard Vallejo of Sterigenics for technical expertise with e-beam and Tesfalem R. Zere for his assistance with DNA sequence result. 


\subsection{Appendix D}

Table 1- Bacterial strains

\begin{tabular}{|l|l|}
\hline Strain & Relevant Marker \\
\hline Escherichia coli & luxS (biolumenesence S) supE44 (suppressor of amber E44) \\
& $\begin{array}{l}\text { DlacU169 (deletion lactose U169) [j80 (bacteriophage phi 80) } \\
\text { dlacZ (deletion lactose Z) DM15 (deletion M15)] hsdR17 recA1 } \\
\text { endA1 (endonuclease A1) gyrA96 thi-1 (thiamine 1) relA1 } \\
\text { (relaxed A1) }\end{array}$ \\
\hline A2 & Escherichia coli DH5 $\alpha$ after 2 times e- beam radiation \\
\hline A4 & Escherichia coli DH5 $\alpha$ after 4 times e- beam radiation \\
\hline
\end{tabular}

Table 2 - Primers used in the study

\begin{tabular}{|l|c|}
\hline \multicolumn{1}{|c|}{ Primer } & Primer sequence $\left(5^{`}{ }^{-3}{ }^{`}\right.$ ) \\
\hline recA Forward & TCGGTCATTGTTGGCCGTGC \\
\hline recA reverse & CCGCGCCGATACGACGGATG \\
\hline gyrA Forward & TCGGTCATTGTTGGCCGTGC \\
\hline gyrA reverse & CGACCGTCTCTTTTTCGAGATCGGC \\
\hline
\end{tabular}


Table 3- Genotypic characters of recA gene of mutant, wild type and radio resistant E.coli

\begin{tabular}{|l|l|c|c|}
\hline Bacterial Strains & Description & $\begin{array}{l}\text { Change in } \\
\text { Nucleotide }^{\text {a }}\end{array}$ & $\begin{array}{l}\text { Change in } \\
\text { Amino acid }^{\mathrm{b}}\end{array}$ \\
\hline E.coli wt & E.coli K12 & ${ }^{(482)} \mathrm{G}$ & Gly \\
\hline E.coli DH5 $\alpha$ & $\begin{array}{l}\text { E.coli DH5 } \alpha \text { from } \\
\text { Stergenics, with } \\
\text { rec A gene mutant }\end{array}$ & ${ }^{(482)} \mathrm{A}$ & Asp \\
\hline E.coli A2 & $\begin{array}{l}\text { E.coli DH5 } \alpha \text { after } \\
\text { 2 times radiation }\end{array}$ & ${ }^{(482)} \mathrm{A}---\mathrm{G}$ & Asp $^{160} \rightarrow$ Gly \\
\hline E.coli A4 & $\begin{array}{l}\text { E.coli DH5 } \alpha \text { after } \\
\text { 4 times radiation }\end{array}$ & ${ }^{\left({ }^{(482)} \mathrm{A}---\mathrm{G}\right.}$ & Asp $^{160} \rightarrow$ Gly \\
\hline
\end{tabular}

a- Numbering based on the start of the $r e c A$ start codon

b- Numbering based on RecA protein

Table 4- Genotypic characters of gyrA gene of E.coli DH5a, wild type and radio resistant (A2 and A4)

\begin{tabular}{|l|l|c|c|}
\hline Bacterial Strains & \multicolumn{1}{|c|}{ Description } & $\begin{array}{c}\text { Change in } \\
\text { Nucleotide }\end{array}$ & $\begin{array}{c}\text { Change in } \\
\text { Amino acid }\end{array}$ \\
\hline E.coli wt & E.coli K12 & ${ }^{(259)} \mathrm{G}$ & Asp \\
\hline E.coli DH5 $\alpha$ & $\begin{array}{l}\text { DH5 } \alpha \text { from } \\
\text { Stergenics, with } \\
\text { gyrA gene mutant }\end{array}$ & ${ }^{(259)} \mathrm{A}$ & Asn \\
\hline E.coli A2 & $\begin{array}{l}\text { DH5 } \alpha \text { after 2 times } \\
\text { radiation }\end{array}$ & ${ }^{(259)} \mathrm{A}---\mathrm{G}$ & $\mathrm{Asn}^{87} \rightarrow$ Asp \\
\hline E.coli A4 & $\begin{array}{l}\text { DH5 } \alpha \text { after 4 times } \\
\text { radiation }\end{array}$ & ${ }^{(259)} \mathrm{A}---\mathrm{G}$ & $\mathrm{Asn}^{87} \rightarrow$ Asp \\
\hline
\end{tabular}

a- Numbering based on the start of the gyrA start codon

b- Numbering based on GyrA protein 
Figure -1 Multiple Sequences alignment comparison of E.coli recA gene: recA, recA_wt, A2,A4 represents for the recA gene of E.coli DH5 $\alpha$, E.coli K12,A2 and A4 respectively

CLUSTAL W (1.83) multiple sequence alignment

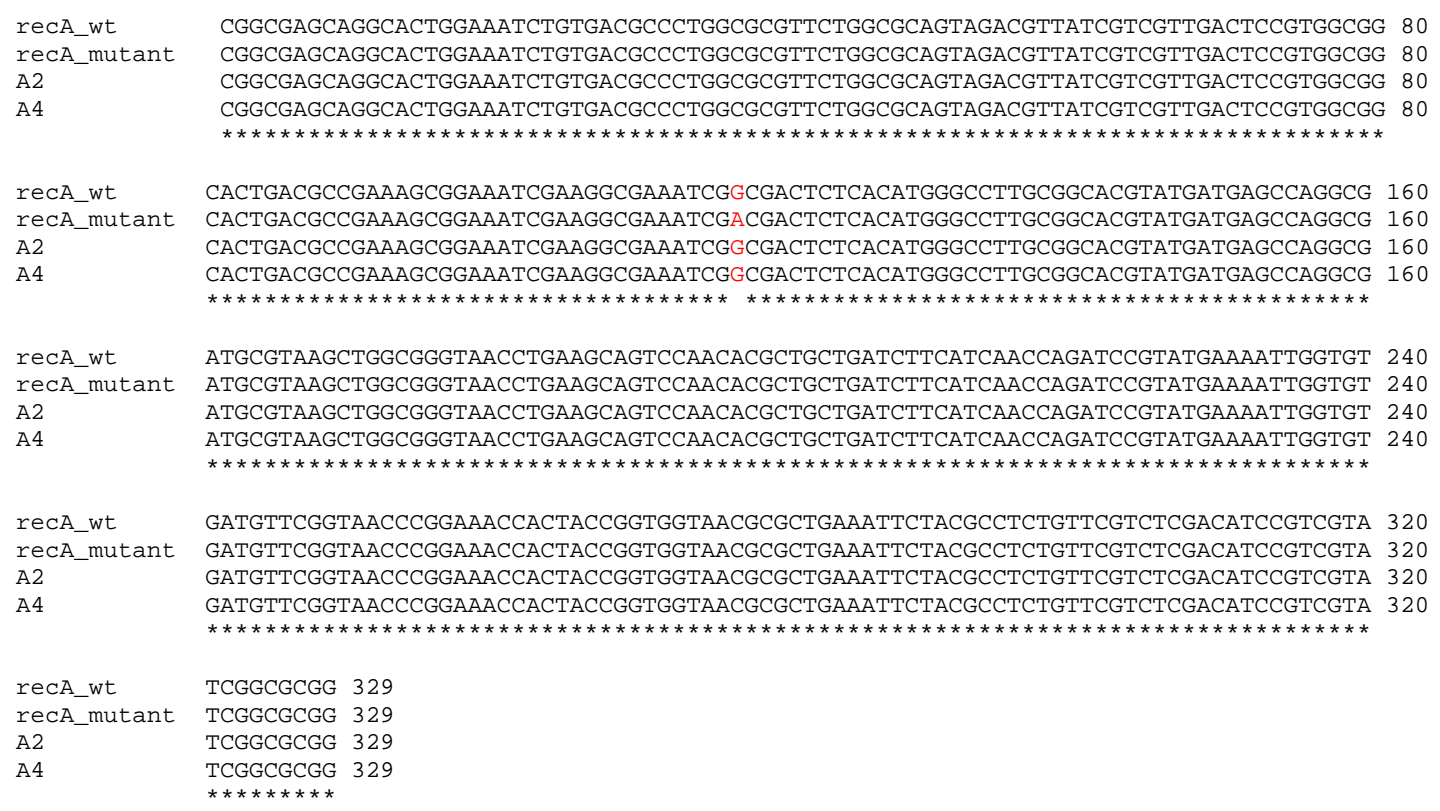


Figure -2 Multiple Sequences alignment comparison of E.coli gyrA gene: gyrA, gyrA_wt, A2,A4 represents for the gyrA gene of E.coli DH5 $\alpha$, E.coli K12,A2 and A4 respectively

\author{
CLUSTAL W (1.83) multiple sequence alignment
}

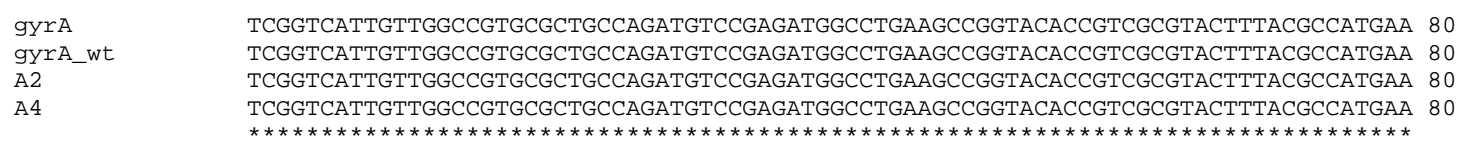

gyra CGTACTAGGCAATGACTGGAACAAAGCCTATAAAAAATCTGCCCGTGTCGTTGGTGACGTAATCGGTAAATACCATCCCC 160 gyrA_wt CGTACTAGGCAATGACTGGAACAAAGCCTATAAAAAATCTGCCCGTGTCGTTGGTGACGTAATCGGTAAATACCATCCCC 160 A2 CGTACTAGGCAATGACTGGAACAAAGCCTATAAAAAATCTGCCCGTGTCGTTGGTGACGTAATCGGTAAATACCATCCCC 160 A4 CGTACTAGGCAATGACTGGAACAAAGCCTATAAAAAATCTGCCCGTGTCGTTGGTGACGTAATCGGTAAATACCATCCCC 160

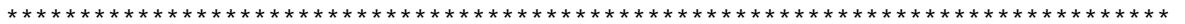

gyra ATGGTGACTCGGCGGTCTATAACACGATCGTCCGCATGGCGCAGCCATTCTCGCTGCGTTATATGCTGGTAGACGGTCAG 240 gyrA_wt ATGGTGACTCGGCGGTCTATGACACGATCGTCCGCATGGCGCAGCCATTCTCGCTGCGTTATATGCTGGTAGACGGTCAG 240 A2 ATGGTGACTCGGCGGTTTATGACACGATCGTCCGTATGGCGCAGCCATTCTCGCTGCGTTACATGCTGGTAGACGGTCAG 240 A4 ATGGTGACTCGGCGGTTTATGACACGATCGTCCGTATGGCGCAGCCATTCTCGCTGCGTTACATGCTGGTAGACGGTCAG 240

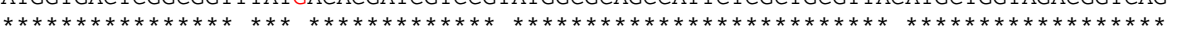

gyrA GGTAACTTCGGTTCTATCGACGGCGACTCTGCGGCGGCAATGCGTTATACGGAAATCCGTCTGGCGAAAATTGCCCATGA 320 gyrA_wt GGTAACTTCGGTTCTATCGACGGCGACTCTGCGGCGGCAATGCGTTATACGGAAATCCGTCTGGCGAAAATTGCCCATGA 320 GGTAACTTCGGTTCCATCGACGGCGACTCTGCGGCGGCAATGCGTTATACGGAAATCCGTCTGGCGAAAATTGCCCATGA 320 A4 GGTAACTTCGGTTCCATCGACGGCGACTCTGCGGCGGCAATGCGTTATACGGAAATCCGTCTGGCGAAATTGCCCATGA 320 GGTAACTTCGGTTCCATCGACGGGGACTCTGCGGCGGCAATGCGTTATACGGAAATCCGTCTGGCGAAAATTGCCCATGA

gyra ACTGATGGCCGATCTCGAAAAAGAGACGGTCG 352

gyra wt ACTGATGGCCGATCTCGAAAAAGAGACGGTCG 352

A2 ACTGATGGCCGATCTCGAAAAAGAGACGGTCG 352

A4 ACTGATGGCCGATCTCGAAAAAGAGACGGTCG 352 


\subsection{References}

Battista, J. R. (1997). Against All Odds: The Survival Strategies of Deinococcus radiodurans. Annual Review of Microbiology, 51:203-224.

Bell, C.,Kyriakides, A.(1999). E.coli, a practical approach to the organism and its control in foods. Blackwell science, London: 200.

Bryant, F. R. (1988). Construction of a recombinase-deficient mutant recA protein that retains single-stranded DNA-dependent ATPase activity. Journal of Biological Chemistry, 263(18), 8716-8723.

Cox, M. M. (1999). Recombinational DNA repair in bacteria and the RecA protein. Progress in nucleic acid research and molecular biology, 63, 311-366.

Cox, M. M., \& Battista, J. R. (2005). Deinococcus radiodurans - the consummate survivor. Nature Reviews Microbiology, 3(11), 882-892.

Daly, M. J., Ouyang, L., Fuchs, P., \& Minton, K. W. (1994). In vivo damage and recAdependent repair of plasmid and chromosomal DNA in the radiation-resistant bacterium Deinococcus radiodurans. Journal of bacteriology, 176(12), 3508-3517.

Daly, M. J., \& Minton, K. W. (1996). An alternative pathway of recombination of chromosomal fragments precedes recA-dependent recombination in the radioresistant bacterium Deinococcus radiodurans. Journal of bacteriology, 178(15), 4461-4471.

Daly, M. J. (2009). A new perspective on radiation resistance based on Deinococcus radiodurans. Nature Reviews Microbiology, 7(3), 237-245.

Daly M. J. (2012). Death by protein damage in irradiated cells. DNA Repair 11, 12-21.

Environmental Protection Agency. (2007). Food Irradiation.

www.epa.gove/radiation/sources/food_irrad.htm

Gutman PD, Fuchs P, Minton KW. (1994). Restoration of the DNA damage resistance of Deinococcus radiodurans DNA polymerase mutants by Escherichia coli DNA polymerase I and Klenow fragment. Mutat Research/DNA Repair, 314: 87-97.

Harris DR, Tanaka M, Saveliev SV, Jolivet E, Earl AM, Cox MM, Battista JR (2004). Preserving genome integrity: the DdrA protein of Deinococcus radiodurans R1. PloS Biology, 2, 304. 
Harris, D. R., Pollock, S. V., Wood, E. A., Goiffon, R. J., Klingele, A. J., Cabot, E. L., ... \& Battista, J. R. (2009). Directed evolution of ionizing radiation resistance in Escherichia coli. Journal of bacteriology, 191(16), 5240-5252.

Kumar JK, Tabor S, Richardson CC. (2004). Proteomic analysis of thioredoxin-targeted proteins in Escherichia coli. Proc Natl Acad Sci U S A ,101,3759-64.

Kuzminov A. (1999). Recombinational repair of DNA damage in Escherichia coli and bacteriophage l. Microbiology and Molecular Biology Reviews 63,751 - 813.

Kornberg, A., \& Baker, T. A. (1992). DNA replication (Vol. 5, pp. 69-73). New York: WH Freeman.

Notredame, C., Higgins, D. G., \& Heringa, J. (2000). T-Coffee: A novel method for fast and accurate multiple sequence alignment. Journal of molecular biology, 302(1), 205217.

Roca A. and Cox M. (1990). The RecA protein: structure and function. Crit. Rev. Biochem. Molecular Biology, 25,415-456.

Scallan, E., Griffin, P. M., Angulo, F. J., Tauxe, R. V., \& Hoekstra, R. M. (2011). Foodborne illness acquired in the United States-unspecified agents. Emerging infectious diseases, 17(1), 16.

Sharan RN, Ryo H, Nomura T. (2007). Critical role of RecA and RecF proteins in strand break rejoining and maintenance of fidelity of rejoining following g-radiation-induced damage to pMTa4 DNA in E. coli. International Journal of Radiation Biology ,83,89-97.

Shimoni, Y., Altuvia, S., Margalit, H., \& Biham, O. (2009). Stochastic analysis of the SOS response in Escherichia coli. PLoS One, 4(5), e5363.

Song, Z., \& Luo, L. (2012). Escherichia coli mutants induced by multi-ion irradiation. Journal of Radiation Research. 53 (6): 854-859.

Tauxe RV . (2001). Food safety and irradiation: protecting the public from foodborne infections. Emerging infectious Diseases. 7(3) Suppl: 516- 521.

Tauxe RV . (2002). Emerging foodborne pathogens. International Journal of Food Microbiology 78, 31-41. 
Tesfai, A. T., Beamer, S. K., Matak, K. E., \& Jaczynski, J. (2011b). Radioresistance development of DNA repair deficient Escherichia coli DH5 $\alpha$ in ground beef subjected to electron beam at sub-lethal doses. International Journal of Radiation Biology, 87(6), 571578.

Xie, C. -X., A. Xu, L.-J. Wu, J.-M. Yao, J.-B. Yang, and Z.-L. Yu. (2004). Comparison of base substitutions in response to nitrogen ion implantation and ${ }^{60} \mathrm{Co}$-gamma ray irradiation in Escherichia coli. Genetics and Molecular Biology, 27, 284-290. 


\title{
CHAPTER 4
}

\section{Effect of electron beam on chemical changes of nutrients in infant formula}

\author{
Adiam Tesfai, Sarah K. Beamer, Kristen E. Matak, Jacek Jaczynski
}

Submitted to Food Chemistry 


\subsection{Abstract}

Infant milk formula has recently been implicated as a transmission vehicle for an emerging foodborne pathogen, Enterobacter sakazakii resulting in high mortality rates. Electron beam (e-beam) efficiently and non-thermally inactivates foodborne pathogens including $E$. sakazakii in infant milk formula. However, the effects of e-beam on chemical changes of nutrients in infant formula have not been determined. Therefore, the objective of this study was to fulfill this gap. Dehydrated infant milk formula was processed with e-beam at 0 (control) to $25 \mathrm{kGy}$. Amino acid, fatty acid, and mineral profiles (AAP, FAP, and MP, respectively), as well as protein degradation and lipid oxidation were determined. There were no differences $(\mathrm{P}>0.05)$ in FAP, AAP, and MP. SDS-PAGE electrophoresis qualitatively detected three major protein bands in all samples up to $25 \mathrm{kGy}$. Densitometry analysis of SDS-PAGE gels confirmed no size degradation ( $\mathrm{P}>0.05)$ as a function of increased e-beam dose. Total-volatile-basic-nitrogen (TVBN) excluded $(\mathrm{P}>0.05)$ protein degradation due to microbial activity. There was no increase ( $\mathrm{P}>0.05)$ in lipid oxidation as assessed with thiobarbituric-reactive-substances (TBARS) except samples processed at $25 \mathrm{kGy}$. Dehydrated formula has low water activity, which likely protected nutrients from e-beam-induced chemical changes. This study demonstrates that proteins, lipids, and minerals in infant milk formula are stable when processed with e-beam up to $25 \mathrm{kGy}$.

Keywords: electron beam; food irradiation; ionizing radiation; nutritional composition; nutritional quality; infant milk formula; fatty acid profile; amino acid profile, lipid oxidation 


\subsection{Introduction}

Infant milk formula has recently been identified as a transfer vehicle for foodborne disease caused by an emerging foodborne pathogen, Enterobacter sakazakii (Iversen \& Forsythe, 2004; Osaili et al., 2008). Ionizing energy is a well-established non-thermal method aimed at improving microbial safety of a wide range of food products. Ionizing radiation such as electron beam (e-beam), gamma radiation, or X-rays efficiently inactivate foodborne pathogens in food products in a non-thermal manner (Farkas, 1998; Jaczynski \& Park, 2004; Black \& Jaczynski, 2006; 2007; 2008; Chalise, Hotta, Matak, \& Jaczynski, 2007; Arvanitoyannis \& Stratakos, 2010; Hvizdzak, Beamer, Jaczynski, \& Matak, 2010; Matak, Hvizdzak, Beamer, \& Jaczynski, 2010; Tesfai, Beamer, Matak, \& Jaczynski, 2011a; 2011b). A non-thermal antimicrobial process is particularly applicable to infant milk formula because it could potentially prevent nutrient losses associated with thermal processing. It could also be applied to infant milk formula in its final stage, after packaging to reduce chances for cross-contamination. It has been shown that ionizing radiation including e-beam inactivates E. sakazakii in rehydrated and dehydrated infant milk formula (Osaili et al., 2008; Hong et al., 2008). Lee, Oh, Kim, Yook, \& Byun (2006) reported no recovery of E. sakazakii in infant milk formula processed with gamma radiation at $5.0 \mathrm{kGy}$. Lee et al. (2006) also reported that the dose of up to $5.0 \mathrm{kGy}$ had no effect on sensory properties of the dehydrated infant milk formula after rehydration and heating.

Ionizing radiation is used on more than 60 types of foods in more than 40 countries (Arvanitoyannis \& Stratakos, 2010; Stefanova, Vasilev, Stefan, \& Spassov, 2011). Food irradiation up to $10 \mathrm{kGy}$ is considered unconditionally safe for human consumption (WHO, 1999). Although macronutrients such as carbohydrates, proteins, and fats are generally unaffected by irradiation; lipid oxidation and protein degradation have been demonstrated 
(WHO, 1999; 1995; 1994). These effects are dose-dependent and are highly variable for different food products and processing conditions.

Because nutritional quality of infant milk formula is of critical importance, it is expectedly one of the most highly regulated and controlled food products. Although microbial inactivation of E. sakazakii in infant milk formula with ionizing radiation including e-beam has been relatively well studied, the chemical changes of nutrients in infant milk formula subjected to ionizing radiation have received insufficient attention. Therefore, the overall objective of the present study was to evaluate effects of e-beam on chemical changes of major nutrients in infant milk formula. This study was focused on determination of amino acid, fatty acid, and mineral profiles, as well as protein degradation (proteolytic degradation with sodium dodecyl sulfatepolyacrylamide gel electrophoresis coupled with densitometry analysis and microbial degradation with total volatile basic nitrogen) and lipid oxidation (thiobarbituric acid reactive substances) in powdered infant milk formula subjected to e-beam up to $25 \mathrm{kGy}$.

\subsection{Materials and methods}

\subsubsection{Sample preparation}

Dehydrated infant milk formula of a national brand was purchased from a chain grocery store. Ionizing radiation may initiate lipid oxidation in food. Since polyunsaturated fatty acids (PUFA) are highly susceptible to lipid oxidation, the formula selected for the present study was

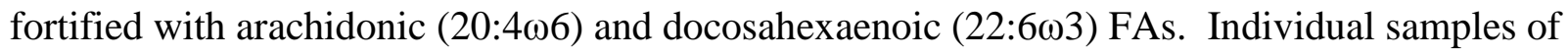
approximately 25 g were anaerobically packed (10 x 15 cm Kapak SealPAK pouches, Kapak Corporation, Minneapolis, MN). Prior to e-beam processing, the infant milk formula was evenly spread in each pouch, resulting in a thickness below $3 \mathrm{~mm}$. This thickness insured complete penetration of e-beam and even distribution of absorbed dose throughout the sample (Jaczynski 
\& Park, 2003a; 2003b). The samples were stored at $-80^{\circ} \mathrm{C}$ until shipment. The storage time did not exceed one week.

\subsubsection{Electron beam processing}

Samples were shipped overnight to the e-beam facility (Sterigenics International, San Diego, CA) in a heavy-duty styrofoam cooler filled with dry ice. At the e-beam facility, the samples were allowed to equilibrate to $4^{\circ} \mathrm{C}$ overnight in a refrigerator prior to e-beam processing. The samples at refrigeration temperature $\left(4^{\circ} \mathrm{C}\right)$ were subjected to the following target doses 0 (control), 5, 10, 15, 20, and 25 kGy of one-sided e-beam with energy fixed at 10 MeV. The target doses were confirmed with film dosimetry (Jaczynski \& Park, 2003a; 2003b). Film dosimeters (FWT-60 series radiochromatic dosimeters, Far West Technology, Inc., Goleta, CA) were attached to the bottom of the Kapak pouches prior to e-beam processing. The absorbed doses were determined with a spectrophotometer (Cary $100 \mathrm{UV}$-Vis, Varian, Inc., Palo Alto, CA) at $605 \mathrm{~nm}$. The absorbed doses were 5.7, 11.6, 18.0, 22.9, and 28.7 kGy, respectively. Immediately following e-beam processing, samples were frozen, packed with dry ice, and shipped overnight back to the food science laboratory at West Virginia University for analysis. Upon arrival, the e-beam processed samples were stored at $-80^{\circ} \mathrm{C}$ until analysis. The storage time did not exceed one month.

\subsubsection{Amino acid profile (AAP)}

The infant milk formula samples processed with e-beam were analyzed for full amino acid profile (AAP) according to the AOAC (1995) method $982.30 \mathrm{E}$ (a, b, c). The e-beam processed samples were subjected to the following three types of hydrolysis: acid hydrolysis with $3 \mathrm{~mol} \mathrm{~L}^{-1} \mathrm{HCl}$ at $110^{\circ} \mathrm{C}$ for $24 \mathrm{~h}$, performic acid oxidation at $0-5^{\circ} \mathrm{C}$ overnight followed by acid hydrolysis ( $3 \mathrm{~mol} \mathrm{~L}^{-1} \mathrm{HCl}$ at $110^{\circ} \mathrm{C}$ for $24 \mathrm{~h}$ ), and alkaline hydrolysis with fresh $2.1 \mathrm{~mol} \mathrm{~L}^{-1}$ 
$\mathrm{NaOH}$ at $110^{\circ} \mathrm{C}$ for $22 \mathrm{~h}$. Following hydrolysis, AAs were quantified using the Beckman Amino Acid Analyzer (model 6300, Beckman Coulter, Inc., Fullerton, CA) employing sodium citrate buffers as step gradients with the cation exchange post-column ninhydrin derivatization method (Chen, Tou, \& Jaczynski, 2008; Taskaya, Chen, Beamer, Tou, \& Jaczynski, 2009; Kassis, Beamer, Matak, Tou, \& Jaczynski, 2010). Although full AAP was determined, taurine, lanthionine, ornithine, and hydroxylysine were either not detected or detected at negligible levels; and therefore, are not reported. However, concentrations of these AAs were included in calculations of the total AAs. The data are reported as mean values ( \pm standard deviation) of at least three replicates. The mean values are expressed as g of AA per $100 \mathrm{~g}$ of e-beam processed sample.

\subsubsection{Total volatile basic nitrogen (TVBN)}

Protein degradation due to potential microbial activity was determined with total volatile basic nitrogen (TVBN) assay (Goulas \& Kontaminas, 2005; Tahergorabi, Beamer, Matak, \& Jaczynski, 2012c). To determine TVBN, $5 \mathrm{~g}$ of a sample processed with e-beam was mixed with $50 \mathrm{ml}$ of distilled deionized water ( $\mathrm{dd}_{2} \mathrm{O}$ ). One drop of silicone and $2 \mathrm{~g}$ of magnesium oxide were added to prevent foaming. The mixture was distilled in a Micro-Kjeldahl unit and the

distillate was titrated with $0.05 \mathrm{~mol} \mathrm{~L}^{-1} \mathrm{HCl}$. The TVBN values are reported as mean values ( \pm standard deviation) of at least three replicates. The mean values are expressed as mg of nitrogen per $100 \mathrm{~g}$ of e-beam processed sample. 
4.3.5 Sodium dodecyl sulfate-polyacrylamide gel electrophoresis (SDS-PAGE) and densitometry analysis

Proteolytic degradation of protein and/or protein polymerization was determined by sodium dodecyl sulfate-polyacrylamide gel electrophoresis (SDS-PAGE) in conjunction with densitometry analysis. SDS-PAGE is considered a qualitative analysis, while densitometry is quantitative. $0.4 \mathrm{~g}$ of a sample processed with e-beam was dissolved in $40 \mathrm{ml}$ of $\mathrm{dd}_{2} \mathrm{O}$. The same protein concentration between formula samples processed at different e-beam doses was verified with Lowry assay (Lowry, Rosenbrough, Farr, \& Randall, 1951). An aliquot of $10 \mu \mathrm{l}$ of the dissolved sample was mixed with $10 \mu \mathrm{l}$ of Laemmli sample buffer (Bio-Rad, Richmond, CA) and heated at $90^{\circ} \mathrm{C}$ for 5 min (Jaczynski \& Park, 2004). Aliquots of $20 \mu$ per well were used for SDS-PAGE.

Ready-to-use 4-20\% gradient gel (Bio-Rad, Richmond, CA) was used for SDS-PAGE. SDS-PAGE was performed under denaturing conditions and constant current of $80 \mathrm{~V}$ (Jaczynski \& Park, 2004). The Precision Plus Protein ${ }^{\mathrm{TM}}$ Kaleidoscope ${ }^{\mathrm{TM}}$ protein standards (10-250 kDa) (Bio-Rad, Richmond, CA) were added to the SDS-PAGE along with the e-beam processed samples. The electrophoretic protein patterns were stained with EZ-Run protein staining solution (Bio-Rad, Richmond, CA), followed by distaining with dd $\mathrm{H}_{2} \mathrm{O}$.

The SDS-PAGE gel images were captured using a digital camera interfaced with a PC (Fluorchem 8000, Alpha Innotech Corp., San Leandro, CA) using transluminating white light (Alpha Innotech Corp., San Leandro, CA) (Gigliotti, Davenport, Beamer, Tou, \& Jaczynski, 2011; Kassis, Gigliotti, Beamer, Tou, \& Jaczynski, 2012). The optical density of protein bands from SDS-PAGE images was analyzed using the Fluorchem software (version 1.0, Alpha Innotech Corp., San Leandro, CA). The densitometry data are reported as mean values ( \pm 
standard deviation) of at least three replicates. The mean values are expressed as integrated pixel density of a protein fraction. A sample representative SDS-PAGE gel image is also reported. 4.3.6 Fatty acid profile (FAP)

The infant milk formula samples processed with e-beam were analyzed for fatty acid profile (FAP). The e-beam processed samples were subjected to lipid extraction with acid hydrolysis into ether followed by their methylation to fatty acid methyl esters (FAMEs) (Chen, Nguyen, Semmens, Beamer, \& Jaczynski, 2007; Pietrowski, Tahergorabi, Matak, Tou, \& Jaczynski, 2011). The FAMEs were quantitatively measured using a capillary gas-liquid chromatograph (GLC) (Model 7890A equipped with a 7683B series injector, Agilent Technologies, Santa Clara, CA) against an internal standard (C19: 1). Helium was used as carrier gas at $0.75 \mathrm{ml} / \mathrm{min}$ flow rate and a 200:1 as split ratio. The initial temperature of $100^{\circ} \mathrm{C}$ was held for $4 \mathrm{~min}$ and then increased to the final temperature of $240^{\circ} \mathrm{C}$ at a rate of $3^{\circ} \mathrm{C} / \mathrm{min}$. The final temperature was held for $15 \mathrm{~min}$. The injector and detector temperatures were 225 and $285^{\circ} \mathrm{C}$, respectively. The data are reported as mean values ( \pm standard deviation) of at least three replicates. The mean values are expressed as percent of a FA in total FAs.

\subsubsection{Thiobarbituric acid reactive substances (TBARS)}

Lipid oxidation in infant milk formula processed with e-beam was determined with thiobarbituric acid reactive substances (TBARS) assay of malondialdehyde (MDA) as previously described (Yu \& Sinnhuber, 1957; Tahergorabi, Beamer, Matak, \& Jaczynski, 2012a). The absorbance was measured at 535 nm using an UV/Vis spectrophotometer (model DU530, Beckman Instruments, Fullerton, CA). The TBARS values were calculated using molar absorptivity of MDA $\left(156,000 \mathrm{M}^{-1} \mathrm{~cm}^{-1}\right)$ at $535 \mathrm{~nm}$. The TBARS values are reported as mean 
values ( \pm standard deviation) of at least three replicates. The mean values are expressed as mg of MDA per kg of e-beam processed sample.

\subsubsection{Mineral Profile (MP)}

The infant milk formula samples processed with e-beam were analyzed for mineral profile (MP). All glassware was washed overnight in a solution of $0.3 \mathrm{~mol} \mathrm{~L}^{-1} \mathrm{HCl}$ in dd $\mathrm{H}_{2} \mathrm{O}$ prior to use. Ashed samples were dissolved in $2 \mathrm{~mL}$ of $7.7 \mathrm{~mol} \mathrm{~L}^{-1}$ nitric acid. The acidified samples were neutralized and filtered through Whatman number 1 paper (Whatman International Ltd., Maidstone, United Kingdom). Samples were diluted to volume with dd $\mathrm{H}_{2} \mathrm{O}$ in a $50 \mathrm{~mL}$ volumetric flask. Mineral (Ca, P, Mg, Fe, Zn, Na, and K) contents were determined using inductively coupled plasma optical emission spectrometry (model P400, Perkin Elmer, Shelton, CN) (Tahergorabi, Beamer, Matak, \& Jaczynski, 2012b; 2012d). The mineral contents are reported as mean values ( \pm standard deviation) of at least three replicates. The mean values are expressed as mg per $100 \mathrm{~g}$ of e-beam processed sample.

\subsubsection{Statistics}

All experiments were independently triplicated $(n=3)$. In each triplicate at least three measurement were performed. Data were subjected to one-way analysis of variance (ANOVA). A significant difference was determined at 0.05 probability level and differences between treatments were tested using Fisher's Least Significant Difference (LSD) test (Freud \& Wilson, 1997). All statistical analyses of data were performed using SAS (SAS, 2002). The data are reported as mean values \pm standard deviation (SD). 


\subsection{Results and discussion}

\subsubsection{Amino acid profile (AAP) and total volatile basic nitrogen (TVBN)}

The amino acid profile (AAP) results shown in Table 1 indicated no difference $(\mathrm{p}>0.05)$ in amino acid composition as a function of increasing e-beam dose up to $25 \mathrm{kGy}$ when compared to the control (0 kGy). The sulfur-containing AAs, methionine and cysteine are the most radiosensitive AAs (Stewart, 2001). From a human nutrition stand point; methionine is considered a limiting essential AA. Because methionine is the most radiosensitive AA with critical nutritional importance to humans, it should be considered an indicator of radiationinduced AA degradation. As shown in Table 1, neither of the two most radiosensitive AAs was affected $(\mathrm{P}>0.05)$ by e-beam in the present study. In fact, the content of all AAs remained unchanged $(P>0.05)$ as the e-beam dose increased to $25 \mathrm{kGy}$.

El-Rawas et al. (2011) also reported no changes in AAP and crude protein content of peanut butter processed with e-beam up to 28 kGy. However, Matloubi et al. (2004) observed very slight changes in AAP of baby food processed with gamma radiation $\left({ }^{60} \mathrm{Co}\right)$ up to $50 \mathrm{kGy}$ at room temperature and in the presence of oxygen. The content of some AAs was slightly increased, while others decreased. Nevertheless, the authors concluded that ionizing radiation generally did not cause chemical changes in AAs. The infant milk formula used in the present study was a dehydrated product with water activity $\left(\mathrm{A}_{\mathrm{w}}\right)$ of 0.45 . Peanut butter also has a comparably low $\mathrm{A}_{\mathrm{w}}$ at approximately 0.35 (Burnett, Gehm, Weissinger, \& Beuchat, 2000). Low $A_{w}$ indicates unavailability of water for chemical reactions such as water radiolysis that produces free radicals. The free radicals may cause AA degradation. Ionizing radiation including e-beam typically initiates water radiolysis in foods with high $A_{w}$. Therefore, low $A_{w}$ reduces potential radiation-induced AA degradation. This is likely a main factor that contributed to the lack of 
changes in AAP reported by El-Rawas et al. (2011) and in the present study. Dehydrated milk powders have been reported to be more resistant to radiation-induced chemical changes (Diehl, 1983). Matloubi et al. (2004) irradiated baby food up to $50 \mathrm{kGy}$ unlike up to 25 and $28 \mathrm{kGy}$ in the present study and by El-Rawas et al. (2011), respectively. Radiation-induced chemical changes are dose-dependent; and thus, the higher doses applied by Matloubi et al. (2004) could have resulted in the observed slight differences. Unlike gamma radiation, e-beam delivers target dose at a much greater rate (e-beam $-10^{3}-10^{5} \mathrm{~Gy} / \mathrm{sec}$; gamma - 0.01-1 Gy/sec); and thus, ebeam processing time is much shorter. The shorter time and greater dose rate of e-beam have also been attributed to less change in e-beam processed food when compared to gamma irradiation. The infant milk formula in the present study was anaerobically packed and processed with e-beam at refrigeration temperature. In addition to the low $\mathrm{A}_{\mathrm{w}}$, the low temperature and relative absence of oxygen likely contributed to the lack of differences in AAP reported in the present study.

The total volatile basic nitrogen (TVBN) indicates protein degradation as a result the release of $\mathrm{N}$-containing volatile compounds from the protein due to microbial activity/spoilage (Gram \& Huss, 1996). The analysis of TVBN for infant milk formula processed with e-beam at 0-25 kGy showed no difference ( $\mathrm{p}>0.05$ ) in protein degradation (Table 1). TVBN content of 30 mg N/100 g is considered as acceptability limit (Sikorski, Kolakowska, \& Burt, 1990). All of the infant milk formula samples in the present study had TVBN below $13 \mathrm{mg} \mathrm{N} / 100$. This indicates that, the protein in the infant milk formula used in the present study was not degraded by microorganisms including the control (0 kGy). Therefore, the only possibility of protein degradation was a chemical degradation mediated by e-beam radiation. The AAP in combination with TVBN showed no changes in AA composition and protein degradation, 
respectively in infant milk formula processed with e-beam up to $25 \mathrm{kGy}$.

\subsubsection{Sodium dodecyl sulfate-polyacrylamide gel electrophoresis (SDS-PAGE) and densitometry analysis}

Fig. 1 shows SDS-PAGE and densitometry analysis. The SDS-PAGE image included in Fig. 1 is a representative sample image, while the densitometry graph in Fig. 1 is a quantification $(n=3)$ of protein bands detected in infant milk formula in the present study. The SDS-PAGE electrophoresis detected three major protein bands. By using protein standards of known molecular weight $\left(\mathrm{M}_{\mathrm{w}}\right)$, the detected protein bands were identified as two isomers of casein with $\mathrm{M}_{\mathrm{w}}$ of approximately 30-32 $\mathrm{kDa}$ and lactalbumin with $\mathrm{M}_{\mathrm{w}}$ of approximately $14 \mathrm{kDa}$. The number of protein bands in the gel did not change with increasing e-beam dose. The increased number of protein bands of smaller $\mathrm{M}_{\mathrm{w}}$ with increasing e-beam dose would indicate a potential size degradation of the original protein fractions present in the un-processed infant milk formula (i.e., control - $0 \mathrm{kGy}$ ).

Although SDS-PAGE showed no qualitative changes in protein (i.e., the number of protein bands did not increase with increasing e-beam dose), SDS-PAGE is not a quantitative analysis. This is why to quantify potential size degradation of protein as a function of increasing e-beam dose; the SDS-PAGE images were analyzed with densitometry. The densitometry analysis of SDS-PAGE gel images showed no difference $(\mathrm{p}>0.05)$ in integrated pixel density of the detected protein fractions. The differences in pixel density of the detected protein fractions would indicate differences in concentration of these fractions. Since protein at the same concentration was injected into each well of the SDS-PAGE cell corresponding to different ebeam doses and there were no differences in pixel density, it can be concluded that the $\mathrm{M}_{\mathrm{w}}$ of the 
detected fractions remained unchanged regardless of e-beam dose up to $25 \mathrm{kGy}$. Thus, the degradation of protein size in infant milk formula processed with e-beam did not occur.

It has been demonstrated that ionizing radiation of food can induce protein radiolysis by breaking peptide bond, leading to the formation of free AAs and some decomposition products such as protein fractions with smaller $\mathrm{M}_{\mathrm{w}}$ and individual peptides (Erkan \& Ozden, 2007). ElRawas et al. (2011) reported no differences ( $\mathrm{P}>0.05$ ) in band pixel density; and hence, protein degradation in peanut butter processed with e-beam at 3.2 and $7.0 \mathrm{kGy}$ when compared to control (0 kGy). In contrast, Jaczynski \& Park (2004) showed size degradation of myosin heavy chain and actin in surimi when processed with e-beam at 10 and $25 \mathrm{kGy}$, although 1-8 kGy did not cause the degradation. However, surimi as a fresh seafood product derived from fish muscle has high $\mathrm{A}_{\mathrm{w}}$ as opposed to peanut butter and infant milk formula. In addition, surimi was irradiated at room temperature and under aerobic conditions. These differences likely explain the differences in protein size degradation reported by Jaczynski \& Park (2004).

\subsubsection{Fatty acid profile (FAP)}

Fats are among the least stable food components. They are susceptible to radiationinduced autoxidation, which may lead to the development of rancidity in addition to reduced nutritional quality including the loss of essential fatty acids (Giroux, 1998; Mexis \& Kontominas, 2009; Cheng et al., 2011). Unsaturated fatty acids (FAs), especially long chain

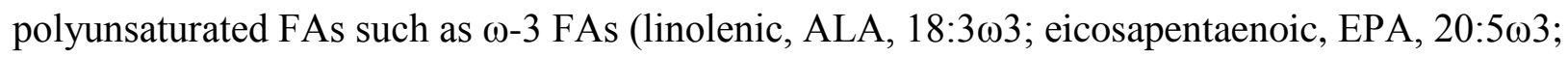

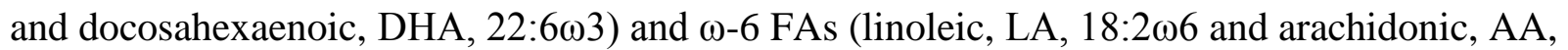

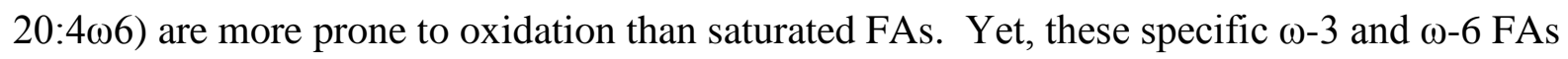
are critical in human nutrition, particularly for infants. This is why although full FAP was 
determined; Table 2 presents only those nutritionally critical $\omega-3$ and $\omega-6$ FAs along with major saturated FAs. No differences $(\mathrm{P}>0.05)$ were detected for any of the FAs in infant milk formula processed with e-beam up to $25 \mathrm{kGy}$. As a consequence, there were no differences $(\mathrm{P}>0.05)$ in the composition of total $\omega-3, \omega-6$, saturated FAs, and unsaturated FAs (Fig. 2) or the ratio of total $\omega-6 /$ total $\omega-3$ and unsaturated FAs/saturated FAs (Table 2).

The results of the present study are in agreement with Alfaia et al. (2007) who reported that gamma irradiation of vacuum packaged frozen lamb meat at $7 \mathrm{kGy}$ did not change FAP or total lipid content. Freezing food causes immobilization of water molecules; and therefore, water becomes less available. As such, $A_{w}$ of frozen food is lower than their unfrozen counterparts. When foods with high $\mathrm{A}_{\mathrm{w}}$ are processed with ionizing radiation, high concentrations of hydroxyl radicals are generated from water radiolysis. These radicals may initiate lipid oxidation, leading to changes in FA composition of irradiated food. Such reactions proceed at significantly slower rates in dehydrated food with low $\mathrm{A}_{\mathrm{w}}$ (Brito, Villavicencio, \& Mancini-filho, 2002; Mexis \& Kontominas, 2009). The infant milk formula used in the present study had low $\mathrm{A}_{\mathrm{w}}$ and it was very likely a reason why changes in FA composition similar to AA composition were not detected.

\subsubsection{Thiobarbituric acid reactive substances (TBARS)}

Thiobarbituric acid reactive substances (TBARS) assay was used to measure the effect of e-beam on oxidation of lipids in infant milk formula. Results showed dose-dependent and gradual, yet insignificantly increasing trend (P > 0.05) for TBARS values up to $20 \mathrm{kGy}$ (Fig. 3). However, e-beam at $25 \mathrm{kGy}$ induced lipid oxidation and greater $(\mathrm{P}<0.05)$ amount of secondary products of lipid oxidation (i.e., malondialdehyde - MDA) was detected with TBARS assay. It needs to be noted that due to inherent variations of TBARS assay, the TBARS value for samples 
processed with e-beam at $25 \mathrm{kGy}$ was only higher $(\mathrm{P}<0.05)$ than the control $(0 \mathrm{kGy})$ and $5 \mathrm{kGy}$ samples, but it was not $(\mathrm{P}>0.05)$ greater than the 10,15 , and $20 \mathrm{kGy}$ samples. The TBARS values increased from $2.48 \pm 0.53 \mathrm{mg} \mathrm{MDA} / \mathrm{kg}$ for the control samples to $6.84 \pm 2.42$ for infant milk formula processed with e-beam at $25 \mathrm{kGy}$.

The results from the present study are in general agreement with previously reported studies showing that ionizing radiation may induce lipid oxidation. However, the extent of lipid oxidation is dose-dependent and it also depends on intrinsic factors such as specific food matrix ( $A_{w}$, added antioxidants and oxygen scavengers) and its lipid composition, as well as extrinsic factors associated with processing conditions, especially oxygen availability (i.e., anaerobic vs. aerobic packaging) and sample temperature during irradiation (Stefanova et al., 2011). El-Rawas et al. (2012) showed that lipid oxidation occurred in peanut butter processed with e-beam at doses over 7 kGy; while Sohn et al. (2009) reported that TBARS values of ground beef irradiated with 5 and $10 \mathrm{kGy}$ were higher than the non-irradiated control. In the present study, all of the factors disfavored radiation-induced lipid oxidation and this is likely why TBARS values did not (P > 0.05) increase until $25 \mathrm{kGy}$.

\subsubsection{Mineral profile (MP)}

Mineral profile (MP) results are shown in Table 4. The minerals studied in the present study were not $(\mathrm{P}>0.05)$ altered by e-beam up to $25 \mathrm{kGy}$. No difference $(\mathrm{P}>0.05)$ was detected in $\mathrm{Ca}, \mathrm{P}, \mathrm{Mg}, \mathrm{Fe}, \mathrm{Zn}, \mathrm{Na}$, and $\mathrm{K}$ content of infant milk formula processed with e-beam up to $25 \mathrm{kGy}$ when compared to the control (0 kGy). However, Bhat \& Sridhar (2008) reported changes $(\mathrm{P}<0.05)$ in mineral composition of tropical legumes processed with e-beam. Although Ca increased $(\mathrm{P}<0.05)$ at $10 \mathrm{kGy}, \mathrm{Zn}$ and $\mathrm{K}$ were reduced $(\mathrm{P}<0.05)$ at 5 and $10 \mathrm{kGy}$, respectively. As mentioned above in the TBARS section, the effects of ionizing radiation such 
as e-beam on food nutritional quality are dose-dependent and depend on several intrinsic and extrinsic factors (Stefanova et al., 2011).

\subsection{Conclusions}

Many studies have demonstrated that nutrients are not largely affected by ionization radiation even at high doses exceeding $10 \mathrm{kGy}$. The present study also shows that proteins, fats, and minerals in dehydrated infant milk formula are stable when processed with electron beam (ebeam) up to $25 \mathrm{kGy}$. Infant milk formula has recently been implicated as a transmission vehicle for an emerging foodborne pathogen, Enterobacter sakazakii, resulting in relatively high mortality rates. As a non-thermal antimicrobial strategy, e-beam processing did not affect nutritional attributes of dehydrated infant milk formula tested in the present study.

\section{Acknowledgment}

Special thanks to Sterigenics International for allowing us to use e-beam facility. Our appreciation extends to Carl A. Zinn and Richard Vallejo of Sterigenics for invaluable technical expertise with e-beam. 


\subsection{Appendix E}

Table 1: Amino Acid Profile (AAP) of powdered infant formula processed with e-beam at 0, 5, $10,15,20$, and $25 \mathrm{kGy}$. Data are given as mean values \pm standard deviation $(\mathrm{n}=3)$. The mean values are expressed as g of AA per $100 \mathrm{~g}$ of e-beam processed sample. Different letters indicate significant differences (Fisher's Least Significant Difference, $\mathrm{P}<0.05$ ) between mean values within the same row. The lack of letters indicates lack of differences. TVBN - Total Volatile Basic Nitrogen (TVBN). The mean values for TVBN are expressed as mg of nitrogen per $100 \mathrm{~g}$ of e-beam processed sample.

\begin{tabular}{|l|c|c|c|c|c|c|}
\hline \multirow{2}{*}{ Amino Acid } & \multicolumn{7}{|c|}{ E-beam dose (kGy) } \\
\cline { 2 - 7 } & $\mathbf{0}$ & $\mathbf{5}$ & $\mathbf{1 0}$ & $\mathbf{1 5}$ & $\mathbf{2 0}$ & $\mathbf{2 5}$ \\
\hline Alanine & $0.43 \pm 0.01$ & $0.43 \pm 0.01$ & $0.43 \pm 0.01$ & $0.43 \pm 0.01$ & $0.43 \pm 0.02$ & $0.43 \pm 0.02$ \\
\hline Arginine & $0.33 \pm 0.00$ & $0.32 \pm 0.01$ & $0.33 \pm 0.01$ & $0.33 \pm 0.00$ & $0.33 \pm 0.01$ & $0.33 \pm 0.01$ \\
\hline Aspartic Acid & $0.96 \pm 0.03$ & $0.96 \pm 0.02$ & $0.96 \pm 0.03$ & $0.96 \pm 0.02$ & $0.96 \pm 0.06$ & $0.96 \pm 0.05$ \\
\hline Cysteine & $0.14 \pm 0.01$ & $0.14 \pm 0.00$ & $0.14 \pm 0.01$ & $0.14 \pm 0.01$ & $0.14 \pm 0.01$ & $0.14 \pm 0.00$ \\
\hline Glutamic Acid & $2.05 \pm 0.01$ & $2.05 \pm 0.01$ & $2.05 \pm 0.00$ & $2.05 \pm 0.01$ & $2.05 \pm 0.01$ & $2.05 \pm 0.01$ \\
\hline Glycine & $0.23 \pm 0.03$ & $0.22 \pm 0.00$ & $0.22 \pm 0.00$ & $0.22 \pm 0.00$ & $0.22 \pm 0.02$ & $0.22 \pm 0.03$ \\
\hline Histidine & $0.27 \pm 0.01$ & $0.27 \pm 0.00$ & $0.27 \pm 0.00$ & $0.27 \pm 0.01$ & $0.27 \pm 0.01$ & $0.27 \pm 0.01$ \\
\hline Isoleucine & $0.63 \pm 0.01$ & $0.64 \pm 0.01$ & $0.63 \pm 0.01$ & $0.63 \pm 0.01$ & $0.63 \pm 0.02$ & $0.63 \pm 0.02$ \\
\hline Leucine & $1.12 \pm 0.01$ & $1.11 \pm 0.01$ & $1.11 \pm 0.01$ & $1.11 \pm 0.01$ & $1.11 \pm 0.03$ & $1.11 \pm 0.03$ \\
\hline Lysine & $0.90 \pm 0.01$ & $0.91 \pm 0.00$ & $0.91 \pm 0.01$ & $0.91 \pm 0.01$ & $0.91 \pm 0.03$ & $0.91 \pm 0.02$ \\
\hline Methionine & $0.25 \pm 0.01$ & $0.25 \pm 0.00$ & $0.25 \pm 0.00$ & $0.25 \pm 0.01$ & $0.25 \pm 0.01$ & $0.25 \pm 0.01$ \\
\hline Phenylalanine & $0.47 \pm 0.01$ & $0.47 \pm 0.01$ & $0.47 \pm 0.01$ & $0.47 \pm 0.01$ & $0.47 \pm 0.01$ & $0.47 \pm 0.02$ \\
\hline Proline+Hydroxyproline $0.92 \pm 0.02$ & $0.92 \pm 0.01$ & $0.92 \pm 0.01$ & $0.92 \pm 0.01$ & $0.92 \pm 0.03$ & $0.92 \pm 0.02$ \\
\hline Serine & $0.49 \pm 0.01$ & $0.48 \pm 0.04$ & $0.49 \pm 0.03$ & $0.49 \pm 0.01$ & $0.48 \pm 0.02$ & $0.48 \pm 0.03$ \\
\hline Threonine & $0.58 \pm 0.01$ & $0.56 \pm 0.02$ & $0.57 \pm 0.02$ & $0.57 \pm 0.01$ & $0.57 \pm 0.02$ & $0.57 \pm 0.02$ \\
\hline Tryptophan & $0.18 \pm 0.03$ & $0.19 \pm 0.01$ & $0.19 \pm 0.01$ & $0.19 \pm 0.01$ & $0.19 \pm 0.02$ & $0.19 \pm 0.03$ \\
\hline Tyrosine & $0.39 \pm 0.01$ & $0.38 \pm 0.01$ & $0.39 \pm 0.01$ & $0.39 \pm 0.01$ & $0.39 \pm 0.02$ & $0.39 \pm 0.01$ \\
\hline Valine & $0.69 \pm 0.02$ & $0.70 \pm 0.01$ & $0.69 \pm 0.02$ & $0.69 \pm 0.01$ & $0.69 \pm 0.02$ & $0.69 \pm 0.02$ \\
\hline Total AAs & $11.08 \pm 0.05$ & $11.14 \pm 0.19$ & $11.26 \pm 0.05$ & $11.00 \pm 0.27$ & $11.19 \pm 0.05$ & $11.05 \pm 0.25$ \\
\hline TVBN & $12.30 \pm 0.23$ & $12.34 \pm 0.07$ & $12.26 \pm 0.88$ & $12.58 \pm 0.26$ & $12.66 \pm 0.30$ & $12.64 \pm 0.15$ \\
\hline
\end{tabular}


Table 2: Fatty Acid Profile (FAP) of powdered infant formula processed with e-beam at 0, 5, 10, 15,20 , and $25 \mathrm{kGy}$. Data are given as mean values \pm standard deviation $(\mathrm{n}=3)$. The mean values are expressed as percent of a FA in total FAs. Different letters indicate significant differences (Fisher's Least Significant Difference, $\mathrm{P}<0.05$ ) between mean values within the same row. The lack of letters indicates lack of differences.

\begin{tabular}{|c|c|c|c|c|c|c|}
\hline \multirow{2}{*}{ Fatty Acid } & \multicolumn{6}{|c|}{ E-beam dose (kGy) } \\
\hline & 0 & 5 & 10 & 15 & 20 & 25 \\
\hline Myristic (14:0) & $4.72 \pm 0.10$ & $4.85 \pm 0.22$ & $4.86 \pm 0.25$ & $4.84 \pm 0.17$ & $4.83 \pm 0.25$ & $4.96 \pm 0.15$ \\
\hline Palmitic (16:0) & $8.69 \pm 0.08$ & $8.60 \pm 0.21$ & $8.57 \pm 0.21$ & $8.66 \pm 0.23$ & $8.62 \pm 0.25$ & $8.50 \pm 0.11$ \\
\hline Stearic (18:0) & $3.58 \pm 0.11$ & $3.47 \pm 0.19$ & $3.44 \pm 0.24$ & $3.47 \pm 0.16$ & $3.49 \pm 0.24$ & $3.38 \pm 0.14$ \\
\hline Oleic (9c-18:1) & $43.05 \pm 0.74$ & $42.44 \pm 1.34$ & $42.20 \pm 0.72$ & $42.51 \pm 1.39$ & $42.44 \pm 0.80$ & $41.56 \pm 0.90$ \\
\hline Linoleic (LA, 18: & $22.64 \pm 0.08$ & $22.66 \pm 0.19$ & $22.58 \pm 0.19$ & $22.59 \pm 0.20$ & $22.47 \pm 0.19$ & $22.29 \pm 0.12$ \\
\hline Linolenic (ALA, 18:303 & $2.02 \pm 0.02$ & $2.06 \pm 0.07$ & $2.05 \pm 0.07$ & $2.03 \pm 0.05$ & $2.00 \pm 0.08$ & $2.04 \pm 0.05$ \\
\hline Arachidonic (AA, 20 & $0.38 \pm 0.01$ & $0.38 \pm 0.03$ & $0.39 \pm 0.03$ & $0.40 \pm 0.02$ & $0.41 \pm 0.02$ & $0.41 \pm 0.02$ \\
\hline Eicosapentaenoic (E & $\mathrm{ND}$ & $\mathrm{ND}$ & $\mathrm{ND}$ & $\mathrm{ND}$ & $\mathrm{ND}$ & ND \\
\hline Docosahexaenoic (DHA, 22:6(13) & $0.16 \pm 0.01$ & $0.16 \pm 0.01$ & $0.16 \pm 0.01$ & $0.16 \pm 0.01$ & $0.16 \pm 0.01$ & $0.15 \pm 0.01$ \\
\hline Total $\omega-6 /$ Total $\omega-3$ & $10.56 \pm 0.12$ & $10.36 \pm 0.30$ & $10.40 \pm 0.36$ & $10.46 \pm 0.31$ & $10.57 \pm 0.47$ & $10.32 \pm 0.19$ \\
\hline Unsaturated FAs / Saturated FAs & $3.85 \pm 0.02$ & $3.84 \pm 0.02$ & $3.83 \pm 0.04$ & $3.84 \pm 0.03$ & $3.83 \pm 0.04$ & $3.80 \pm 0.01$ \\
\hline
\end{tabular}

ND - Not Detected. 
Table 3. Mineral Profile (MP) of powdered infant formula processed with e-beam at $0,5,10,15$, 20 , and $25 \mathrm{kGy}$. Data are given as mean values \pm standard deviation $(\mathrm{n}=3)$. The mean values are expressed as mg per $100 \mathrm{~g}$ of e-beam processed sample. Different letters indicate significant differences (Fisher's Least Significant Difference, $\mathrm{P}<0.05$ ) between mean values within the same row. The lack of letters indicates lack of differences.

\begin{tabular}{|c|c|c|c|c|c|c|}
\hline \multirow{2}{*}{ Mineral } & \multicolumn{7}{|c|}{ E-beam dose (kGy) } \\
\cline { 2 - 7 } & $\mathbf{0}$ & $\mathbf{5}$ & $\mathbf{1 0}$ & $\mathbf{1 5}$ & $\mathbf{2 0}$ & $\mathbf{2 5}$ \\
\hline $\mathrm{Ca}$ & $419.1 \pm 27.1$ & $443.8 \pm 36.6$ & $441.0 \pm 35.0$ & $433.2 \pm 22.1$ & $403.8 \pm 29.7$ & $429.1 \pm 27.6$ \\
\hline $\mathrm{P}$ & $230.3 \pm 4.3$ & $246.6 \pm 19.7$ & $247.4 \pm 35.9$ & $236.7 \pm 11.1$ & $221.5 \pm 16.6$ & $231.9 \pm 15.3$ \\
\hline $\mathrm{Mg}$ & $39.4 \pm 0.6$ & $41.8 \pm 3.1$ & $41.6 \pm 3.1$ & $40.7 \pm 1.7$ & $39.3 \pm 2.2$ & $40.2 \pm 0.8$ \\
\hline $\mathrm{Fe}$ & $10.3 \pm 0.2$ & $11.1 \pm 1.1$ & $11.3 \pm 0.8$ & $10.8 \pm 0.8$ & $10.4 \pm 0.6$ & $10.9 \pm 0.4$ \\
\hline $\mathrm{Zn}$ & $4.5 \pm 0.2$ & $4.5 \pm 0.2$ & $4.5 \pm 0.0$ & $4.2 \pm 0.1$ & $4.3 \pm 0.3$ & $4.5 \pm 0.1$ \\
\hline $\mathrm{Na}$ & $151.6 \pm 11.3$ & $178.6 \pm 34.5$ & $150.1 \pm 19.0$ & $154.1 \pm 3.7$ & $142.8 \pm 11.4$ & $158.0 \pm 17.4$ \\
\hline $\mathrm{K}$ & $732.4 \pm 45.1$ & $742.6 \pm 60.8$ & $719.6 \pm 105.1$ & $772.3 \pm 33.3$ & $704.3 \pm 63.7$ & $672.0 \pm 39.4$ \\
\hline
\end{tabular}




\section{E-beam dose (kGy)}

$\begin{array}{llllll}0 & 5 & 10 & 15 & 20 & 25\end{array}$

Caseins (30-32 kDa)

Lactalbumin (14 kDa)

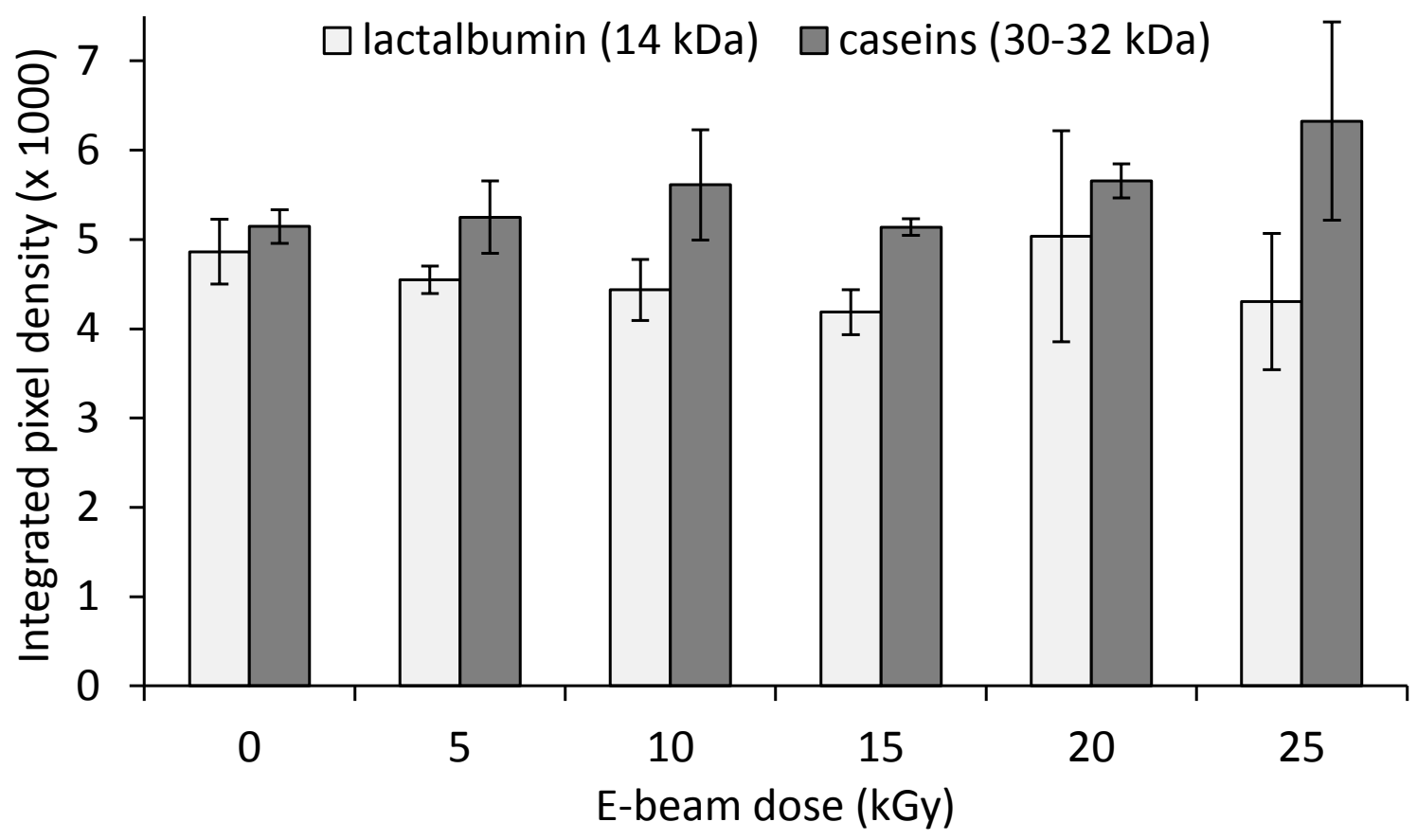

\section{Figure 1:}

A sample representative SDS-PAGE gel image (top) and densitometry analysis (bottom) of protein in powdered infant formula processed with e-beam at 0, 5, 10, 15, 20, and $25 \mathrm{kGy}$. The densitometry data are reported as mean values \pm standard deviation $(\mathrm{SD})(\mathrm{n}=3)$. The mean values are expressed as integrated pixel density of a protein. The small bars of the top of data bars indicate SD. Different letters on the top of SD bars indicate significant differences between mean values (Fisher's Least Significant Difference, $\mathrm{P}<0.05$ ) within the same protein type. However, the lack of letters indicates lack of differences. 


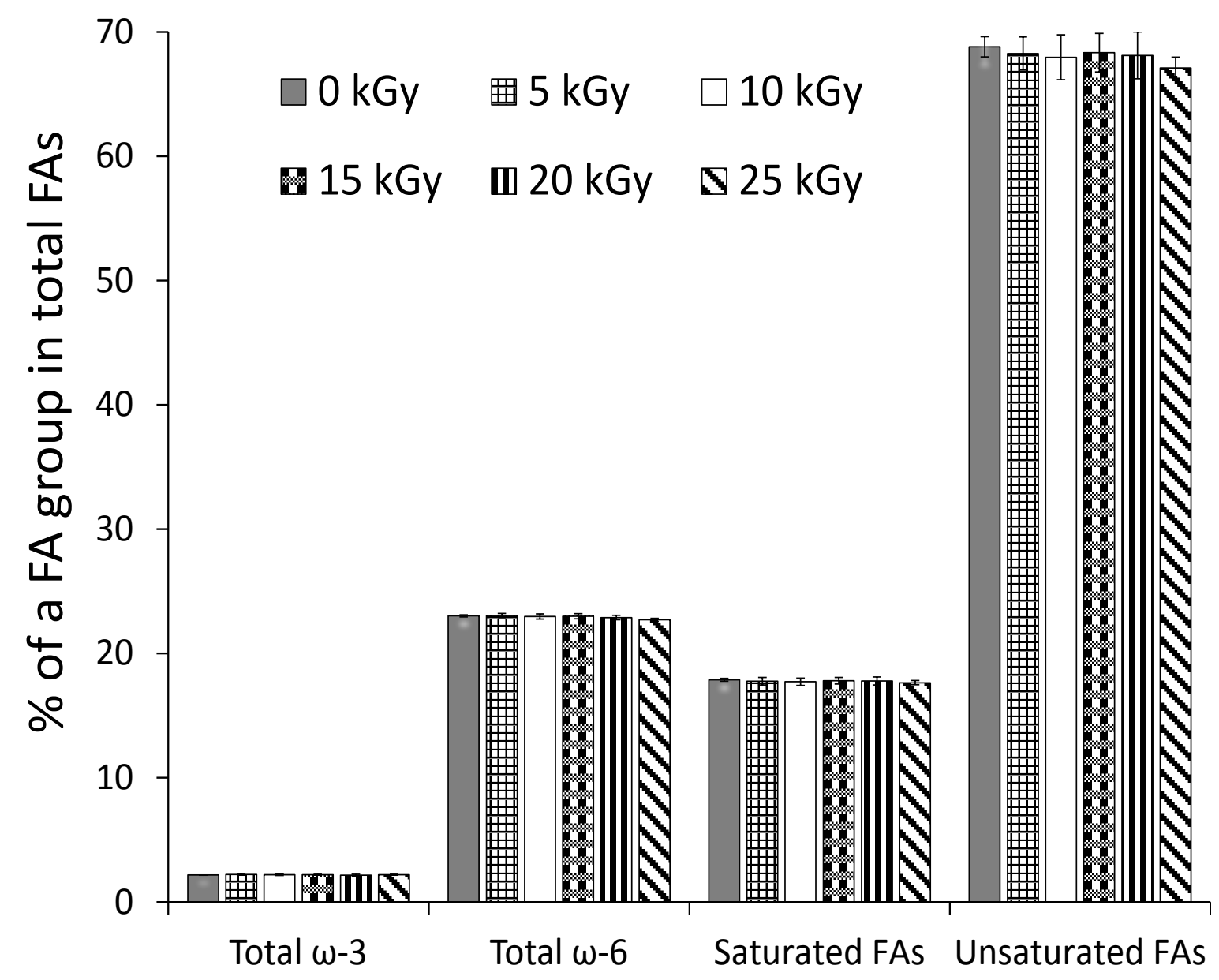

Figure 2:

Major groups of fatty acids (FAs) in powdered infant formula processed with e-beam at $0,5,10,15,20$, and $25 \mathrm{kGy}$. Data are given as mean values \pm standard deviation (SD) (n $=3$ ). The mean values are expressed as percent of a FA group in total FAs. The small bars of the top of data bars indicate SD. Different letters on the top of SD bars indicate significant differences between mean values (Fisher's Least Significant Difference, $\mathrm{P}<$ 0.05) within the same FA group. However, the lack of letters indicates lack of differences. 


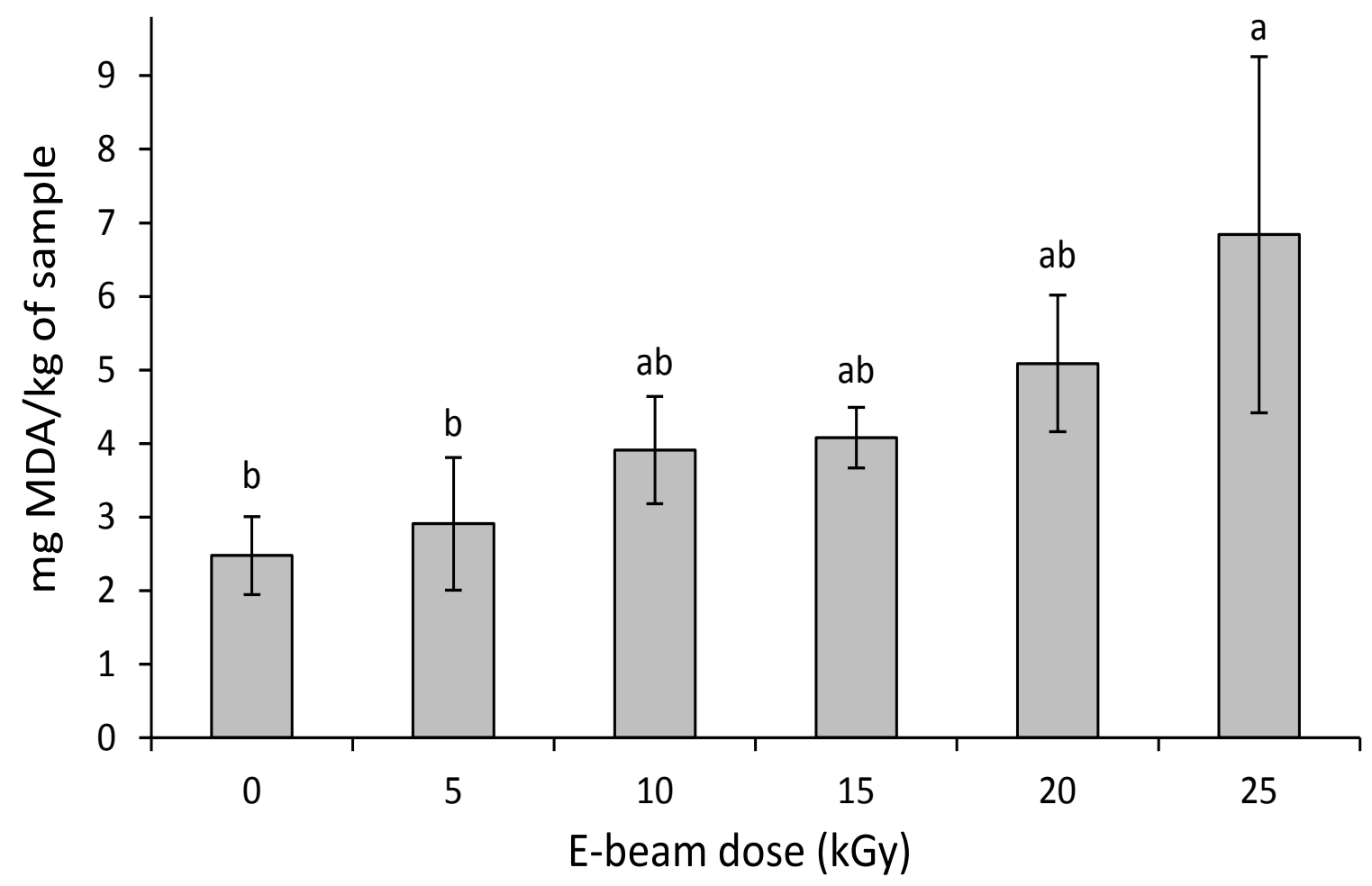

\section{Figure 3:}

TBARS (thiobarbituric acid reactive substances) values of powdered infant formula processed with e-beam at $0,5,10,15,20$, and $25 \mathrm{kGy}$. Data are given as mean values \pm standard deviation (SD) $(n=3)$. The mean values are expressed as mg of MDA (malondialdehyde) per kg of e-beam processed sample. The small bars of the top of data bars indicate SD. Different letters on the top of SD bars indicate significant differences between mean values (Fisher's Least Significant Difference, $\mathrm{P}<0.05$ ). 


\subsection{References}

Alfaia, C. M. M., Ribeiro, P. J. L. C., Trigo, M. J. P., Alfaia, A. J. I., Castro, M. L. F., Fontes, C. M. G. A., Bessa, R. J. B., \& Prates, J. A. M. (2007). Irradiation effect on fatty acid composition and conjugated linoleic acid isomers in frozen lamb meat. Meat Science, 77(4): 689-695

Arvanitoyannis, I. S., \& Stratakos, A. C. (2010). Applications of irradiation on meat and meat products. In I. S. Arvanitoyannis (Ed.), Irradiation of food commodities:

Techniques, applications, detection, legislation, and safety and consumer opinion (): 171221.

Association of Official Analytical Chemists. (1995). Official methods of analysis. (16th ed.). Washington, DC: Association of Official Analytical Chemists.

Bhat, R., \& Sridhar, K. R. (2008). Effect of electron beam irradiation on the quality characteristics of an economically valued tropical legume Mucuna prurines. Electronic Journal of Environmental, Agricultural and Food Chemistry, 7(12): 2578-2581.

Black, J. L., \& Jaczynski, J. (2006). Temperature effect on inactivation kinetics of Escherichia coli O157:H7 by electron beam in ground beef, chicken breast meat, and trout fillets. Journal of Food Science, 71(6): M221-227.

Black, J. L., \& Jaczynski, J. (2007). Effect of ionic strength on inactivation kinetics of Escherichia coli O157:H7 by electron beam in ground beef, chicken breast meat, and trout fillets. International Journal of Food Science and Technology, 42(7): 894-902.

Black, J. L., \& Jaczynski, J. (2008). Effect of water activity on inactivation kinetics of Escherichia coli O157:H7 by electron beam in ground beef, chicken breast meat, and trout fillets. International Journal of Food Science and Technology, 43(4), 579-586.

Brito, M. S., Villavicencio, A. L. C. H., \& Mancini-filho, J. (2002). Effects of irradiation on trans fatty acids formation in ground beef. Radiation Physics and Chemistry, 63(3), 337-340.

Bryant, F. R. (1988). Construction of a recombinase-deficient mutant recA protein that retains single-stranded DNA-dependent ATPase activity. Journal of Biological Chemistry, 263(18), 8716-8723.

Burnett, S., Gehm, E., Weissinger, W. R., \& Beuchat, L. R. (2000). Survival of Salmonella in peanut butter and peanut butter spread. Journal of Applied Microbiology, 89(3), 472-477.

Chalise, P. R., Hotta, E., Matak, K. E., \& Jaczynski, J. (2007). Inactivation kinetics of Escherichia coli by pulsed electron beam. Journal of Food Science, 72(7), M280-285. 
Chen, Y. C., Nguyen, J., Semmens, K., Beamer, S., \& Jaczynski, J. (2007).

Physicochemical changes in omega-3-enhanced farmed rainbow trout (Oncorhynchus mykiss) muscle during refrigerated storage. Food Chemistry, 104(3), 1143-1152.

Chen, Y. C., Tou, J. C., \& Jaczynski, J. (2008). Amino acid and mineral composition of protein and other components and their recovery yields from whole Antarctic krill (Euphausia superba) using isoelectric solubilization/precipitation. Journal of Food Science, 74(2), H31-H39.

Cheng, A., Wan, F., Xu, T., Du, F., Wang, W., \& Zhu, Q. (2011). Effect of irradiation and storage time on lipid oxidation of chilled pork. Radiation Physics and Chemistry, 80(3), 475-480.

Diehl J. (1995). Safety of irradiated food. (2nd ed.). New York: Marcel Dekker.

El-Rawas, A., Hvizdzak, A. L., Davenport M., Beamer, S., Jaczynski, J., \& Matak, K. (2012). Effect of electron beam irradiation on quality indicators of peanut butter over a storage period. Food Chemistry, 133(1), 212-219.

Erkan, N., \& Ozden, O. (2007). The changes of fatty acid and amino acid compositions in sea bream (Sparus aurata) during irradiation process. Radiation Physics and Chemistry, 76(10), 1636-1641.

Farkas, J. (1998). Irradiation as a method for decontaminating food. International Journal of Food Microbiology, 44, 189-204.

Freud, R. J., \& Wilson, W. J. (1997). Design of experiments. San Diego (CA): Academic Press.

Gigliotti, J. C., Davenport, M. P., Beamer, S. K., Tou, J. C., \& Jaczynski, J. (2011). Extraction and characterization of lipids from Antarctic krill (Euphausia superba). Food Chemistry, 125(3), 1028-1036.

Giroux M., \& Lacroix M. (1998). Nutritional adequacy of irradiated meat: A review. Food Research International, 31(4), 257-264.

Goulas, A. E., \& Kontominas, M. G. (2005). Effect of salting and smoking-method on the keeping quality of chub mackerel (Scomber japonicus): biochemical and sensory attributes. Food Chemistry, 93(3), 511-520.

Gram, L., \& Huss, H. H. (1996). Microbial spoilage of fish and fish products. International Journal of Food Microbiology, 33, 121-137.

Hong, Y. H., Park, J. Y., Park, J. H., Chung, M. S., Kwon, K. S., Chung, K., Won, M., \& Song, K. B. (2008). Inactivation of Enterobacter sakazakii, Bacillus cereus, and 
Salmonella Typhimurium in powdered weaning food by electron-beam irradiation. Radiation Physics and Chemistry, 77(9), 1097-1100.

Hvizdzak, A. L., Beamer, S., Jaczynski, J., \& Matak, K. E. (2010). Use of electron beam radiation for the reduction of Salmonella enterica serovars Typhimurium and Tennessee in peanut butter. Journal of Food Protection, 73(2), 353-357.

Iversen, C., \& Forsythe, S. (2004). Isolation of Enterobacter sakazakii and other Enterobacteriaceae from powdered infant formula milk and related products. Food Microbiology, 21,771-777.

Jaczynski, J., \& Park, J. W. (2004). Physicochemical changes in Alaska pollock surimi and surimi gel as affected by electron beam. Journal of Food Science, 69(1), FCT53-57.

Jaczynski, J., \& Park, J. W. (2003a). Microbial inactivation and electron penetration in surimi seafood during electron beam processing. Journal of Food Science, 68(5), 17881792.

Jaczynski, J., \& Park, J. W. (2003b). Physicochemical properties of surimi seafood as affected by electron beam and heat. Journal of Food Science, 68(5), 1626-1630.

James, D. L., Jaczynski, J., \& Matak, K. E. (2010). Electron beam irradiation on nalidixic acid resistant Salmonella Montevideo in cooked tomato puree of various $\mathrm{pH}$ values. Journal of Food Safety, 30(3), 515-525.

Kassis, N., Beamer, S. K., Matak, K. E., Tou, J. C., \& Jaczynski, J. (2010). Nutritional composition of novel nutraceutical egg products developed with omega-3 rich oils. $L W T$ - Food Science and Technology, 43(8), 1204-1212.

Kassis, N., Gigliotti, J. C., Beamer, S. K., Tou, J. C., \& Jaczynski, J. (2012). Characterization of lipids and antioxidant capacity of novel nutraceutical egg products developed with omega-3-rich oils. Journal of the Science of Food and Agriculture, 92(1), 66-73.

Lee, J. W., Oh, S. H., Kim, J. H., Yook, H. S., \& Byun, M. W. (2006). Gamma radiation sensitivity of Enterobacter sakazakii in dehydrated powdered infant formula. Journal of Food Protection, 69(6), 1434-1437.

Levanduski, L., \& Jaczynski, J. (2008). Increased resistance of Escherichia coli O157:H7 to electron beam following repetitive irradiation at sub-lethal doses. International Journal of Food Microbiology, 121(3), 328-334.

Lowry, O. H., Rosenbrough, N. J., Farr, A. L., \& Randall, R. J. (1951). Protein measurements with Folin phenol reagent. Journal of Biological Chemistry, 193, 256-275. 
Matak, K. E., Hvizdzak, A. L., Beamer, S. K., \& Jaczynski, J. (2010). Recovery of Salmonella enterica serovars Typhimurium and Tennessee in peanut butter after electron beam exposure. Journal of Food Science, 75(7), M462-467.

Matloubi, H., Aflaki, F., \& Hadjiezadegan, M. (2004). Effect of gamma irradiation on amino acids content of baby food proteins. Journal of Food Composition and Analysis, 17(2), 133-139.

Mexis, S. F., \& Kontominas, M. G. (2009). Effect of $\gamma$-irradiation on the physicochemical and sensory properties of cashew nuts (Anacardium occidentale L.). LWT - Food Science and Technology, 42(9), 1501-1507.

Osaili, T. M., Al-Nabulsi, A. A., Shaker, R. R., Ayyash, M. M., Olaimat, A. N., AlHasan, A., Ashraf, S., Kadora, K. M., \& Holley, R. A. (2008). Effects of extended dry storage of powdered infant milk formula on susceptibility of Enterobacter sakazakii to hot water and ionizing radiation. Journal of Food Protection, 71(5), 934-939.

Pietrowski, B. N., Tahergorabi, R., Matak, K. E., Tou, J. C., \& Jaczynski, J. (2011). Chemical properties of surimi seafood nutrified with $\omega-3$ rich oils. Food Chemistry, 129(3), 912-919.

SAS Institute. (2002). SAS/STAT guide for personal computers, version 8.1. Cary (NC): SAS Institute.

Sikorski, Z., Kolakowska, A., \& Burt, J. R. (1990). Postharvest biochemical and microbial changes. In Z. E. Sikorski (Ed.), Seafood resources, nutritional composition and preservation (pp. 55-76). Boca Raton (FL): CRC Press.

Sohn, S. H., Jang, A., Kim, J. K., Song, H. P., Kim, J. H., Lee, M., \& Jo, C. (2009). Reduction of irradiation off-odor and lipid oxidation in ground beef by $\alpha$-tocopherol addition and the use of a charcoal pack. Radiation Physics and Chemistry, 78, 141-146.

Stefanova, R., Vasilev, N. V., \& Spassov, S. L. (2010). Irradiation of food, current legislation framework and detection of irradiated foods. Food Analytical Methods, 3(3), 225-252.

Stewart, E. M. (2001). Food irradiation chemistry, food irradiation principles and applications. New York: John Wiley Sons Inc.

Tahergorabi, R., Beamer, S. K., Matak, K. E., Jaczynski, J. (2012a). Isoelectric solubilization/precipitation as a means to recover protein isolate from striped bass (Morone saxatilis) and its physicochemical properties in a nutraceutical seafood product. Journal of Agricultural and Food Chemistry, 60(23), 5979-5987.

Tahergorabi, R., Beamer, S. K., Matak, K. E., \& Jaczynski, J. (2012b). Functional food products made from fish protein isolate recovered with isoelectric 
solubilization/precipitation. LWT - Food Science and Technology, 48(1), 89-95.

Tahergorabi, R., Beamer, S. K., Matak, K. E., \& Jaczynski, J. (2012c). Chemical properties of $\omega$-3 fortified gels made of protein isolate recovered with isoelectric solubilization/precipitation from whole fish. Food Chemistry. In Press.

Tahergorabi, R., Beamer, S. K., Matak, K. E., \& Jaczynski, J. (2012d). Salt substitution in surimi seafood and its effects on instrumental quality attributes. LWT-Food Science and Technology, 48(2), 175-181.

Taskaya, L., Chen, Y. C., Beamer, S., Tou, J. C., \& Jaczynski, J. (2009). Compositional characteristics of materials recovered from whole gutted silver carp (Hypophthalmichthys molitrix) using isoelectric solubilization/precipitation. Journal of Agricultural and Food Chemistry, 57(10), 4259-4266.

Tesfai, A.T., Beamer, S. K., Matak, K. E., \& Jaczynski, J. (2011a). Microbial radioresistance of Salmonella Typhimurium in egg increases due to repetitive irradiation with electron beam. Radiation Physics and Chemistry, 80(4), 591-596.

Tesfai, A.T., Beamer, S. K., Matak, K. E., \& Jaczynski, J. (2011b). Radioresistance development of DNA repair deficient Escherichia coli DH5 $\alpha$ in ground beef subjected to electron beam at sub-lethal doses. International Journal of Radiation Biology, 87(6), 571578.

Thayer, D. W., \& Boyd, G. (2001). Effect of irradiation temperature on inactivation of Escherichia coli O157:H7 and Staphylococcus aureus. Journal of Food Protection, 64, 1624-1626.

World Health Organization. (1994). Safety and nutritional adequacy of irradiated food. Geneva: World Health Organization.

World Health Organization. (1995). Review of data on high dose (10-70 kGy) irradiation of food. International Consultative Group on Food Irradiation. Report of Consultation in Karlsruhe Aug/Sept 1994. Geneva: World Health Organization.

World Health Organization. (1999). High-dose irradiation: wholesomeness of food irradiated with doses above 10 kGy. WHO Technical Report Series \#890. Geneva: World Health Organization.

Yu, T. C., \& Sinnhuber, R. O. (1957). 2-thiobarbituric acid method for the measurement of rancidity in fishery products. Food Technology, 11, 104-108. 


\section{Dissertation Summary and Implications}

Electron beam radiation has been receiving increased attention as a non-thermal food processing. Our study demonstrated e-beam efficiently inactivate $S$. Typhimurium in raw egg and there was no growth after $3 \mathrm{KGy}$; however, similar to other inactivation techniques and factors affecting microbial growth, $S$. Typhimurium develops increased radio-resistance if repetitively processed with e-beam at sub-lethal doses. The $\mathrm{D}_{10}$-values for $S$. Typhimurium enumerated on non-selective media (TSA) were greater $(\mathrm{P}<0.05)$ than on selective (XLD) media for all five cycles of e-beam irradiation, indicating sublethal injury followed by cellular repair and recovery are important aspects of microbial inactivation with e-beam. E-beam as a non-thermal process can be used as an alternative method to efficiently control S.Typhimurium in egg.

Our results demonstrate $E$. coli DH5 $\alpha$ increases radio-resistance to e-beam as a result of repetitive exposure to sub-lethal doses despite its DNA repair deficiency. The radio resistance phenotype observed in DNA repair deficient E.coli DH5 $\alpha$ could be arisen from active DNA repair process due to back mutation of both genes (recA and gyrA) after sub lethal e-beam irradiations. Based on our result we can conclude, DNA repair mechanism is important in radio-resistance development in E.coli. Understanding the microbial resistance of food borne microorganisms to irradiation is important and it has implication for determining the efficacy of irradiation in reducing levels of those microorganisms in food.

From the result of our last study, e- beam radiation doesn’t affect the nutritional content of infant formula thus it can be applicable in processing infant formula. Our result shows proteins, fats, and minerals in dehydrated infant milk formula are stable when processed with electron beam (e-beam) up to $25 \mathrm{kGy}$. This application has not yet been exploited and has the potential to enhance the safety of infant milk formula. Losses of vitamins can be caused by e- beam radiation, which is not covered in our experiment, thus it is recommended to study the effect of e-beam on vitamins in infant formula. 
Studying the inactivation and radio-resistance development of foodborne microorganisms is important to scientists, food processing industry and regulatory agencies for adaptation of new processing technology, making decision and formulation of law and policies. 